\title{
Engaging for Success:
}

enhancing performance through employee engagement

A report to Government by David MacLeod and Nita Clarke 


\section{Engaging for success: enhancing performance through employee engagement}

A report to Government

David MacLeod

Nita Clarke 
The text in this document may be reproduced free of charge in any format or medium providing it is reproduced accurately and not used in a misleading context. The material must be acknowledged as Crown copyright and the title of the document specified.

Where we have identified any third party material you will need to obtain permission from the parties concerned.

For any other use of this material please write to Office of Public Sector Information, Information Policy Team, Kew, Richmond, Surrey TW9 4DU or e-mail: licensing@opsi.gov.uk

The views expressed in this report are the authors' and do not necessarily reflect those of the Department or the Government. The authors are not responsible for any third party material. Original material for the case studies has been supplied by the organisations themselves and were chosen to reflect a range of sectors of the UK economy, but do not constitute a representative sample. 


\section{Contents}

Foreword by Secretary of State 1

Introduction 3

Chapter 1: Employee Engagement - What, why and how 7

Chapter 2: The Case for Employee Engagement - The Evidence 34

Chapter 3: The Barriers to Engagement 66

Chapter 4: Enablers of Engagement - What has to happen to make engagement work 74

$\begin{array}{ll}\text { Chapter 5: Recommendations } & 117\end{array}$

$\begin{array}{ll}\text { Annexes } & 124\end{array}$ 


\section{Foreword by Secretary of State}

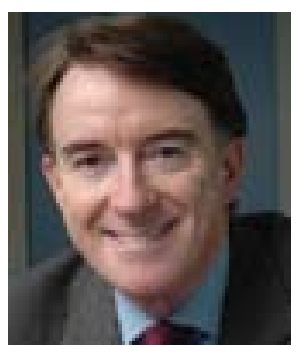

This timely Report sets out for the first time the evidence that underpins what we all know intuitively, which is that only organisations that truly engage and inspire their employees produce world class levels of innovation, productivity and performance.

The lessons that flow from that evidence can and should shape the way leaders and managers in both the private and public sectors think about the people who work for them. They should also shape the way employees approach their jobs and careers.

A recession might seem an unusual time for such reflection - in fact, the opposite is the case. Because Britain's economic recovery and its competitive strengths in a global economy will be built on strong, innovative companies and confident employees, there has never been a more important time to think about employee engagement in Britain.

This report helps take forward that debate. It sets out what government can do to help promote an understanding of just how much greater employee engagement can help improve innovation, performance and productivity across the economy. It launches a challenge that my department will take forward in the months ahead.

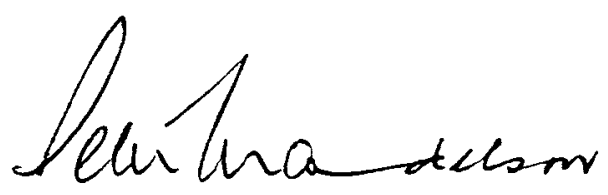

Rt Hon Lord Mandelson

Secretary of State for Business, Innovation and Skills 



\section{Introduction}

1 We were asked by the then Secretary of State for Business in the autumn of 2008 to take an in-depth look at employee engagement and to report on its potential benefits for companies, organisations and individual employees. When the new Secretary of State, Lord Mandelson, met us in the spring, as the recession was biting, he encouraged us to examine in particular whether a wider take up of engagement approaches could impact positively on UK competitiveness and performance, as part of the country's efforts to come through the current economic difficulties, take maximum advantage of the upturn when it comes, and meet the challenges of increased global competition.

2 Our answer is an unequivocal yes. In the course of the past eight months we have seen many examples of companies and organisations where performance and profitability have been transformed by employee engagement; we have met many employees who are only too keen to explain how their working lives have been transformed; and we have read many studies which show a clear correlation between engagement and performance - and most importantly between improving engagement and improving performance.

3 We believe that if employee engagement and the principles that lie behind it were more widely understood, if good practice was more widely shared, if the potential that resides in the country's workforce was more fully unleashed, we could see a step change in workplace performance and in employee well-being, for the considerable benefit of UK plc.

$4 \quad$ Engagement, going to the heart of the workplace relationship between employee and employer, can be a key to unlocking productivity and to transforming the working lives of many people for whom Monday morning is an especially low point of the week.

5 We deal with the different definitions of engagement in the report. But at its core is a blindingly obvious but nevertheless often overlooked truth. If it is how the workforce performs that determines to a large extent whether companies or organisations succeed, then whether or not the workforce is positively encouraged to perform at its best should be a prime consideration for every leader and manager, and be placed at the heart of business strategy.

6 Where this happens, in places like John Lewis Partnership, Tesco, the London Ambulance Service, Sainsbury's, Standard Chartered Bank, BAE Systems, Toyota, Babcock Marine Clyde, Google, Telefónica O2 UK and many more, the results can be transformational - because employee engagement enables an adult, two-way relationship between leaders and managers, and employees, where challenges can 
be met, and goals achieved, whether it be improved patient care, higher quality production, or more satisfied customers.

7 Of course a sustainable business strategy and access to cash are vital, just as good policy and planning are for successful public services. But in a world where most factors of production are increasingly standardised, where a production line or the goods on a supermarket shelf are much the same the world over, employee engagement is the difference that makes the difference - and could make all the difference as we face the realities of globalised competition and of the millions of graduates and even more skilled and committed workers that China, India and other economies are producing each year.

8 As our public services face the reality of an end to the years of rapid growth in investment, it is hard to see how the quality of service we all aspire to see employees and citizens alike - can be achieved without putting the enthusiasm, commitment and knowledge of public service employees at the forefront of delivery strategies.

9 Nor is employee engagement only relevant in retail, where customers expect a cheerful face on the till, rather than a languid hand waving them to a far-off aisle in response to a query about the availability of marmalade, and where employees' attitudes demonstrably and immediately impact on customer satisfaction. As Sir Alan Jones, Chairman Emeritus of Toyota UK told us: "Wherever you work, your job as a manager is to make your people be the best they can be - and usually they don't know just how good they could be. It's individuals that make the difference". For Toyota, this approach is not based on altruism - though it is based on a profound respect for its members. It is predicated on the firm belief that the most valuable asset the company has is its people, and that enabling them to have an intellectual and emotional relationship with their work, as well as a financial stake in the success of the company, is the key to continuous product and productivity improvement from the shop floor to the boardroom. Toyota's people are their competitive advantage.

10 The way employee engagement operates can take many forms - that is one of the most fascinating aspects of the topic - and the best models are those which have been custom-developed for the institution. As everyone knows, John Lewis Partnership is a company owned by its employees - but the company is clear that its model of shop-floor voice and engagement, which is such a critical factor in its continued success, is not simply a function of its ownership structure, but stems from a profound belief, first articulated by its founder, that people working in the business are central to its success.

11 Many company leaders described to us the 'light-bulb moment' when an understanding of the full potential significance of employee engagement dawned. Tesco Chief Executive Terry Leahy has recorded his reaction when he realised that the company knew more about its customers than it did about its employees, and 
how the company then set about understanding what the workforce wanted, what motivated them at work and what workplace approaches would best build on those understandings, working in partnership with the retail workers' union USDAW. As Tim Besley, leading economist and member of the Monetary Policy Committee put it, "there is an increasing understanding that people are the source of productive gain, which can give you competitive advantage."

12 Individual employees in companies with strong engagement strategies described to us how their working lives have been transformed for the better. Mandy Symonds of United Welsh said: "Being involved not only gives me real opportunities to influence the decisions which affect me and my future, it also means I am more aware of the wider picture. As a result I can be confident United Welsh are going places, so for me it's the place to be."

13 Company accounts that show the workforce as a cost on the balance sheet, alongside capital depreciation, encourage a boardroom mindset which ignores the people factors. Many people we spoke to also pointed to the limitations of an approach which regards the workforce en masse as 'human resources' leading to a monolithic and one-dimensional view of people. As Will Hutton, Executive Vice Chair of the Work Foundation told us: "We think of organisations as a network of transactions. They are of course also a social network. Ignoring the people dimension, treating people as simply cogs in the machine, results in the full contribution they can make being lost."

14 Within the public sector there is a growing understanding of the importance of engagement as a medium for driving the performance and well-being of public servants. This is reflected in the decision of the Civil Service to carry out its first service-wide survey of employee engagement later this year; it is expected to be one of the largest single surveys of its kind ever carried out in the UK, covering some 500,000 civil servants.

15 We hope this report will set out a compelling case to encourage more companies and organisations to adopt engagement approaches. We believe the evidence we cite of a positive correlation between an engaged workforce and improving performance is convincing. We have also set out to demystify engagement by defining what it is and what it can do for organisations and individuals. We look at the crucial role of leadership, of so-called soft skills, the role of line managers, the importance of employee voice and the positive role trade unions and employee representatives can play.

16 Furthermore we hope it makes the case why, faced with the challenges of recession, "although adopting employee engagement strategies is challenging for firms at this juncture, actually it's more important than ever." In the words of David Yeandle of the EEF, the manufacturers' organisation: "It will be hard to get through the recession without engaging your workforce." 
17 That is why our core recommendation to government is a concerted effort involving all the stakeholders in the employment field, to raise the profile of this topic, so more and more people 'get it'. We propose a national awareness campaign, facilitated by the Department for Business, Innovation and Skills (BIS). We are delighted that so many of the leading business figures we have spoken to in the course of this review have agreed to join a national high level sponsor group to promote a real discussion, should the Secretary of State accept our recommendations.

18 Engagement is about establishing mutual respect in the workplace for what people can do and be, given the right context, which serves us all, as individual employees, as companies and organisations and as consumers of public services. It is our firm belief that it can be a triple win: for the individual at work, the enterprise or service, and for the country as a whole.

19 During this review we have heard from hundreds of people with fascinating and often inspirational stories to tell. We have spoken to many individual leaders, companies and organisations, as well as representative bodies including the Confederation of British Industries (CBI), the Trades Union Congress (TUC), the Institute of Directors (IoD), the Federation of Small Businesses (FSB), Business in the Community (BITC) and British Chambers of Commerce (BCC), as well as professional bodies such as the Chartered Institute of Personnel and Development (CIPD) and the Chartered Management Institute (CMI). We've discussed the topic with practitioners, and with academics and thought leaders in the field. A series of regional road shows was also held, attended by a wide range of stakeholders. We also visited many organisations practising engagement. We received a wide range of evidence, and an open call for submissions on the BIS website recorded over 300 responses. $A$ full list of contributors is included at Annex A-D.

20 We are also very grateful for the time and commitment from the practitioners, experts and leaders, who so generously gave their time individually and collectively to greatly enrich this report. Throughout, we have been supported by a superb team from BIS, led by Tom Ridge. Rob Vondy, Area Director of Acas North West, has also been an invaluable source of advice and support. We owe them all a huge debt; this report could not have been produced without them.

David MacLeod

Nita Clarke 


\section{Chapter 1}

\section{Employee Engagement - What, why and how}

1 This chapter summarises our findings on the importance of employee engagement to the UK, looks at some of the barriers to engagement as well as some of its characteristics, and outlines our recommendations to the government.

2 The following chapters detail more of the evidence about engagement (chapter 2), the barriers (chapter 3 ) and some of the factors that lie behind successful engagement (chapter 4). Our recommendations in full can be found in chapter 5 .

3 This report is about unlocking people's potential at work and the measurable benefits of doing so for the individual, the organisation and, ultimately, for the UK.

4 It is about retaining and building on the commitment, energy and desire to do a good job that characterises most people, that 'first day at work' feeling, to maximise individual and organisational performance.

5 Business and organisations function best when they make their employees' commitment, potential, creativity and capability central to their operation. Clearly, having enough cash, and a sensible strategy, are vital. But how people behave at work can make the crucial difference between business and operational success or failure.

6 Employee engagement strategies enable people to be the best they can at work, recognising that this can only happen if they feel respected, involved, heard, well led and valued by those they work for and with. As a representative of the home insulation company $\mathrm{KHI}$ put it: "employee engagement is when the business values the employee and the employee values the business" (submitted via the review's online call for evidence).

$7 \quad$ Engaged employees have a sense of personal attachment to their work and organisation; they are motivated and able to give of their best to help it succeed and from that flows a series of tangible benefits for organisation and individual alike.

8 "You sort of smell it, don't you, that engagement of people as people. What goes on in meetings, how people talk to each other. You get the sense of energy, engagement, commitment, belief in what the organisation stands for, "is how Lord Currie, former Chair of the Office of Communications (Ofcom) and Dean of Cass Business School, puts it. As a number of business leaders told us, "You know it when you see it." 
9 It is of course not that simple. There is no one agreed definition of employee engagement - during the course of this review we have come across more than 50 definitions; three of them are quoted below.

"Engagement is about creating opportunities for employees to connect with their colleagues, managers and wider organisation. It is also about creating an environment where employees are motivated to want to connect with their work and really care about doing a good job...It is a concept that places flexibility, change and continuous improvement at the heart of what it means to be an employee and an employer in a twenty-first century workplace." (Professor Katie Truss $\left.{ }^{1}\right)$

"A positive attitude held by the employee towards the organisation and its values. An engaged employee is aware of the business context, and works with colleagues to improve performance within the job for the benefit of the organisation. The organisation must work to develop and nurture engagement, which requires a two-way relationship between employee and employer." (Institute of Employment Studies²)

"A set of positive attitudes and behaviours enabling high job performance of a kind which are in tune with the organisation's mission." (Professor John Storey ${ }^{3}$ )

10 Early on in the review, when we spoke to David Guest, Professor of Organisational Psychology and Human Resource Management at Kings College London, he pointed out that much of the discussion of engagement tends to get muddled as to whether it is an attitude, a behaviour or an outcome or, indeed, all three. He went on to suggest that "... the concept of employee engagement needs to be more clearly defined [...] or it needs to be abandoned". "We have decided, however, that there is too much momentum and indeed excellent work being done under the banner of employee engagement to abandon the term.

Not everyone who practices engagement uses the term: Liz Sands, Buyouts Director at 3i Private Equity, told us 3i probably doesn't use the term 'employee engagement' at Board level but "it is fundamental to driving improved performance in the business and the organisation as a whole is signed up to it for that reason".

\footnotetext{
1 Gatenby, M., Rees, C., Soane, E. and Truss, C (2009) Employee engagement in context. London: Chartered Institute of Personnel and Development

2 Robinson, D., Perryman S., \& Hayday, S. (2004). The drivers of employee engagement. IES Report 408

3 John Storey, Patrick M Wright, David Ulrich eds. (2008). The Routledge Companion to Strategic Human Resource Management.

4 David Guest, 'Review of Employee Engagement: Notes for a Discussion, December 2008' unpublished paper prepared specifically for the MacLeod Review
} 
11 There are differences between attitude, behaviour and outcomes in terms of engagement. An employee might feel pride and loyalty (attitude); be a great advocate of their company to clients, or go the extra mile to finish a piece of work (behaviour). Outcomes may include lower accident rates, higher productivity, fewer conflicts, more innovation, lower numbers leaving and reduced sickness rates. But we believe all three - attitudes, behaviours and outcomes - are part of the engagement story. There is a virtuous circle when the pre-conditions of engagement are met when these three aspects of engagement trigger and reinforce one another.

12 For the purposes of this report, and building on David Guest's input, we believe it is most helpful to see employee engagement as a workplace approach designed to ensure that employees are committed to their organisation's goals and values, motivated to contribute to organisational success, and are able at the same time to enhance their own sense of well-being.

13 Engaged organisations have strong and authentic values, with clear evidence of trust and fairness based on mutual respect, where two way promises and commitments - between employers and staff - are understood, and are fulfilled.

14. Although improved performance and productivity is at the heart of engagement, it cannot be achieved by a mechanistic approach which tries to extract discretionary effort by manipulating employees' commitment and emotions. Employees see through such attempts very quickly; they lead instead to cynicism and disillusionment. By contrast, engaged employees freely and willingly give discretionary effort, not as an 'add on', but as an integral part of their daily activity at work.

15 But is employee engagement something new, or simply old wine (long-standing management approaches) in new (fashionable management-speak) bottles. Is it just the latest management fad? We believe that while it does have clear overlaps with analytical antecedents such as commitment, 'organisational citizenship behaviour', job involvement and job satisfaction, there are also crucial differences.

16 In particular, engagement is two way: organisations must work to engage the employee, who in turn has a choice about the level of engagement to offer the employer. Each reinforces the other.

17 As IES say, an engaged employee experiences a blend of job satisfaction, organisational commitment, job involvement and feelings of empowerment. It is a concept that is greater than the sum of its parts.

18 Employee satisfaction and engagement differ in their predictive power over outcomes. Measuring satisfaction or morale per se does not tell you how employees are behaving - measuring engagement can go a long way towards doing so.

\footnotetext{
5 Robinson, D. (2008) 'Employee engagement: an IES perspective', Presentation to the IES HR Network.
} 
19 Despite there being some debate about the precise meaning of employee engagement there are three things we know about it: it is measurable; it can be correlated with performance; and it varies from poor to great. Most importantly employers can do a great deal to impact on people's level of engagement. That is what makes it so important, as a tool for business success. ${ }^{6}$

\section{Engagement is measurable}

20 To deal with measurability briefly first - since that is a foundation for insights for action. Employee engagement is not a science, but the development of survey tools and questionnaires such as Gallup's $\mathrm{Q}^{7}{ }^{7}$ allow levels of 'engagement' within an organisation to be measured. Exactly what aspect of engagement these questionnaires analyse will vary. Some describe the level of engagement within the organisation on a scale, or as a percentage. This can enable a comparison between different parts of the same organisation - engagement levels between different branches of the same bank for example - and can enable benchmarking of results against significant external databases, often for the same industry. Some enable the identification of the prime drivers of employee engagement for an organisation through regression analysis. The nature of the engagement - with the job, with the team, with the organisation - can also be identified.

21 Again, measurement of engagement is not an exact science. Some surveys look at the preconditions for engagement, and/or the outcomes of engagement, while others emphasise employee attitudes. Typical questions might include: 'Do you have the right materials and equipment to do your job properly'?; or the employee might be asked to register their agreement with statements such as 'I am personally motivated to help this organisation', or 'I have useful conversations with my line manager'. Employees at Accenture, for example, are asked to complete a 'Personal Engagement List' and rank a range of factors such as reward and recognition and quality of life. They then discuss the results with their 'career counsellor' assigned to them by the organisation and action plans are put into place to close any gaps between importance and satisfaction.

22 But the data gleaned from engagement surveys should be good enough to allow organisations to address their identified issues - for example where the scores might be lower than expected - and analyse the factors behind their success, for example increased scores year on year, within the context of their organisation's strategy and goals. The most important thing is for an organisation to be able to arrive at a shared definition in the context of their business, and for this to translate into action.

\footnotetext{
6 To be clear, this report presents the evidence available; it has not been part of the scope of this review to validate it.

7 The Q12 was developed by and is owned by the Gallup Organisation. http://www.gallup.com/consulting/52/employee-engagement.asp Other employee engagement measurement tools also exist.
} 
23 That is not to say that a sophisticated or expensive survey or questionnaire is always appropriate or necessary to measure engagement levels; many organisations supplement questionnaires with staff focus groups. For small organisations in particular the cost will almost certainly be prohibitive and may seem bureaucratic and burdensome. However, many leaders of small and medium businesses told us that once a business grows to a size where, in the words of one of the employers we spoke to, "we can't all go to the pub together", gauging levels of engagement makes good business sense. We deal with some of the specific issues for SMEs in chapter 4.

24 We have also been struck by the number of people who told us of the equal importance of using instinct and judgment. It is also clear that simply doing a survey and publishing the results is not the same as an engagement strategy. Measuring engagement is simply a tool to allow you to find out how engaged your people are. Pfizer emphasised to us that engagement is a process not an event. Mark Mitcheson, Talent and Organisation Capability Lead at Pfizer, says: "We work hard to avoid falling into the trap that some other organisations make - assuming that doing a survey is doing engagement - it's an important part of the process, but only part of it. There is a danger that you can spend too long looking at and analysing the figures, rather than engaging with staff on how to improve." As Andrew Templeman, of the Cabinet Office Capability Building Programme put it to us: "No one ever got a pig fat by weighing it".

\section{It correlates with performance}

25 Levels of engagement matter because employee engagement can correlate with performance. Even more significantly, there is evidence that improving engagement correlates with improving performance - and this is at the heart of our argument why employee engagement matters to the UK.

26 The following chapter sets out the major evidence for these correlations. Here we highlight some of the findings.

27 Gallup in $2006^{8}$ examined 23,910 business units and compared top quartile and bottom quartile financial performance with engagement scores. They found that:

- Those with engagement scores in the bottom quartile averaged 31 - 51 per cent more employee turnover, 51 per cent more inventory shrinkage and 62 per cent more accidents.

- Those with engagement scores in the top quartile averaged 12 per cent higher customer advocacy, 18 per cent higher productivity and 12 per cent higher profitability.

28 A second Gallup study of the same year of earnings per share (EPS) growth of 89 organisations found that the EPS growth rate of organisations with engagement scores in the top quartile was 2.6 times that of organisations with below-average engagement scores. ${ }^{9}$

\footnotetext{
8 Harter, J.K. et al (2006), Gallup Q12 Meta-Analysis

9 Gallup Organisation (2006). 'Engagement predicts earnings per share'.
} 
29 Tower Perrins-ISR ${ }^{10}$ carried out a global survey in 2006 which included data gathered from opinion surveys of over 664,000 employees from over 50 companies around the world, representing a range of industries and sizes. The survey compared the financial performance of organisations with a highly-engaged workforce to their peers with a less-engaged workforce, over a 12 month period.

- The results indicated a significant difference in bottom-line results in companies with highly-engaged employees when compared with companies with low levels of employee engagement.

- Most noticeable was the near 52 per cent gap in the performance improvement in operating income over the year between companies with highly-engaged employees versus companies whose employees had low engagement scores. Companies with high levels of employee engagement improved 19.2 per cent in operating income while companies with low levels of employee engagement declined 32.7 percent over the study period.

30 In evidence to the review, Standard Chartered Bank reported that in 2007 they found that branches with a statistically significant increase in levels of employee engagement ( 0.2 or more on a scale of five) had a 16 per cent higher profit margin growth than branches with decreased levels of employee engagement.

\section{It correlates with innovation}

31 Gallup indicate that higher levels of engagement are strongly related to higher levels of innovation. Fifty-nine per cent of engaged employees say that their job brings out their most creative ideas against only three per cent of disengaged employees. ${ }^{11}$ This finding was echoed in research for the Chartered Management Institute in 2007 which found a significant association and influence between employee engagement and innovation. Based on survey findings from approximately 1,500 managers throughout the UK, where respondents identified the prevailing management style of their organisation as innovative, 92 per cent of managers felt proud to work there. ${ }^{12}$

32 As Professor Julian Birkinshaw of the London Business School told us: "employee engagement is the sine qua non of innovation. In my experience you can have engaged employees who invest their time in multiple directions (such as servicing clients, creating quality products) but you cannot foster true innovation without engaged employees." His view was echoed by Kieran Preston, director general of Metro, the public transport provider for West Yorkshire: "Employee engagement is important to Metro as it drives challenge and innovation and keeps Metro at the forefront of best practice in transport."

33 Both Sainsbury's and O2, two companies that have recorded significant recent successes, believe that their recent growth has been predicated on a transformation

\footnotetext{
${ }^{10}$ Towers Perrin-ISR (2006) The ISR Employee Engagement Report.

${ }^{11}$ Krueger, J. \& Killham, E (2007) 'The Innovation Equation'. Gallup Management Journal

${ }^{12}$ Kumar, V. and Wilton, P. (2008) 'Briefing note for the MacLeod Review', Chartered Management Institute
} 
of their approach to their workforce, based on highly developed engagement models. "In our business with almost 150,000 people, engagement is a key concern. In businesses of our scale, you don't even get started without engagement," Justin King, CEO of Sainsbury's told us.

\section{Public sector impacts}

34. In the Civil Service indicative evidence suggests that departments with high engagement levels (measured through staff surveys) also tend to perform well in capability reviews - a key metric of departmental performance. Seventy-eight per cent of highly engaged public sector staff believe they can have an impact on public services delivery or customer service - against only 29 per cent of the disengaged. (Towers Perrin 2007) Research in Canada suggests that the link between engagement, customer service and profitability in the private sector could translate to the public sector - with trust and public confidence at the end of the chain, rather than profit. ${ }^{13}$

"The Civil Service faces unprecedented challenges tackling complex policy issues every day. In order to meet these challenges we must harness the talents of all our staff to the full. Our employee engagement programme enables us to do this by understanding and improving civil servants' experience of work, helping to ensure that they have access to the opportunities they need to achieve success in their roles. This, in turn, supports our drive to deliver improved public services and better outcomes for citizens." Sir Gus O'Donnell, Cabinet Secretary and Head of the Home Civil Service.

35 Some have questioned which is the chicken and which the egg - does engagement lead to performance or is it the other way around? Marcus Buckingham, who has studied this area for many years, concludes from various longitudinal studies that it is engagement that leads to performance, and this is a four times stronger relationship than performance leading to engagement. ${ }^{14}$ ISR, from different studies, have reached the same conclusion.

36 However, there is no single study that has proved beyond doubt that engagement explains higher performance, or improving engagement causes improved productivity and performance; it is difficult to imagine comparators where all factors are the same, which is what would be required to prove causality. But while each of the studies indicated above, together with individual company studies, are all open to some degree of challenge, taken together they offer a very compelling case.

37 And as Professor Chris Bones, Dean of Henley Business School, pointed out, it is hard to believe that the many blue chip and admired companies and organisations putting substantial effort and resources into assessing and improving engagement -

\footnotetext{
${ }^{13}$ Canadian Government Executive: June/July 2006 - http://www.tbs-sct.gc.ca/rp/pstc-eng.asp

Acccessed 1 July 2009

${ }^{14}$ Quoted during telephone conversation with Review team, 2009
} 
such as Diageo, Rolls-Royce, AstraZeneca, first direct and many more - would be doing so if they were not convinced of its importance to their bottom line.

"The way employers treat employees has a direct effect on how employees treat customers. Customers, or service users, vote with their feet depending on the quality of the interaction they experience with any given organisation. Quality customer and employee interactions are, over the long run, the lifeblood of any business. These quality interactions ensure brand loyalty, advocacy and can give an organisation a competitive edge, which if rooted in their 'culture' can be hard if not impossible to replicate". Jonathan Austin, Best Companies

\section{Other outcomes of engagement}

- Engaged employees in the UK take an average of 2.69 sick days per year; the disengaged take $6.19 .{ }^{15}$ The CBI reports that sickness absence costs the UK economy $£ 13.4$ bn a year. ${ }^{16}$

- Seventy per cent of engaged employees indicate they have a good understanding of how to meet customer needs; only 17 per cent of nonengaged employees say the same. ${ }^{17}$

- Engaged employees are 87 per cent less likely to leave the organisation than the disengaged. ${ }^{18}$ The cost of high turnover among disengaged employees is significant; some estimates put the cost of replacing each employee at equal to annual salary.

- Engaged employees advocate their company or organisation - 67 per cent against only three per cent of the disengaged. Seventy-eight per cent would recommend their company's products of services, against 13 per cent of the disengaged (Gallup 2003). ${ }^{19}$ Public sector employees are less likely to be advocates for their organisation than private sector staff. ${ }^{20}$

- Research by Ipsos Mori on Audit Commission data showed that staff in councils rated as 'excellent' had much better results than those in weak or poor councils when asked about factors such as being informed and consulted, having confidence in senior managers and understanding the overall objectives of their organisation; they were also twice as likely to be advocates for their organisation than staff in weak or poor councils. ${ }^{21}$

\footnotetext{
${ }^{15}$ Gallup, 2003, cited in Melcrum (2005), Employee Engagement: How to Build A High Performance Workforce

${ }^{16} \mathrm{CBI}$-AXA (2007), Annual Absence and Labour Turnover Survey

${ }^{17}$ Right Management (2006), Measuring True Employee Engagement, A CIPD Report

${ }^{18}$ Corporate Leadership Council, Corporate Executive Board (2004)'Driving Performance and Retention through Employee Engagement: a quantitative analysis of effective engagement strategies' 


\section{Engagement levels in the UK are low - and vary widely}

38 There is a wide variation in engagement levels in the UK within organisations and companies, and between them. The Corporate Leadership Council (CLC) report that the highest scoring companies record 23.8 per cent of their people in the high engaged category; in the lowest scoring companies only 2.9 per cent of their people are in the highly engaged category, using the same measurement techniques. ${ }^{22}$ IES found engagement in organisations varied between age groups, between the type of organisation and between different job roles. ${ }^{23}$ The most recent Workplace Employee Relations Survey (WERS) from 2004 indicates that job-related satisfaction varied across workplaces, suggesting that it was partly determined by the workplace itself not just by demographic or job-related characteristics. ${ }^{24}$

39 A study by Professor Katie Truss and Kingston Business School for CIPD in $2006^{25}$ found that only three in ten of UK employees were actively engaged with their work, findings echoed by a YouGov survey for the TUC in $2008 .^{26}$ Recent work from CLC indicates that one in five UK workers may be disengaged - with only four per cent exhibiting the highest levels of engagement. ${ }^{27}$

40 Within the public sector, levels of engagement are comparable. According to Towers Perrin, 12 per cent of UK public sector staff are highly engaged and 22 per cent are disengaged ${ }^{28}$, figures borne out by results from the annual NHS staff survey. ${ }^{29}$

41 Even if these figures are only indicative, they still suggest that overall levels of engagement in the UK are lower than they could be.

42 Evidence about the effect of the current economic climate on engagement is mixed. The $\mathrm{CLC}^{\mathbf{3 0}}$ findings from across 60 companies in the third and fourth quarters of 2008 suggest that the number of highly disengaged employees has increased from one in ten to one in five from the first half of 2007 to the second half of 2008.

43 On the other hand recent evidence from the CIPD suggests that job satisfaction and employee loyalty levels are holding up (in comparison to figures from 2006). ${ }^{31}$

\footnotetext{
${ }^{22}$ Corporate Leadership Council, Coporate Executive Board (2004) 'Driving performance and retention through employee engagement - a quantitative analysis of effective engagement strategies'

${ }^{23}$ Institute for Employement Studies evidence to IES HR network, March 2008.

${ }^{24}$ Kelsey, Alpin, Forth et al (2006) Inside the Workplace: Findings from the 2004 Workplace Employment Relations Survey also at

http://www.berr.gov.uk/whatwedo/employment/research-evaluation/wers-2004 .Accessed 1 July 2009

${ }^{25}$ Truss, C., Soane, E., Edwards, C., Wisdom, K., Croll, A., and Burnett, J. (2006). 'Working life: employee attitudes and engagement 2006' CIPD.

${ }^{26}$ TUC, 'What do Workers Want?'; YouGov poll for the TUC August 2008

${ }^{27}$ Corporate Leadership Council /Corporate Executive Board (2008). 'Improving Employee Performance in the Economic Downturn'

${ }^{28}$ Towers Perrin, Executive Briefing: Engagement in the Public Sector, 2007.

${ }^{29}$ Healthcare Commission (2008). Sixth Annual National NHS staff survey

${ }^{30}$ Ibid.

${ }^{31}$ C Truss et al, CIPD and Ipsos MORI, revised 2009
} 


\section{The impact of the engagement deficit}

44 Even though according to $\mathrm{CLC}$ research ${ }^{32} 97$ per cent of business leaders say that innovation will become more important over the next three years, managers appear to be increasingly less likely to encourage and support employees to try new things. From 2008 - 2009 the numbers saying their manager supported new ways of doing things declined from 51 per cent to 40 per cent; the numbers reporting that managers were encouraging them to develop their own ideas declined from 51 to 43 per cent; and those reporting their manager encouraged them to try new ideas out declined from 48 to 38 per cent. No fewer than 42 per cent of employees would refuse to recommend their organisation as an employer to friends and family, according to a report by ACCOR. ${ }^{33}$

45 Engagement and involvement are critical in managing change at work; according to PricewaterhouseCoopers (PwC), nine out of ten of the key barriers to the success of change programmes are people related ${ }^{34}$; only 24 per cent of private sector employees believe change is well managed in their organisations (15 per cent in the public sector) according to Ipsos MORI. ${ }^{35}$

46 The increasing evidence that individuals' skills are being under-utilised at work a significant source of disengagement for the individuals affected - also suggests significant wastage and is a concern highlighted by the UK Commission for Employment and Skills (UKCES). The most recent WERS survey ${ }^{36}$ found that over half of employees surveyed thought the skills they possessed were higher than those required to do their job.

47 A further challenge is that employees' freedom to take decisions and organise their work - an important component of engagement - appears to be falling, according to the British Skills Survey. Task discretion declined between 1992 and 2001, and the proportion of people saying they had a great deal of discretion over how to do their work fell from 57 to 43 per cent over the same period.

48 The disengagement gap may also be a factor behind Britain's continued lag in the international productivity league table, according to a recent report from the Advanced Institute of Management Research on the Organisation of Productivity (December 2006).

49 Concern over engagement levels is widely shared. From a global sample of 60 corporations the Corporate Leadership Council found that over 80 per cent of senior

\footnotetext{
32 Ibid.

${ }^{33}$ Accor: Reward to Engage: Rewards, Benefits and Employee Engagement in Today's Organisations and at http://engagement.accorservices.co.uk/website/employee-engagement-whitepaper-form.htm, Accessed 1 July 2009

${ }^{34}$ PwC, Managing Change in Your Business, September 2000.

35 Ibid.

${ }^{36}$ Kelsey, Alpin, Forth et al (2006) Inside the Workplace: Findings from the 2004 Workplace Employment Relations Survey. Also at http://www.berr.gov.uk/whatwedo/employment/research-evaluation/wers-2004 Accessed 1 July 2009
} 
human resources (HR) professionals agreed that employee engagement was a high priority for 2009 and 40 per cent claimed it had become more of a priority over the last year. ${ }^{37}$ Senior private sector HR managers believe that the top challenge they face now is maintaining employee engagement.

50 PWC research ${ }^{38}$ suggests that CEOs identify the availability of people and talent as the top barrier to growth, more than the downturn; to compete for talent "we need to change the way we recruit, motivate and develop people."

51 If higher engagement is associated with higher performance, the low levels of engagement described above may be costing the UK dear in terms of lost performance. Gallup suggest that in 2008 the cost of disengagement to the economy was between $£ 59.4$ billion and $£ 64.7$ billion. ${ }^{39}$ The IES/Work Foundation report People and the Bottom Line ${ }^{40}$ found that if organisations increased investment in a range of good workplace practices which relate to engagement by just ten per cent, they would increase profits by $£ 1,500$ per employee per year.

\section{The positive story}

52 However, there is another side to the picture. In the course of our review we have encountered compelling examples of organisations which have radically improved their performance through employee engagement approaches. These organisations without exception are committed to extending and developing their employee engagement strategies because they believe employee engagement to be fundamental to their future success. Many are protecting their staff development and training budgets despite difficult circumstances, as a result.

53 These exemplars can be found in the private, public and third sector, in very large and very small organisations, in manufacturing and in the service sector. They also demonstrate that engagement is not just for white collar or retail staff.

\footnotetext{
${ }^{37}$ Ibid.

38 Ibid.

${ }^{39}$ Annual cost of actively disengaged employees estimated by Gallup through a three-step process. First, it applied its proprietary formula to the Q12 survey results to calculate the number of actively disengaged employees in the UK. Next, widely used published statistical guides (standard utility analysis methods) were applied to the 24,002 GBP per year median salary in the UK. This yielded 2,048 GBP in losses per worker, multiplied by 29 million British workers who are 18 years old or older, produced the 59.48 billion GBP estimate. The 64.7 billion GBP estimate was based on a different economic measure - the UK's Gross Domestic Product in the year 2007. The GDP figure was divided by the total number of British workers to yield 52,221 GBP worth of goods or services per worker last year. Again applying standard utility analysis methods, the Gallup statisticians found that a 4.3 per cent increase in output per worker would be attributable to eliminating active disengagement from the workforce. This 4.3 per cent increase, applied against the 52,221 GDP average output figure amounts to 2,228 per person in the total workforce, or 64.7 billion USD overall.

40 Tamkin P, Cowling M, Hunt W (2008) People and the Bottom Line Report 448, Institute for Employment Studies
} 


\section{Case Study}

\section{Serco}

Serco is a FTSE 100 international service company with more than 40,000 employees delivering services to government and private clients in over 30 countries.

A new business unit within one of Serco's largest divisions was formed in early 2006 with over 3,000 employees across nearly 50 contract sites in the UK. The team carried out a variety of roles from cleaners and caterers to security guards and engineers. To deliver revenue and margin growth plans the business leaders needed to make significant changes to improve customer satisfaction. The changes needed to be sustained and the risk to the customer, minimised.

Employee engagement was at the heart of the strategy. Clear communication about the need for change was essential to sustain performance improvement. The employee engagement survey provided critical data on where improvements were needed. Action plans were developed locally with employees. Managers discussed the results with their teams and collectively agreed what to do differently. The actions formed part of the manager's performance management objectives.

Managers found that the key to their success was to proactively identify, recognise and publicise great performance. Employees seeing their managers take action as a result of the survey, positively improved engagement scores.

Participation in the survey increased from a low of 56 per cent, in the first year, to 71 per cent two years later. Positive responses to questions on clarity of roles, how employees contributed to their wider team, and understanding of how they fitted into Serco's vision and strategy all increased each year. More employees now feel that they play an important part in the success of the business, and that they are recognised and valued for their contribution.

Through the survey Serco were able to measure the significant impact their leaders had on creating a values-led environment focused on delivering great service. Increased employee engagement was accompanied by a 12 per cent increase in customer satisfaction and significant double-digit revenue and margin growth over the past three years. 


\section{Case Study Blackpool, Fylde and Wyre NHS Foundation Trust}

Blackpool, Fylde and Wyre NHS Foundation Trust has embedded engagement and partnership working across the whole of the Trust's operation. Engagement and partnership working are described as 'the Blackpool way; it's how we do things around here.' Its foundation is a clear statement of the Trust's aims and values, and a well-communicated strategy, which identifies and builds on the issues of most importance to staff. An engaged workforce enabled the trust to undertake significant reform and achieve Foundation status, while taking the staff with them.

In 2006 the Trust faced a financial crisis with a projected budget deficit of $£ 21$ million. The service had the ambition to become a Foundation Trust, but was faced with too many hospital sites, significant bed pressures, and a lack of clinical engagement as well as high reference costs.

Working in partnership with trade unions, the Trust undertook a full public consultation to agree a way forward - and to deliver the changes needed in one year. These included the closure of outlying sites, the centralisation of day case surgery, the relocation of services including stroke services, the reconfiguration of medicine and surgery services, an overall reduction of 200 beds and a reduction of over 500 posts.

Partnership and engagement with staff was based on an underlying emphasis on clinical improvement across the board. Plans were agreed with the Clinical Policy Forum, the staff side and the patients' forum. A complete staff mapping exercise was carried out, accompanied by aspirational interviews. Strict controls were placed on vacancies and bank staff. As a result only two grievances were lodged as a direct result of the changes - and Foundation status was achieved.

The partnership working has continued with the delivery of the Trust's workforce plan, which is underpinned by a comprehensive workforce engagement strategy which operates across every department and operation in the Trust. Blackpool wants to be a model employer, based on the quality of its communications with staff and relations between staff and managers. The emphasis is on continuous improvement and staff development, tackling sickness and absence and reducing stress, recognising work well done and ensuring equality and diversity; progress is monitored through regular staff surveys and the Trust has a well-developed staff awards system.

One of the most significant partnership outcomes has been the 'partnership for learning' project supported by the Trust, UNISON and Blackpool and the Fylde College, to improve literacy and numeracy skills, improve the motivation and confidence of staff and widen participation in learning. 
The learning partnership has seen over 1,000 members of staff undertake a wide variety of courses. In particular literacy and numeracy skills have been improved as well as basic IT skills, and all partners believe it has been significant in breaking down barriers to learning.

The project now aims to expand its horizons by offering financial advice and support, working with the Financial Services Authority, Blackpool Council and a local credit union.

The trust won the Healthcare People Management Association (HPMA) partnership award in 2008.

\section{Case Study \\ Broadway}

Broadway is a small charity providing a range of services and support to homeless people. It employs 180 people in London. Competition for service contracts and talent is fierce in the social care sector, and so Broadway have invested in their employment offer and HR practices to attract the highest quality people, who are looking for engagement at work, and given them the freedom to deliver quality services.

Broadway gathered data from its staff survey and bench-marked it against 13 other homelessness charities. Broadway scored highest in 9 out of the 11 categories and achieved the highest organisational score for engagement. They have also been listed in the Sunday Times 100 Best Small Companies for the last three years.

Broadway places a lot of emphasis on only recruiting people who are willing to be engaged, and have developed recruitment processes that identify those people.

Employees are offered challenging work and the autonomy and flexibility to improve the services they deliver. Broadway has flexible working practices and staff are trusted to manage their time effectively. However, Broadway ensure that all staff understand the organisation's values and standards, and that they have clarity on what is expected of them. Staff are given the information they need to do their jobs well, and 80 per cent agree that they have plenty of ways to feed their views up the organisation.

The result is quality services that are rated highly by clients, and a reputation as an employer of choice. Eighty-one per cent of clients said they were fully satisfied with Broadway's services in 2008 and demand for jobs continues to be considerably higher than for other charities. 


\section{Case Study ROK (previously EBC)}

In 2000, Garvis Snook joined a building company in trouble following the 90's recession which had hit the construction industry particularly hard. EBC employed 600 people, had a turnover of $£ 85$ million, was running at a loss of $£ 2$ million a year and was on the point of going bust.

The company had always been run on a command and control basis with a 'them' and 'us' attitude not just between the board and the staff but between the managerial staff and the trades people on the front line.

Garvis Snook changed all that with a complete transformation of the company ethos which centred on creating a shared vision of EBC, now renamed Rok, as your 'local builder' offering exceptional customer service. Garvis introduced the same terms and conditions for both blue and white collar staff, incentivised good performance and asked those delivering on the front line to input their views into how things could be done better.

This was not an easy journey and success was hard won. But the results have been outstanding. Rok has seen growth in turnover from $£ 85$ million in 2000 to $£ 1$ billion in 2008. The workforce has grown from 600 to over 5,000. In an industry which expects to make returns of about one per cent from subcontractors, Rok is making around six per cent from deploying its direct workforce. They have a committed, highly skilled and loyal workforce and a long waiting list of people wanting to join the company. Garvis Snook says: "When I started this journey people thought I was mad and the Board were not universally enthused. But I knew that without getting the workforce fully engaged and committed the company would die. Instead of which it was reborn."

\section{Case Study}

\section{Department for Work and Pension's State Pension Forecasting and Pension Tracing Service Unit}

The State Pension Forecasting \& Pension Tracing Service Unit at the Department for Work and Pensions (DWP) is responsible for providing forecasts of individuals' State Retirement Pension when they are approaching pensionable age. They also offer a private pension tracing service for individuals who have been in a private pension scheme but have not retained links with the scheme. The unit deals with clerical applications and telephone queries through its Call Centre in Newcastle. 
A number of years ago the unit was not operating to its potential, had high attrition rates and sickness absence levels which were having a negative effect on service levels. These issues were considered to be a risk to an organisation operating in a target driven environment and needed to be addressed.

The manager and his team agreed that it was clearly time for change and that the only effective way to make that work was by getting everyone in the organisation involved. The key was to engage with staff and to ensure that all staff policies, including those surrounding performance and attendance management, were seen to be fair and consistently applied to all. Workshops were held where every team and each team leader was given the opportunity to express their views about how improvements could be made and how teams should be managed. What evolved was a new way of working that was endorsed by the staff.

A number of things were initiated surrounding improving engagement and communication with staff underpinned by a Staff and Management Charter; describing the expectations that staff had of managers and vice-versa.

A network of 'Change Agents' was created to represent staff and provide a route for views and ideas so that they can be taken into account. The network also provides a means for information and updates from the management teams to be cascaded to staff.

All of the above was premised on the principle that if staff are given sufficient information and involvement to help them understand and commit to an idea they will then be willing to engage with it. Once they see and experience the benefits of the changes it quickly becomes 'standard practice' and just 'the way we do things'.

Overall the efficiency of the unit has increased significantly and it has won many awards including the DWP Call Centre of the Year for two consecutive years. It has high staff engagement scores in the DWP Staff Survey with over 80 per cent of staff participating.

Dave Stirling the Manager of the unit says: "The activities are not magical or new, they are all common sense and good management but in this case engaging with employees has shown just what can be done. The important thing is to make a start". 


\section{Case Study \\ Reed Elsevier}

Reed Elsevier's journey started in 2006 when they had the output to their Employee Opinion Survey and realised that they could not truly identify what made them a high performing organisation and a great place to work. They visited twenty globally-recognised 'best places to work' in Reed Elsevier, as well as 15 external organisations. Internally, focus groups were also run. This helped define a number of leader characteristics unique to Reed Elsevier which could be correlated with a high performance work environment - as well as with the effectiveness of both engagement and talent management.

At the same time, studies were being carried out within Reed Elsevier to gain understanding of customer loyalty, based on the principles of Reichheld's Net Promoter Score.

The benefits of this approach allows them to identify people based drivers of employee engagement, customer satisfaction and financial performance.

54. Steve Elliott, Chief Executive of the Chemical Industries Association, told us: "Effective employee engagement is crucial to chemical and pharmaceutical businesses located in the UK. The health and safety nature of the industry and our successful performance in this field, combined with the unprecedented levels of restructuring over the past decade achieved with significant employee support, means that the sector has a strong employer/employee relationship. The joint work of employers, workforces and their representatives is a key feature of what we do."

\section{Case Study \\ The VT Group}

The VT Group is one of the UK's leading defence and support services companies. The Group employs over 12,000 people, primarily in the UK and the US, and has a turnover of $£ 1.6$ billion. Historically a shipbuilder, VT has responded to the changing nature of the market by dramatically transforming its business, restructuring and moving from a manufacturing to an engineering based support services business. 
Paul Lester, CEO said: "Achieving our business goals requires the company to develop the skills, leadership and, in particular, the engagement of its people. This issue is vital: our research shows that engaged employees come out of restructuring quicker and achieve the commercial benefits faster than employees who are not engaged. People in the organisation therefore need to develop their skills and approach. This means continuing to change the mindset of employees from that of a traditional manufacturer to one that is more flexible, dynamic and entrepreneurial."

Key to this is ensuring that the senior management team effectively communicate a clear, consistent and compelling case for change and encourage feedback from staff to ensure that they understand and take on board messages.

VT has also worked on making sure the business structure, values and culture support their new business goals to make the transition as smooth as possible. VT started by restructuring the group's business units around markets and centralising some corporate functions. It also undertook an extensive exercise of communicating and discussing organisational vision and values at workshops with all employees, explaining what they mean in practice for each individual. The values focus on empowering people and supporting individual personal development; adopting a results-focused 'can-do/will-do' approach which supports innovation and creativity; and understanding the needs of customers and suppliers.

The VT values underpin a number of vital transformation processes in the organisation, including an extensive programme of coaching to bring the best out of their people, a new performance-related appraisal scheme, a commitment to challenging poor behaviour, designing rewards to encourage the type of behaviour and action required to meet business aims, and customer surveys to keep abreast of the views of their client group.

VT's emphasis on values-driven engagement has led to improved team working, mutual support, greater personal responsibility, autonomy, collaboration and influencing which are resulting in greater innovation: more ideas, and of a higher quality. Although still on the journey to becoming the business set out in their vision, the organisation is confident it will achieve its objectives. The Group's financial performance has continued to improve, despite a testing economic environment and it was recently ranked as the top performing supplier to the MoD.

55 These and many other examples suggest that when it comes to engagement, it is not a case of inventing something new; good practice is out there, transforming organisations and transforming lives. 


\section{Dealing with the recession}

56 Employee engagement approaches can help companies and organisations deal with the challenges of recession because by establishing trust, they can unlock more of the knowledge and commitment of individual employees, for example in developing ways of performing tasks more effectively and efficiently. As Paul Drechsler, CEO of Wates Group, told us, "a leader's focus on engagement is even more important during difficult times to motivate, engage and ultimately retain your people." Engagement can enable organisations to retain their employees' support while taking and implementing difficult decisions. Indeed unlike the experience in previous recessions, many companies have in the past year worked closely and collaboratively with staff to mitigate the effects of scarce credit and collapsing markets on the workforce. There is also evidence that companies are trying to protect training and staff development budgets, despite cost pressures ( $C B I$ Employment Trends, 2009).

57 Professor John Purcell's current research, presented to a CIPD/Acas conference on 11 June 2009, has uncovered a variety of 'Black Monday' stories illustrating individual cases where the effects of the recession have been badly handled, leading to a collapse of confidence, breach of trust and a withdrawal of engagement. On the other hand he points to an example of a company forced into hard choices, but done in a way which has led to an increase in engagement and protected both workforce and company prospects. The American-owned company, making medical equipment, proposed to off-shore aspects of production to eastern Europe, leading to doubts about the viability of the factory. The leadership engaged the workforce, individually and through the union and non-union representatives, with very extensive consultation and communication, explaining the reasons behind the decisions and examining alternatives. Managers were highly visible throughout the process. Agreed strategies included ending the use of agency work, new shift patterns resulting in reductions in pay, new production processes, training for all staff, in-filling posts with more qualified personnel, good treatment for those leaving. A detailed staff survey taken before and after the downsizing - which reduced the workforce from 450 to 100 employees - showed that key engagement indicators rose: the proportion of staff saying management were good at seeking views rose from 41 to 79 per cent; those saying managers could be relied on to keep their promises rose from 37 to 72 per cent; managers treat employees fairly rose from 50 to 76 per cent. Pre-existing high commitment levels - which provided a platform for the joint approach - rose even further; the numbers saying they shared the values of the organisation rose from 70 to 90 per cent, which the proportion saying they felt proud to tell people where they worked increased from 78 to 86 per cent. 


\section{Case Study JC Banford Excavators (JCB)}

JCB's most successful year in its 64-year history was 2007. Over 72,000 machines were produced during that year for the global construction equipment market, which had enjoyed five successive years of strong growth. But during the first half of 2008 , the credit crunch started to have an impact on the construction sector, and in particular on the residential housing market. This resulted in a slowdown in orders for all construction equipment manufacturers and JCB was the first company to announce redundancies in response to this situation.

During late September/early October, the credit crunch became a global financial crisis. Business and consumer confidence collapsed to a new low and this accelerated the order intake slowdown that JCB was already experiencing. More redundancies were inevitable but the company was determined to mitigate the impact on employees as much as possible and retain skills in anticipation of an upturn the following year. During October, JCB proposed a shorter working week to the GMB union as an alternative to hundreds of redundancies. Following detailed discussions between company management, the GMB union and employees, the union balloted their members to establish if they would accept a 34-hour working week in order to protect 332 jobs that would otherwise be at risk. The result was two-to-one in favour of the shorter working week for a minimum six month period.

In the weeks running up to the ballot, and on a regular basis since then, JCB has actively communicated with employees in face-to-face sessions to explain the background to the overall business situation and the measures that are being taken in response. This has meant that each employee has clearly understood the rationale behind all proposals and decisions, even though these were difficult for all concerned and in some cases, meant redundancy or reduced pay for certain employees. Separately, JCB also needed to secure the active participation of all employees in a wider cost reduction exercise to ensure that the business was 'right-sized' and 'right-costed' in light of the more difficult market conditions. This is widely regarded in JCB as a successful employee engagement exercise during the most difficult trading environment that the company has ever seen with sales down 50 per cent year-on-year. 


\section{Case Study}

\section{KPMG}

KPMG has worked hard to develop a high level of engagement within the organisation. Staff expect managers to tell them how it really is - in good times and bad, and this has been the foundation of developing its Flexible Futures programme as one of the approaches to help weather the uncertainty of the recession. Following extensive communication on the effects of the recession on the business, staff were consulted on the design and implementation of a programme of voluntary short-term working reduced hours. Having set itself a target of 65 per cent sign up, KPMG were delighted that 85 per cent of staff were willing to sign up for reducing their hours by one day a week, or taking 4-12 weeks off on 30 per cent pay, if business need required it. Sarah Bond, Head of Engagement, says: "We were open with colleagues about the need to introduce additional flexibility in our staffing arrangements to help prepare for uncertain times. It is a clear indicator that staff at KPMG feel a shared ownership for the organisation's fortunes, and I am very sure that we would not have achieved such a positive response without the high level of engagement between staff and management."

\section{Case Study}

\section{Lloydspharmacy}

The recession came early for Lloydspharmacy, the chain of 1,700 pharmacies, when in 2007 the Government imposed a greater than expected levy, removing significant bottom line profit. Lloydspharmacy maintained its 2008 training budget, supporting over 11,000 passes in recognised pharmacy qualifications plus investing in a programme around customer best care for all 16,500 employees.

European parent company, Celesio has questioned their position on capital investment; however, support for the annual multi-million pound investment in training and communication events has continued. 2009 started with a major conference for 1500 managers and training is scheduled for every pharmacy management position. Despite ever tougher targets and a major restructure, 2008 saw an improvement in engagement levels, with more staff posting positive responses in the staff survey to questions concerning satisfaction, motivation, pride and product and employer advocacy.

Results of the survey also demonstrated a positive link between staff engagement and the growth of optional service provision. Engagement levels were highest where staff had the greatest success in growing additional services such as methadone dispensing or needle exchange - the message quite clearly being, the more engaged the people, the more willing they are to go the extra mile. 


\section{Case Study}

\section{Freshfields Bruckhaus Deringer}

Leading international law firm Freshfields Bruckhaus Deringer sees employee engagement as a central lever to drive results in unprecedented market conditions which have hugely impacted on their traditional work of acquisitions and mergers.

Freshfields now encourage their associates to work with more flexibility and with greater creativity of thought; take much greater responsibility for crossteam working; and to have an ability to talk with skill about a broader and deeper range of market and legal developments. In order to retain the enthusiasm and energy of their associates and help them better face the challenges ahead, they decided to complement technical training programmes with an engagement approach that highlighted the new set of skills that the firm required but which had not, until now, been formally developed. In these markets it was also critical that such programmes were cost efficient.

They designed and implemented two engagement activities in London - the firm's largest office. One was the creation of an Associate Engagement Group (AEG) and the second was an intensive two week programme of engagement and communication called the London Festival.

The AEG runs on an annual basis and its role is to give associates a greater say in decisions that impact them. The group acts as an information and consultation conduit between the partnership and the associates. It is now in its third year and continues to gain prominence. The London Festival, which ran for the first time in February of this year, was designed to give everyone in the London office a better understanding of what other departments do, and to allow staff to get to know their colleagues better in different and more informal surroundings. It was a major engagement programme which included presentations from across the organisation on all different parts of the business - legal teams and business support services and was designed to convey the very latest developments in their areas. Over 1,000 people attended Festival events each week. The Festival was staffed entirely using internal resources and to a very small budget.

During the first year following implementation of their employee engagement strategy, the firm's profitability reached a new high and this year, despite continuing global market volatility, their results are holding up extremely well. Whilst of course difficult to quantify, Freshfields attribute these results, at least in part, to the new skills, motivation and commitment they believe their engagement strategy is developing. 
Freshfields have had to be fleet of foot in responding to new lines of work and partly as a result of this new versatility have been able to contain the impact of the market volatility. In the view of Tim Jones, London Managing Partner, the firm could not have responded as quickly to the change in market conditions without the extra creativity and preparedness to innovate that has been facilitated by their engagement programmes.

\section{The challenges ahead}

58 But dealing with the recession is only part of the story. Engaged organisations, releasing the talents, creativity and innovation that resides in their workforce, will be at the heart of the UK's efforts to meet the new challenges from the emerging economies. A 21st century developed economy like the UK increasingly relies on skilled, motivated and productive employees in every sector to succeed, particularly in the growth sectors of the economy: high end manufacturing, business services, retail, the knowledge and cultural industries, and health and social care services. Miles Templeman, Director General of the Institute of Directors told us, "Everyone has access to the same information, so making the most of human capital is fundamental. Think of it this way: if you are a manufacturer with the same production line process as everyone else in the world, what can you do to gain a competitive advantage? It starts with your people. They are what will give UK plc an edge over competitors."

59 At the same time, the evidence is that many people, particularly younger employees, want more out of work than simply a wage packet at the end of the week. As Matthew Taylor, the Chief Executive of the Royal Society of Arts reminded us, many people are taking increasing personal responsibility for themselves and others in their everyday lives, whether it be care for elderly relatives or healthy and sustainable lifestyles for themselves; they will be less and less willing to abandon that desire for self-determination when they enter work. "You have to negotiate authority now, and achieve it through consent", a point echoed by John Earls, from the trade union UNITE.

60 Notwithstanding the effects of the current economic climate, nor will the greatly increasing number of young graduates be likely to put up with working lives where they are expected to hang their brains and individuality at the door, or buckle down under a command and control management style. A less deferential population is less and less willing to subsume their individuality in any area of their lives. They want choice - and voice.

61 Admiral Sir Mark Stanhope, the Royal Navy's Commander-in-Chief Fleet, put the new reality well when he pointed out that even in the armed forces young men and women putting their lives at risk will, at an appropriate moment, ask and expect to 
have answered the question: 'why?' And answering that question satisfactorily is the precondition for them being willing to obey orders unquestioningly when they are on the front line.

62 Professor John Purcell made a related point to us when he emphasised that the new ways of working - team working, collaboration, joint problem solving - which business and services increasingly demand, cannot thrive in an environment where staff's abilities are not valued or trusted, particularly since many of the new approaches depend on discretionary effort willingly given. The 2004 WERS study ${ }^{41}$ indicated that staff working in teams with greater autonomy were more satisfied with the amount of influence they had over their jobs.

\section{Engagement and the individual}

63 Engagement is not just about macro-economics. There is a measurable and significant win for the individual engaged employee. Studies in this field demonstrate beyond doubt that individuals maximise their psychological well-being when they are engaged in meaningful work that provides positive emotional experiences. As our working lives extend with growing longevity, people will want and demand a greater sense of well-being at work.

$64 \mathrm{CMI}$ reported a strong association between motivation and personal productivity levels. More than two-thirds of those managers who reported that they were motivated at work also claimed high productivity levels (defined as more than 90 per cent). Only 15 per cent who were motivated experienced low levels of productivity (defined as less than 70 per cent).

65 Eighty-six per cent of engaged employees say they very often feel happy at work, as against 11 per cent of the disengaged. Forty-five per cent of the engaged say they get a great deal of their life happiness from work, against eight per cent of the disengaged. (Gallup 2006)

66 Gallup also point to the negative effects of disengagement. Fifty-four per cent of the actively disengaged say that work stress caused them to behave poorly with friends or family members in the previous three months, against 17 per cent of the engaged. More alarmingly, 54 per cent of the actively disengaged say their work lives are having a negative effect on their physical health, versus 12 per cent of the engaged. ${ }^{42}$

67 This damaging effect of disengagement was a theme emphasised to us by Dame Carol Black, the author of the influential review of the health of the working age

\footnotetext{
${ }^{41}$ Ibid.

42 Crabtree S. (2005), 'Engagement Keeps the Doctor Away', Gallup Management Journal; and Gallup Study: (2005); 'Feeling Good Matters in the Workplace', Gallup Management Journal,
} 
population, Working for a Healthier Tomorrow. ${ }^{43}$ She emphasised to us the importance of people's experience of work on their health and the harm that can result when relations between employees and line managers are poor. Dame Carol told us, 'If I could wave a magic wand, the one thing I would do is to improve the relationship between line managers and employees [...] health and well-being is not just a medical issue. The nature and characteristics of the jobs that employees are required to do in terms of satisfaction, reward and esteem and a degree of control in the task, are vitally important to them. The line manager has a key role. Good line management can promote better health and well-being and improved performance." The Government's response to the review 'Improving Health and Work: Changing Lives' also highlighted the importance of line managers in bringing about the better experience of work and the workplace that people are right to seek.

Jonathan Austin of Best Companies told us that their research shows that engaged organisations deliver something valuable for the employee. 'They get leaders who listen to and inspire them, they get an organisation they feel proud to work for, their managers are more likely to listen and care for them, they get more opportunities for personal growth, the teams within these organisations support each other, the "deal" the employee gets is perceived by them to be fairer, and they get lower levels of stress related symptoms and a better work-life balance.'

\section{Explaining the engagement deficit}

69 If employee engagement can deliver so many benefits, what blocks the capture of this private and public value? Chapters 3 and 4 look in more detail at the barriers to engagement and at some of the positive enablers which can form part of a successful strategy. But it is worth summarising some of the significant factors that recur again and again in the research literature and in first hand experience.

70 Firstly, there are still too many chief executives and senior managers who are unaware of employee engagement or are still to be convinced of its benefits. Some are put off by evidence that the benefits of investing in engagement approaches may take time to show through in performance. Others experience little external incentive: data from America shows that the stock market does not fully value intangibles such as employee engagement, even when they are made visible by a publicly available employee survey, even though higher employee satisfaction is associated with stronger company share price performance. ${ }^{44}$ Accenture point out that under half of chief financial officers appear to understand the return on their investments in human capital. ${ }^{45}$ And many people we spoke to pointed to the

\footnotetext{
${ }^{43}$ Black, Carol (2008) Working for a Healthier Tomorrow: Review of the Health of Britain's Working Age Population and at: http://www.workingforhealth.gov.uk/documents/working-for-a-healthier-tomorrow-tagged.pdf (Accessed 1 July 2009)

44 Ednams A. (2008) 'Does the Stock Market Fully Value Intangibles? Employee Satisfaction and Equity Prices'

${ }^{45}$ Accenture (2008) 'An Accenture point of view on employee engagement - what it is, why it matters, how you can you change it'
} 
danger of engagement being written off as 'soft and fluffy' rather than as a bottom line issue; others listed reasons which enabled leaders to avoid dealing with the issue, particularly 'it won't work here' and 'I don't have time'.

71 Secondly, even those who are interested often don't know how to address the topic or where to go to get practical advice and support. Evidence from a survey by the Involvement and Participation Association (IPA) in 2007 found that while most organisations were aware of the need for employee engagement, less than half knew how to implement it. Getting started can be a challenge. The FSB suggested to us that this is particularly the case for small businesses who are in addition concerned about the possible cost.

72 Thirdly, there persists a managerial mindset that 'demeans human beings as human resources and human capital' in the words of Henry Mintzberg, as opposed to creative and productive human beings - as one of many factors of production rather than as the wellspring of success. Behind this mindset lies a fear of losing control of the reins. And as one chief executive asserted to us: "Balance sheets don't answer back. The risk of listening is that you may hear things you don't want to hear."

73 Poor leadership inexorably leads to poor management practice, where line managers fail to engage their staff. Where there is no pressure for engagement, poor line management can quickly douse enthusiasm. Poor management skills in dealing with people lie behind many of the factors of disengagement. As more than one person reminded us: people join organisations - but they leave managers. Mike Emmott of the CIPD pointed to the "seriously defective default assumptions" which he believes are still around, that managers get people to perform by telling them what to do - the traditional command and control model of management - or that the only thing that motivates people at work is pay.

74 Towers Perrin reported in $2007^{46}$ that only 29 per cent of UK employees believed their senior managers were sincerely interested in their well-being; only 31 per cent thought their senior managers communicated openly and honestly; only three per cent thought their managers treated them as key parts of the organisation and no fewer than 60 per cent felt their senior managers treated them as just another organisational asset to be managed. The 2008 NHS staff survey ${ }^{47}$ revealed that only 51 per cent of staff felt they were involved or consulted on decisions that might affect their work area, team or department; only 27 per cent thought senior managers involved staff in important decisions.

75 In our view this joint and consequential failure of leadership and management is the main cause of poor employee engagement.

\footnotetext{
46 Ibid.

${ }^{47}$ Healthcare Commission (2008) Sixth Annual NHS Staff Survey.
} 


\section{The way ahead}

76 There is no silver bullet that will deliver high levels of employee engagement overnight and certainly there is no one size fits all solution. This report does not aim to be a 'how to' guide, and we will not set out the twelve steps to engagement enlightenment. Nevertheless, chapter 4 looks in some detail at the enablers commonly agreed to lie behind successful engagement approaches. Among the drivers are:

- Leadership which ensures a strong, transparent and explicit organisational culture which gives employees a line of sight between their job and the vision and aims of the organisation.

- Engaging managers who offer clarity, appreciation of employees' effort and contribution, who treat their people as individuals and who ensure that work is organised efficiently and effectively so that employees feel they are valued, and equipped and supported to do their job.

- Employees feeling they are able to voice their ideas and be listened to, both about how they do their job and in decision-making in their own department, with joint sharing of problems and challenges and a commitment to arrive at joint solutions.

- A belief among employees that the organisation lives its values, and that espoused behavioural norms are adhered to, resulting in trust and a sense of integrity.

77 We believe the early benefits of adopting a listening and engaging approach will lead to some quick wins. Engagement does not necessarily involve outlay on consultants or expensive surveys. However it will involve behavioural and cultural change which takes time and effort.

78 In our view, the best way of increasing engagement levels in the UK is to ensure more leaders understand the concept and what it can deliver, and that stakeholders in the employment field are geared up to support its implementation.

79 That is why we are recommending to government that rather than set targets or propose new regulations, it uses its unique power to convene a nationwide discussion involving all stakeholders to ensure the widest possible understanding of the case for engagement, and to encourage more organisations to adopt this approach. At the same time, we want to see all the relevant organisations gear up to meet the anticipated increased demand, and the government to ensure the resources it expends that are relevant to engagement - both as a direct employer and as an important source of support for business - reflect the importance of engagement. We believe that by adopting these recommendations we will be in a position to offer more practical support for organisations seeking to enhance levels of employee engagement, by March 2010. The full recommendations are set out in chapter 5 . 


\section{Chapter 2}

\section{The Case for Employee Engagement - The Evidence}

1 We have spoken to many who believe the case for workplace engagement has been so clearly made that the task in hand is to just 'get on with it'. There are however, others who are either less convinced or who are looking for arguments that will persuade those leading their organisations that engagement is about driving up performance, and therefore worth the investment in time and effort it will take. This chapter is for them.

2 Critics of employee engagement have made the point to us that there are organisations, which run on a command and control basis, on the surface disregarding their staff, who are doing well. Organisations do of course exist where the product or service is in such strong demand or is sufficiently differentiated, or where the competition is weak, that commercial success follows. The challenge to these organisations, however, is whether they could be doing even better if they secured the added value which employee engagement brings. As Telefonica $\mathrm{O} 2$ put it to us, an organisation that does not enlist its own staff to its 'fan base' is not maximising its long-term value.

3 The growing currency of engagement has generated a large number of studies from academics, consultancies, and organisations that look at the impact of high levels of engagement on outcomes for the business or organisation. This research, together with anecdotal evidence, exists across a wide range of industries and suggests there is a strong story to be told about the link between employee engagement and positive outcomes. In particular, there are a number of studies that demonstrate that private sector organisations with higher levels of employee engagement have better financial performance, and high levels of engagement are associated with better outcomes in the public sector.

4 As discussed in chapter 1, there are studies across multiple organisations and studies within a particular organisation. Both have contributed to the overall understanding of the impact of employee engagement that underpins the recommendations in this report. Original material for the case studies has been supplied by the organisations themselves.

5 One of the first studies of what we now refer to as employee engagement linked customer service to the profit chain, but also investigated what factors were likely to bring about better customer service. ${ }^{48}$ This study was based on 3 years of work by

\footnotetext{
48 Anthony J Rucci, Steven P Kirn, and Richard T Quinn (1998) 'The Employee-Customer Profit Chain at Sears', Harvard Business Review Jan-Feb
} 
executives at Sears, Roebuck and Co., rebuilding the company around its customers. The resulting service - profit chain model was based on then newly developed measurement techniques and concluded that 'there is a chain of cause and effect running from employee behaviour to customer behaviour to profits.' The Sears model has been subsequently criticised; however, as one of the first serious attempts to quantify and analyse the effects of employee engagement, it sparked much of the subsequent debate.

6 As we set out in chapter 1, research into the extent to which reliable associations can be found between levels of engagement and performance outcomes is increasingly available.

7 However, it is important to bear in mind that this research covers a multitude of sectors and follows different methodologies, so comparisons between studies should be avoided unless care is taken to match the methodologies, particularly the variables being measured. The studies vary in a number of ways. For example, there are varying definitions of engagement; some focus on one element of engagement (emotional, cognitive, behavioural); others focus on one or several but not all of the drivers. Still other studies look at different performance outcomes (such as retention, performance measures, profit, productivity, customer service); at the contextual nature of engagement; and different levels, such as the group, or the organisation.

8 Although the output from research houses and consultancies tends to be more widely quoted, there is also an important series of studies by academics and business schools looking at various aspects of engagement, in particular looking inside what Professor John Purcell calls the 'black box', the impact of HR strategies on performance. ${ }^{49}$

9 We have not attempted to validate each and every study cited in this report. Many can be challenged at some level. However, taken together, and supported by the case studies of organisations who are using employee engagement to boost performance, we suggest the overall picture becomes compelling.

10 As John Purcell told us. "Despite the difficulties and weaknesses it is hard to ignore the volume of studies which show, to varying degrees, with varying sophistication, a positive relationship between high performance/involvement work practices and outcome measures."

11 Some of these studies are outlined in chapter 1; for the sake of completeness we include them here, in this more comprehensive list.

\footnotetext{
49 For example, Purcell, J., Kinnie, N., Hutchinson, S., Rayton, B and Swart, J. (2003) Understanding the People and Performance Link: Unlocking the Black Box. London, CIPD or Kahn W A (1990) 'Psychological conditions of personal engagement and disengagement at work', Academy of Management Journal; Macey W H, Schneider B (2008) The meaning of employee engagement, Industrial and Organisational Psychology; Maslach C, Schaufeli W B, Leiter M P (2001) 'Job burnout', Annual Review of Psychology; Saks A M (2006) 'Antecedents and consequences of employee engagement', Journal of Managerial Psychology.
} 


\section{Cross-Organisational Studies}

12 A global study carried out by Towers Perrin-ISR ${ }^{50}$ compared the financial performance of organisations with a more engaged workforce to their peers with a less engaged workforce over a period of 12 months. The data comprised of 664,000 employees from 50 companies, of all sizes, around the world, representing a range of different industries. Engagement was measured alongside more traditional business performance measures such as operating income, net income and earnings per share. Towers Perrin-ISR's findings included the following:

- Those companies with a highly engaged workforce improved operating income by 19.2 per cent over a period of 12 months, whilst those companies with low engagement scores saw operating income decline by 32.7 per cent over the same period.

- Over a 12 month period, those companies with high engagement scores demonstrated a 13.7 per cent improvement in net income growth whilst those with low engagement saw net income growth decline by 3.8 per cent.

13 The 2006 Meta-Analysis by Gallup ${ }^{51}$ looked at 23,910 business units and compared units with engagement scores in the top quartile with those who had below average engagement scores. Those business units in the top half of engagement scores had 27 per cent higher profitability than those in the bottom half. Gallup found that engagement levels can be predictors of sickness absence, with more highly engaged employees taking an average of 2.7 days per year, compared with disengaged employees taking an average of 6.2 days per year.

14 A second Gallup study ${ }^{52}$ of the same year on earnings per share in 89 organisations found that growth rates of those units with engagement scores in the top quartile were 2.6 times those of units with below average engagement scores. Those in the top quartile averaged 12 per cent higher profitability.

\footnotetext{
${ }^{50}$ Towers Perrin-ISR (2006) The ISR Employee Engagement Report.

${ }^{51}$ Harter, JK et al (2006) Q12 Meta-analysis Gallup

${ }^{52}$ Gallup Organisation (2006). 'Engagement predicts earnings per share'.
} 


\section{Employee engagement and links to performance - other studies}

- The Corporate Leadership Council reported that engaged organisations grew profits as much as three times faster than their competitors. They report that highly engaged organisations have the potential to reduce staff turnover by 87 per cent and improve performance by 20 per cent. ${ }^{53}$

- Shifting levels of employee engagement upwards also correlates with improved performance. For example, Gallup research for a UK retailer with 174 stores in a study over two years concluded that stores that improved engagement year on year grew their profits by 3.8 per cent. Stores that did not improve their engagement saw their profits decrease by 2 per cent. ${ }^{54}$

- CLC's 2004 Driving Performance and Retention through Employee Engagement report, found that companies with above average employee commitment were in 71 per cent of cases achieving above average company performance for their sectors. Companies with below average employee commitment found only 40 per cent of their organisations achieving above average company performance. ${ }^{55}$

- The Institute of Work Psychology at Sheffield University in 2001 demonstrated that among manufacturing companies in their study, people management practices were a better predictor of company performance than strategy, technology, research and development.

- Companies in the Best Companies to Work for in the period $2004-2008$ increased their turn-over by 94 per cent and their profits by 315 per cent.

- The Chartered Management Institute Quality of Working Life 2007 research programme found a significant association and influence between employee engagement and innovation. ${ }^{\mathbf{5 6}}$

\footnotetext{
${ }^{53}$ Corporate Leadership Council /Corporate Executive Board (2008). 'Improving Employee Performance in the Economic Downturn'

${ }^{54}$ Gallup (2008) UK retailer - 174 stores over two years

${ }^{55}$ Corporate Leadership Council (2004) Driving Performance and Retention through Employee Engagement Executive Summary

56 Worrall, L. \& Cooper, C. L. (2007). The Quality of Working Life: Managers' health, motivation and productivity. Chartered Management Institute.
} 
- A Watson Wyatt study of 115 companies suggested that a company with highly engaged employees achieves a financial performance four times greater than companies with poor engagement. They also reported in $2008 / 9$ that the highly engaged are more than twice as likely to be top performers - almost 60 per cent of them exceed or far exceed expectations for performance. Moreover the highly engaged missed 43 per cent fewer days of work due to illness. ${ }^{57}$

- Gallup found that engagement levels can be predictors of sickness absence, with more highly engaged employees taking an average of 2.7 days per year, compared with disengaged employees taking an average of 6.2 days per year. $^{58}$

- Hewitt reported that companies with a greater than 10 per cent profit growth had 39 per cent more engaged employees and 45 per cent fewer disengaged employees than those with less than 10 per cent growth. ${ }^{\mathbf{9}}$

- Development Dimension International (DDI) reported that in a Fortune 100 manufacturing company, turnover in low engagement teams averaged 14.5 per cent, compared with 4.8 per cent in high engagement teams. Absenteeism in low engagement teams hovered around 8 per cent, but was down to 4.1 per cent in high engagement teams. Quality errors were significantly higher for poorly engaged teams. ${ }^{60}$

- Towers Perrin found that broadly three-quarters of the highly engaged believe they can impact costs, quality and customer service; and only 25 per cent of the disengaged believe they can.

- PricewaterhouseCoopers, who use staff and customer engagement levels as one of their four Key Performance Indicators (KPIs) have found a strong correlation between highly engaged staff and client satisfaction.

\footnotetext{
${ }^{57}$ Watson Wyatt, Continuous Engagement: The Key to Unlocking the Value of Your People During Tough Times, Work Europe Survey - 2008-2009.

58 Harter, J. K., Schmidt, F. L., Kilham, E. A., Asplund, J.W. (2006) Q12 Meta-Analysis, The Gallup Organisation

59 Hewitt Associates (2004) Employee Engagement higher in double digit growth companies. Research Brief.

${ }^{60}$ Wellins, R. S., Bernthal, P. and Phelps, M (2005). 'Employee engagement: the key to realising competitive advantage', DDI and at: http://www.ddiworld.com/pdf/ddi_employeeengagement_mg.pdf [accessed 1 July 2009]
} 
- A paper by Harter et al in the Harvard Business Review found that customer and employee engagement augment each other at the local level, creating an opportunity for accelerated improvement and growth of overall financial performance. Analysis of the performance of 1,979 business units in ten companies revealed that those units that scored above the median on both employee and customer engagement were on average 3.4 times more effective financially (in terms of total sales and revenue performance to target and year over year gain in sales and revenue) than units in the bottom half of both measures. ${ }^{61}$

- IES in their 1999 study From People to Profits found a link between employee satisfaction, customer satisfaction and increases in sales, based on a study of 65,000 employees and 25,000 customers from 100 stores, over two years. Employee commitment acted on sales through three routes: directly on sales, mediated through customer satisfaction, and through reduction in staff absence. They concluded a one per cent increase in employee commitment (using a five point scale) can lead to a monthly increase of nine per cent in sales. ${ }^{62}$

- Hay Group in their publication Engage Employees and Boost Performance 2001 conclude that engaged employees generate 43 per cent more revenue than disengaged ones. ${ }^{63}$

\section{Individual Employers in the Private Sector}

15 The Nationwide Building Society has invested considerable effort in measuring levels of employee engagement across its branch network and comparing those results against a number of performance metrics, which are also measurable by retail area. ${ }^{64}$

16 Since April 2008, the building society has produced an Area Directors measurement pack that includes information on business performance (i.e. lending; general insurance; protection and investments; banking; and savings), customer experience, operational and regulatory risk, staff performance review results, voluntary employee turnover and working time lost to employee absence. The retail areas are then divided into three categories according to their staff engagement scores, which enables the company to compare 41 areas, where the 14 areas with the highest engagement levels are classed as 'high engagement', the next 14 as 'medium engagement' and the bottom 13 as 'low engagement'.

\footnotetext{
${ }^{61}$ Fleming J, Coffman C, and Harter J (2005) 'Manage Your Human Sigma', Harvard Business Review

62 Barber, L., Hayday, S., \& Bevan, S (1999) From People to Profits Institute for Employment Studies

${ }^{63}$ Hay Group, 'Engage Employees and Boost Performance' (2001)

${ }^{64}$ Information provided by Nationwide to the MacLeod Review
} 
17 Table 1 below relates to sales data and plots the sales achieved against the relative engagement scores of retail areas. It shows that those areas with high engagement scored 14 percentage points higher on sales of banking products that those with low engagement scores, and were 34 percentage points higher on sales of general insurance.

\section{Table 1: Nationwide - Employee Engagement and Sales}

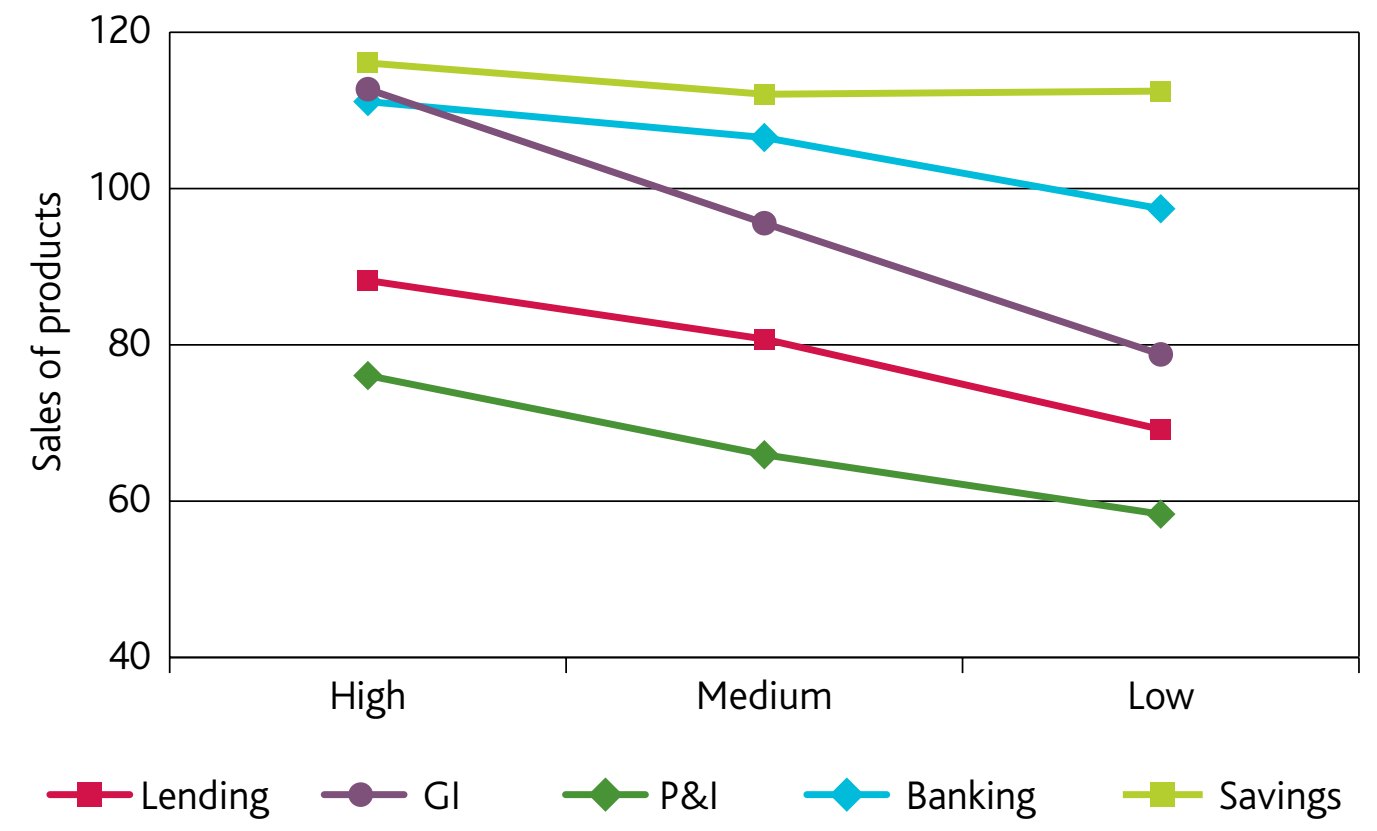

18 Table 2 shows the results on risk. Here, low scores are positive and the finding was that those areas with high engagement scored much better on risk than those areas with low engagement.

\section{Table 2: Nationwide - Employee Engagement and Risk}

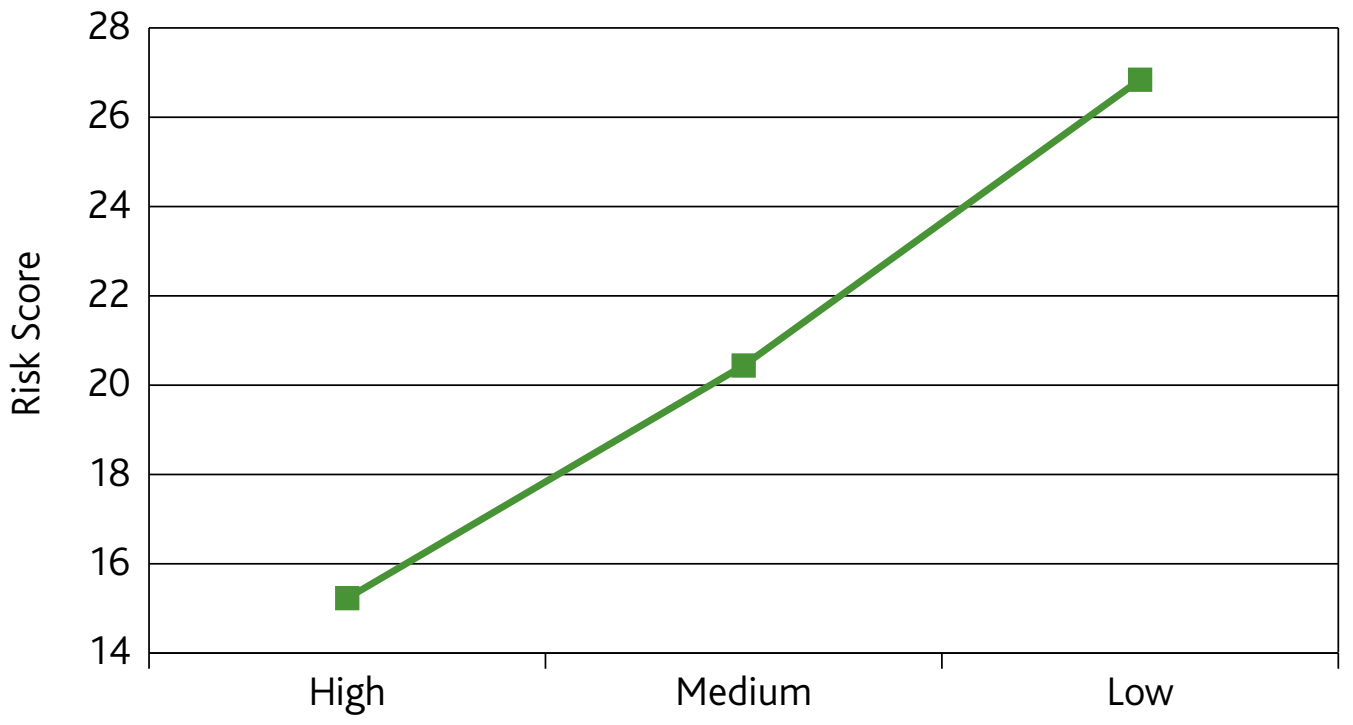

Correlation $=-0.60$ 
- In terms of customer service, Nationwide found significantly higher scores for customer experience in areas of high engagement: there was a difference of eight percentage points between 'high' and 'low'.

- Those retail areas within Nationwide's branch network with areas of high engagement had a voluntary employee turnover rate of just over ten per cent, whilst in those with low engagement it was around 17 per cent.

- Nationwide also found that retail areas that were in the top third of their relative engagement index had lower absence levels. They calculate that if all retail areas brought their engagement scores up to those in top third, and there was a parallel improvement in the number of days lost, this could represent a financial saving of $£ 800,000$ per annum.

19 A study by Standard Chartered ${ }^{65}$ compared the results from 2002/3 and 2003/4 from the branches of two countries: Hong Kong and Ghana. Both quantitative and qualitative data was obtained. The quantitative research was carried out in the bank's retail branches in Hong Kong between 2002 and 2004. Three sets of data were examined: employee engagement (using the Gallup Q12 measurement tool), workplace climate (13 questions) and business performance data, as indicated by branch revenue, profit growth and employee turnover. The additional qualitative data was obtained from focus groups with employees and one to one semistructured interviews with managers.

20 Standard Chartered found that branches where employee engagement was high achieved 16 per cent higher profit margin growth than branches where employee engagement was low and had $\mathbf{4 6}$ per cent lower voluntary turnover.

21 The study emphasises the importance of the engaged manager in inspiring and engaging the workforce, in contrast to human resource management practices alone. This research builds on previous findings in both academic and practitioner literature and suggests a strong correlation between an engaged manager and performance.

22 Not all organisations who believe in engagement carry out the very detailed analysis that Nationwide and Standard Chartered do, but they also have convincing stories to tell about the impact it has made on their performance and bottom line.

23 After receiving the third set of average annual engagement scores for its 1,200 staff working in one of their UK divisions, Accenture assigned a member of staff to work on employee engagement full-time, bringing together all of their different efforts towards people and building one robust programme. Six months later, engagement scores had significantly improved, and their net revenue increased by 21.6 per cent. ${ }^{66}$

\footnotetext{
${ }^{65}$ Provided by Standard Chartered to the MacLeod Review

${ }^{66}$ Accenture, Presentation to MacLeod Review, December 2008
} 
24 In their evidence to our review, The Co-operative Group cited research from their Talkback engagement and performance programme. The Group tracked levels of engagement against store performance in its food retail estate in 2006 and 2007. Although food retail stores are complex environments, and as many external factors as internal can affect operational performance and success, the Group has evidence of direct correlations between levels of employee engagement and store business performance. An analysis of employee engagement in individual stores against key business performance indicators, showed that where engagement improved by an average of 5.24 points or more, the level of food wastage fell by $£ 62.25$ per period per store, saving a total of $£ 400,000$ per annum. Where engagement scores rose by between 0.6 points and 5.23 points, the level of wastage fell by $£ 31.02$ per period, saving $£ 200,000$.

Results from Boots Great Place to Work Survey indicated that shops with the highest engagement scores (72 per cent against 67 per cent) had lower absence rates, lower turnover and a higher profit contribution (3 per cent higher than targets). ${ }^{67}$

\section{Case Study \\ Freshfields Bruckhaus Deringer}

Like many of its direct competitors, retention of talent was becoming a significant issue for the business. Freshfields supports successful graduate candidates for legal posts through one or two years of further training before they join the organisation. During this period, the individuals generate no income revenue, with the break-even point on Freshfields' investment coming at around two years after qualification. Freshfields were finding that despite joining with high levels of commitment and energy, after around four years an unacceptably high proportion of staff were choosing to leave.

From talking to staff, Freshfields realised that many felt that while they were valued for their technical competence as lawyers they didn't have as much opportunity as they would have liked to get involved in the broader development of the firm's business. Freshfields addressed this by introducing a number of measures, including creating the Associate Engagement Group (AEG) which gives associate lawyers a greater say in decisions that impact them. The group acts as an information and consultation conduit between the partnership and the associates. It is now in its third year and continues to gain prominence. Recent market conditions have obviously had an important impact on staff retention, but Freshfields have seen improved metrics in employee engagement since they introduced the AEG.

\footnotetext{
${ }^{67}$ Health Work Wellbeing (2007). Organisational Case Studies - Boots [Online]. Available: http://www.workingforhealth.gov.uk/Case-Studies/Organisations/Organisation-detail.aspx?CaseStudyID=44 [accessed 30 June 2009]
} 


\section{Case Study}

\section{Ultra Electronics Holdings plc}

Ultra Electronics Holdings plc is a FTSE250 defence and aerospace company with 4,000 employees in 24 businesses based mainly in the UK, US, Canada and UAE.

In 2000 Ultra initiated an internal employee survey process called YOURviews which each business conducts about every 18 months. The survey gives invaluable feedback on employee views and provides important input into the improvement plans in each business. Since its introduction the survey has been developed incrementally and is now also available for completion on-line. In 2005 an employee engagement score was included in the YOURviews report for the first time. This was based on 12 existing questions and replaced a number of other ratings.

Internal studies have shown a positive correlation between employee engagement and business growth. This has provided a strong encouragement to use the level of employee engagement as one of the key business performance indicators. In addition, it was noted that, when two businesses coincidentally experienced market-related downturns, the business that recovered most quickly was the one with the higher engagement score.

Ultra has Information \& Consultation groups at all its UK businesses and these have been closely involved in many of the YOURviews surveys. The groups are often able to access more information about specific questions as well as recommending improvements to improve performance.

Since the YOURviews process started in 2000, Ultra's sales have increased from $£ 227 \mathrm{~m}$ to $£ 515 \mathrm{~m}$ in 2008 . Operating profit rose from $£ 30 \mathrm{~m}$ to $£ 77 \mathrm{~m}$ over the same period, a sustained annual growth rate of over 12 per cent. It is the view of Ultra management that its excellent employees are central to the Group's success and that employee engagement is a very useful way of assessing the level of enthusiasm and commitment. 


\section{Case Study}

\section{Amey}

Amey is a leading provider of services to both the public and private sector working with clients from the aviation, central government, defence, education, local government, rail and strategic highways markets. Eleven thousand people work for Amey, and the organisation is clear that there is a compelling case for improving employee engagement to achieve business objectives, recognising it as an ongoing journey rather than a quick fix.

"Employee engagement is a critical issue for Amey if we are to continually improve our service to the customer and ultimately the public. Line managers are key in improving engagement, so supporting them to truly engage with their teams is a priority for Amey," says Chief Executive, Mel Ewell.

Amey's annual survey results show that the most engaged teams correlate to some of the best performing teams in terms of achieving business KPIs. Many of Amey's engagement initiatives, including the self-nomination talent process, ensure the organisation helps its employees develop the capability required by the business and in turn retains its people.

In 2006, Amey launched an engagement survey, tailored to the organisation's values. In its third year, the survey has an action planning process around it that has taken root throughout the business. Amey also has a network of engagement champions, armed with the tools to help drive engagement at a local level and support line managers in improving their people management capability.

In addition, Amey's recent Investor in People accreditation has given the business a competitive edge in winning work and attracting new employees. The organisation has also seen a significant decline in attrition rates over the last twelve months, leading to a reduction in lost productivity hours and lower recruitment and training costs.

Despite the improvements facilitated by positive employee engagement, Amey recognises that there is still more to do. Key challenges include identifying the scope of engagement, and engaging at an individual level in what is a complex and diverse organisation, with a significant proportion of employees based outside the traditional office environment. Amey is a member of the Kingston Business School Engagement consortium, which is sponsored by the CIPD, with the aim of developing greater insight into the drivers of employee engagement. 


\section{Case Study}

\section{The Co-operative Group}

In 2004 The Co-operative Group embarked upon a journey to reinvent itself as a business relevant to 21 st century customers and to turn around its gently declining performance.

Introduced by Richard Bide, the then recently appointed Director of HR, the purpose of the Group's engagement strategy was to encourage employees to support this transformation - both in their hearts and minds.

"The engagement strategy was a catalyst for re-building trust and confidence between individuals, their line managers and the organisation. We asked people how they felt about working here, why they felt that way and what should be done to change things," said Bide.

"At the same time though, and just as importantly, we knew that a real and sustained improvement in levels of employee engagement and commitment would flow through to the bottom line - and we've now proven that to be the case."

The findings of the first engagement survey made sobering reading for the then executive team and a number of things happened quickly in response. To focus minds, the Group Board included a measure of employee engagement within the Group's balanced scorecard. Senior manager incentives were also re-designed to reward increases in engagement.

Practical actions were taken quickly across each of the family of businesses to ensure that the basics were right. Some things were simple: the decision to withdraw free tea and coffee for Food store teams, was reversed.

Survey insights flowed through to the Group's newly emerging People strategy, helping to shape (amongst others) diversity, pay and benefits and development strategies, that were aligned to both long held Co-operative values and the Group's newly emerging brand values.

Bide explained: "How could we expect our people to be ambassadors for, say, the 'rewarding' element of our brand and to encourage customers to become members, if they themselves weren't members, and didn't feel that they were rewarded competitively and fairly?"

The Group Communications function was re-defined, and using a deep understanding of the drivers of engagement, began to create messages that helped people re-appreciate what the Group was about and find the evidence they needed to begin to feel more committed. 
One of the deepest insights that emerged was the role of the line manager in enabling and building engagement. As a result, there has been a steady and sustained commitment to improving the capabilities of all managers and to educating them in their role as team leaders.

Richard Bide is not complacent though: "We are doing well, engagement levels and profitability have improved very significantly and we have successfully completed a huge business integration. We know we still have some way to go, however our successful approach to sharing the responsibility for engagement across our leadership, business operations, human resources, communications and marketing teams, is something we are extremely proud of and we believe is paying real dividends." 


\section{Case Study}

\section{KPMG}

In 2003, the business climate was challenging for consultancy and large accountancy firms such as KPMG. The workforce demographics were changing and the attitude towards 'careers for life' was shifting. KPMG was experiencing high turnover rates - approximately 50 per cent for newly qualified professionals - and it was proving difficult to retain exceptional performers. Staff feedback revealed that managers did not have the capability (skills, time, attitude) to fulfil their role in developing their staff, contributing to high turnover. This forced KPMG to become smarter about how it managed and engaged its people.

Rachel Campbell was appointed to the KPMG Board as Head of People. She spent her first six months listening and talking to people managers and those they managed, to get a real feel for the issues. From this, KPMG developed the 'Managing for Excellence' (MfE) change management and engagement programme. MfE has underpinned some significant changes to the way KPMG manages and in particular has elevated the status and focus on effective people management.

A key innovation was in the development of the role of the People Management Leaders (PML) which was introduced across all business areas. Around 350 people, typically senior manager grade, were identified as great people managers and given full accountability for people management activities for a group of people in their department (between 20-100 people). KPMG has developed a support structure behind the PML network, including one-to-one coaching, annual conferences and development centres. Now, this role has a high profile in the firm and is seen as career enhancing for many, and is ensuring that all staff are managed effectively and fairly in a way which brings out their best.

In the first five years following the introduction of the MfE programme KPMG saw greater commercial success resulting in increased bottom line performance. 


\section{Case Study Google}

Google has grown from an idea generated by two students at Stanford University in 1998 to one of the world's most well known and successful companies. Liane Hornsey, Director of People Operations for Europe, the Middle East and Africa says that the company "would not have been able to innovate as quickly as it has, nor create the products it has in such a short space of time without highly valuing employee engagement."

As Google has grown rapidly over the last decade, one of its main challenges has been to retain the 'small-company feel'. In order to do this, Google firstly takes recruiting very seriously. Well-being of employees is also high on the agenda, and a large amount of money and effort is invested in social activities intended to foster a sense of belonging, a team culture and a sense that there is a psychological contract between employer and employee, not just a transactional one. For example, in the London office, the canteen is free to employees, and tables are designed so that people have to sit together and communicate. Google believe that creating the right culture will mean that employees get a buzz from working there, will want to help Google stay a market leader, and will always strive to deliver for the company as well as they possibly can.

Just as Google has focused on providing the best user experience possible online, so it also puts its employees first when it comes to daily life. There is an emphasis on team achievements and pride in individual accomplishments that contribute to the company's overall success. Ideas are traded, tested and put into practice with an enthusiasm that can make you dizzy. Meetings that would take hours elsewhere are frequently little more than a conversation in the lunch queue and not many walls separate those who write the code from those who write the cheques. This highly communicative environment fosters productivity and camaraderie fuelled by the realisation that millions of people rely on Google results. The ethos at Google is, give the proper tools to a group of people who like to make a difference, and they will. 


\section{Case Study \\ Malmaison}

MWB, the owner of Malmaison, acquired Hotel du Vin in 2004, bringing together the two hotel chains under the same ownership. Although the brands remain separate, the company was keen to initiate greater integration of the workforce and support services. The two hotel chains had very different cultures which had to be brought together, while maintaining the engagement of staff during a period of expansion. Good people management and practices were seen as key to maintaining good service standards.

The hospitality sector has traditionally suffered from a long hours culture and a high turnover of staff, which can be barriers to engagement. As part of the acquisition and expansion plans, the company put in place new performance management systems, greater learning and development opportunities, new management development programmes, employee recognition schemes, and new rotas and flexible working practices.

The result has been increased retention and more senior positions being filled from within, which has also reduced costs for recruitment; 70 per cent of general managers have made their way through the company's ranks, as have 90 per cent of head chefs and deputies. The average working week has been reduced and staff turnover has reduced significantly. These changes have led to steadily improving scores in the employee survey, and sales and profit targets at each chain have been achieved for the last two years. 


\section{Case Study}

\section{Metro}

Yorkshire based public transport provider, Metro has seen the difference that employee engagement can make. It has transformed itself from a traditional bureaucratic rigid culture to a 'can do' culture, where innovation and energy are embraced resulting in improved performance and a number of business accolades including recognition as one of Britain's Top Employers (The Guardian 2007 and 2008).

Metro has introduced a range of activities including improved communication on organisational objectives, an extensive management development programme and 2-way communication throughout the organisation, aimed at increasing employee engagement. The results speak for themselves - increased productivity, and staff and customer satisfaction scores. Since 2004/05, when Metro introduced its engagement programme, it has improved its engagement score from 3.73 to 3.98 (out of 5) and has seen sick days per employee fall consistently from 8.9 to 7.65 , and retention rates increase from 82 per cent to almost 93 per cent.

\section{Small and Medium-sized Businesses}

26 There is, not surprisingly, less evidence on the correlation between engagement and performance in SMEs (Small and Medium-sized Enterprises). There is a tendency to assume that those working in smaller organisations are automatically more engaged. Our discussions with both employers and employees from SMEs suggest, however, that is not always the case. On the one hand $\mathrm{ACCOR}^{68}$ found that almost half (45 per cent) of respondents working for organisations with fewer than 100 employees say they feel involved in the organisation compared to fewer than one in four (24 per cent) of UK employees overall. Although this figure is higher for smaller organisations, it is still less than half; there has also been a large drop in the number of employees in small businesses willing to recommend their firms as a place to work: down from 74 per cent in 2005 to 52 per cent in 2009.

\footnotetext{
${ }^{68}$ Accor: Reward to Engage: Rewards, Benefits and Employee Engagement in Today's Organisations and at http://engagement.accorservices.co.uk/website/employee-engagement-whitepaper-form.html. Accessed 1 July 2009
} 


\section{Case Study \\ HansenGlass}

When HansenGroup acquired HansenGlass, it was a small classic brownfield company with under 90 employees, under intense competitive pressure with many negative attributes: a long, troubled history; traditional, hardened attitudes; 'us and them' practices; and a strong unionised environment with a high reliance on overtime. Each machine centre operated separately producing as much as it could oblivious to adjacent centres. Product damage was high.

The new directors had heard of world class manufacturing but knew they did not have the knowledge or experience of introducing and establishing lean enterprise. After attending the 'Chief Executive Course' at Leyland Trucks the directors were clear on what to do and how to do it.

HansenGlass have now embraced employee engagement as a way of working in a much healthier and democratically accountable environment. By engaging their staff through a series of techniques and processes they have changed the emphasis from direct supervision of employees to self-managing teams.

'Change Initiation', training on leadership, communication, recognition, team working and continuous improvement led to teams setting their own goals.

The results have transformed the business: on-time delivery improved to 98 per cent meeting the world-class benchmark; productivity increased by 250 per cent with 67 per cent less wastage and a 73 per cent reduction in customer complaints; stock was reduced by 50 per cent. Profitability was three times the industry average which led to a $£ 4 m$ investment in new equipment including $£ 600,000$ of Regional Selective Assistance. The company won 'Business Excellence North of England SME' award in 2007. HansenGlass has just received reaccreditation to Investors in Excellence for a second time making it one of the first companies in the country to receive such a distinction. The principles learned have been embodied in the South West Regional Development Agency's Survival Guide and Strategic Development Programme run by Northern Arc Business Link.

Small changes in an organisation can have big results as Chess plc, a Cheshire based SME found out. Chess introduced a range of health and well-being initiatives including encouraging healthy eating, free flu jabs, introducing the Government bike scheme and active management of sickness absence: the average number of sick days per person is now 1.73 a year, well below the national average. ${ }^{69}$

\footnotetext{
${ }^{69}$ Health Work Wellbeing (2007). Organisational Case Studies - Chess plc [Online]. Available: http://www.workingforhealth.gov.uk/Case-Studies/Organisations/Organisation-detail.aspx?CaseStudyID=11 [accessed 30 June 2009]
} 


\section{The Public Sector}

28 Seventy-eight per cent of highly engaged employees in the UK public sector say they can make an impact on public services delivery or customer service, as against just 29 per cent of the disengaged, according to a 2007 Towers Perrin report. ${ }^{70}$

29 Two recent studies in the public sector found that one key characteristic of employee engagement - staff advocacy - was strongly associated with better organisational performance as measured by external regulators. A survey carried out by Ipsos Mori of staff in local councils ${ }^{71}$ found that councils rated 'excellent' by the Audit Commission were more likely to have higher levels of staff advocacy (i.e. staff who would speak highly about the authority to others outside the organisation) than those rated as 'weak'. These results are illustrated in Table 3 below:

\section{Table 3: Best councils are most likely to tell people outside they are great}

\% Strongly agree that they would speak highly of the authority to others outside the organisation

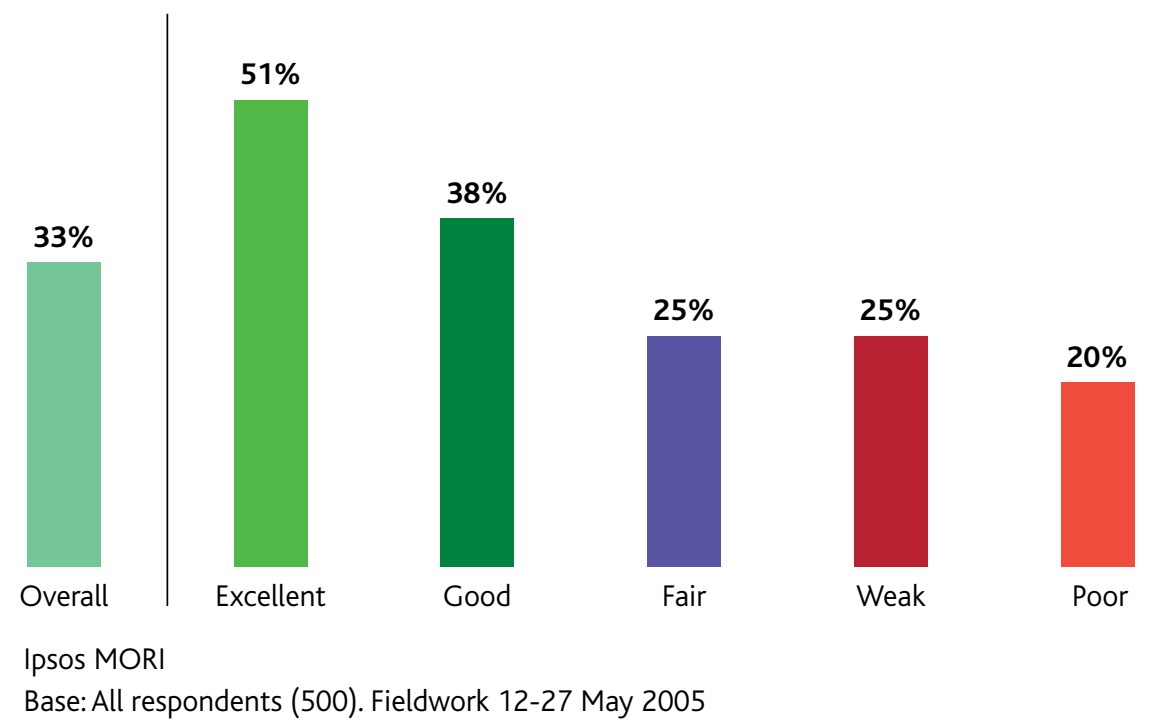

30 A similar finding emerged when the rating of Hospital Trusts by the Healthcare Commission were compared to their staff survey results. ${ }^{72}$ Those Trusts rated 'excellent' were twice as likely to include strong advocates of their organisation than those rated as 'weak' (64 per cent as opposed to 31 per cent).

31 Both these studies found that certain aspects of engagement seemed to explain more of the difference between the best and worst organisations than others. In particular, differentiating elements appear to be: communication (especially senior management having a clear vision of the organisation and this being expressed to staff, enabling them to understand how their role fitted in to the bigger picture);

\footnotetext{
${ }^{70}$ Towers Perrin - Executive Briefing: Engagement in the Public Sector, 2007

${ }^{71}$ Ipsos MORI/Improvement and Development Agency (2006). "Lessons in Leadership"

72 Healthcare Commission (2008) Sixth Annual National NHS staff survey
} 
providing staff with feedback on their performance and listening to their concerns; giving staff autonomy and control, by allowing them the opportunity to show initiative and input into their own job-plans; and having confidence in the senior management team and in their concern for the employee.

32 A study by ORC in local authorities cited six significant associations between overall resident satisfaction and positive employee attitudes, including pride in working for the council and being treated with fairness and respect, clarity of expectations in the job, and awareness of the council's long term goals. The results of a schools survey by West Berkshire Council found significant correlations between staff attitudes and pupil attainment. ${ }^{73}$

33 This emphasis on good leadership and management as a crucial enabler of employee engagement recurs in the work of Beverly Alimo-Metcalfe, Professor of Leadership at Bradford University. Metcalfe has carried out a three year longitudinal study of 46 mental health teams working in the NHS. Her study indicated that a culture of engagement predicted performance, and was more important than other variables including competence: "We were able to provide evidence that engaging leadership does, in fact, predict productivity. We also found that this style of leadership increases employees' motivation, job satisfaction and commitment, while reducing job-related stress. Leadership skills alone do not have such a transformational effect. "74

34 The study identified three dimensions of leadership culture: engaging with others, visionary leadership and leadership capabilities. "We found that all three dimensions positively and significantly affected several aspects of staff's attitudes to work and their well-being at work. [...] However, only 'engaging with others' significantly affects all aspects of positive attitudes to work, and all aspects of well-being, including a strong sense of team spirit, which neither of the other two leadership dimensions predicts" [our emphasis]. ${ }^{75}$

35 Metcalfe's study went on to examine whether any of these three dimensions assessed in 2005 significantly predicted the productivity of the teams 12 months later: "Again we found that, of the three, only 'engaging with others' was a significant predictor of performance [our emphasis], defined in terms of meeting the government target of reducing in-patient bed occupancy by treating patients in their own homes. This was the case even when we allowed for contextual factors. ${ }^{176}$

36 Based on work in a wide range of private and public sector organisations Metcalfe argues that the validity of these findings is not limited to the health and social care arena and that the key is buy-in to engaging leadership from the top: "Our experience of working with organisations in which the CEO and the top team accept that creating

\footnotetext{
${ }^{73}$ ORC presentation to MacLeod Review, February 2009

${ }_{75}^{74}$ Beverly Alimo-Metcalfe \& Margaret Bradley (2008) 'Cast in a New Light', People Management, 24 January 2008

${ }^{75}$ Ibid

${ }^{76}$ Ibid
} 
an engaging culture must start with them is that the effects can be extraordinary, and do not require substantial intervention; in fact, that would defeat the purpose." ${ }^{\prime 77}$

37 There are many other public sector examples where employee engagement has improved performance.

\section{Case Study \\ Wychavon District Council}

Wychavon District Council in Worcestershire serves 117,000 people in Worcestershire and has seen performance and engagement levels rocket from a mediocre position several years ago where departmentalism was rife, customer service patchy and inspection meant unwelcome interference. Running now what is described by the Leader as an "entrepreneurial, not municipal style of business" the Council was voted by staff as The Times Best Council to Work For in 2008, was Council of the Year in 2007 and is the only district council to score top marks in use of resources and value for money audit assessments for 4 years running. As Jack Hegarty, MD, explains "our strong performance is all down to the engagement of our people; we simply couldn't deliver the great deal residents expect from us without the motivated team we now have."

\section{Case Study Runshaw College}

Until Runshaw College carried out an employee survey in 1993 it did not really know how its staff felt or how to harness all of their expertise and energy. In light of the results, Runshaw developed and agreed a common mission and values and allowed managers more autonomy and the responsibility to nurture leadership capacity in others.

Each year Runshaw's commitment to desired leadership behaviours and management strategies is tested through a management style survey. Values and strategies are communicated through a weekly student and staff newsletter, monthly management meetings, termly briefings, and a college commitment to fundraising at home and overseas. There is also a strong focus on volunteering and citizenship and holistic development. 
Thanks to this focus on communication and development, staff at Runshaw are now much more committed to a common set of values. The College agrees an annual theme to reinforce the message of supportive zero tolerance and a focus on higher and higher standards which permeates the organisation. There is considerable emphasis on a teaching and learning academy which supports all staff to uphold the college ethos. The organisational values are discussed by the Principal with all new staff and everyone belongs to an improvement team which meets regularly to ensure that there is a clear focus on the college mission, and that this is being achieved on a day-to-day basis.

Ofsted recently recognised the success of the values-based approach in their report which stated: "The culture of respect that now permeates the college is backed by rigorous systems to ensure all students reach their full potential".

\section{Case Study \\ South Tyneside Council}

In South Tyneside Council, a 'hard nosed, warm hearted approach' empowers employees to deliver innovative solutions and better services.

South Tyneside Council has developed a one team approach, working with partners who share a determination to deliver a better future and the best possible services for the people of South Tyneside.

Innovation is key with a recognition that creative solutions come from everyone - the people on the ground and partners, as well as experts. To deliver innovative solutions, everyone, including employees, needs support to be the best they can possibly be.

South Tyneside's Blitz-it and graffiti team leaders all have Blackberries so the customer contact centre can send through immediate reports of littering or graffiti. Customers are often surprised to see such a quick response from the teams out in the community, who are empowered through instant information and technology to respond so quickly - an innovative solution that saves time and money, and gives greater satisfaction for the community and employees.

Individuals and team achievements are recognised in the annual 'Big Thank You awards' with a golden sock award for employees who knock the customer's socks off by their excellent customer service. Caring colleagues are also recognised, supporting the well-being of employees and the wider community. 
The council's 'hard nosed, warm hearted' approach was developed to ensure that employees knew what was expected of them and that the council was business-like, and highly efficient, with clear objectives and priorities.

The approach is also about celebrating diversity, placing compassion and flexibility at the heart of everything the council does, accepting risk and listening and trusting people to try new and innovative ways of working. Employees who have an emergency, whether it is a washing machine breaking down or an immediate caring issue, know that they can phone in 'stuck not sick' with flexible managers who will allow them time off to deal with their emergency, and they will be trusted to make up the time later.

The South Tyneside approach has led to:

- an excellent rating by the Audit Commission in Comprehensive Performance Assessment.

- positive results including growing satisfaction by residents with South Tyneside as a place to live, up four per cent between 2006 and 2008 to 77 per cent. A total of 77 per cent of residents in the Place Survey felt that the council was working to make the area safer, up 12 per cent since 2006.

- Within the council, sickness absence dropping from an average per employee of 14 days in 2001 to 9 days in 2008. 


\section{Case Study \\ Birmingham City Council}

Birmingham City Council is the largest local authority in Europe with a workforce of 55,000 serving one million residents, yet in 2006 the council was facing some serious challenges. It had been struggling to improve its two-star performance rating. Staff did not feel engaged with the organisation and surveys showed that only around half of staff felt motivated, while confidence in management was even lower.

The council put in place a $£ 450$ million transformation plan with the aim of reforming its back office activities, including IT, finance and procurement. At the same time as this project was tackling the big things, Birmingham designed a workshop programme around four values; Belief, Excellence, Success, Trust (BEST) to empower the workforce and tackle the thousands of little things which would collectively make a substantial difference to the service the council provided.

The council set up a network of 1,800 BEST leaders, selected from each council team who were trained to run group workshops to come up with three or four actions for improvements around customer service, partnerships or team working. In the first year alone, more than 6,000 service improvement actions were suggested. These included everything from ensuring people say "good morning" to re-working the way services are delivered.

More than 25,000 staff have been involved in the BEST workshops so far and feedback suggests they are having a major impact. Scores from surveys undertaken in 2006 and 2008 show the positive progress. Staff motivation has increased from 56 to 86 per cent, confidence in management has gone up from 29 to 68 per cent and the percentage agreeing that they feel proud to work for Birmingham City Council has increased from 50 to 84 per cent within two years.

Chief Executive Stephen Hughes is delighted with the results: "So often change causes anxiety and resistance because staff aren't part of the process and feel powerless. We wanted them to feel this was their change and be able to personally commit to plans which they had decided upon together. I am immensely proud of the BEST programme and specifically the passion, energy and commitment that our staff have shown to making it a success. We should not underestimate the power of us all working together as one organisation."

Birmingham City Council's success has been reinforced through the awards it has won in light of its BEST programme, including the Public Sector People Managers' Association HR Innovation of the Year Award 2009 and Employee Engagement Strategy of the Year and overall Gold award for HR Excellence at the HR Excellence awards 2009. 


\section{Case Study}

\section{Department for Work and Pension}

The Engagement results from the Department for Work and Pension's 2008 survey highlighted that 18 per cent of staff were 'disengaged'. As a large Department, this meant nearly 20,000 people; most were in frontline delivery roles in Jobcentre Plus offices or contact centres, and most were in junior grades.

The organisational context at that time included implementing an efficiency challenge involving a 30 per cent reduction in staff over three years whilst streamlining and modernising services to customers. In response DWP outlined a series of Engagement Priorities which looked at increasing the capability, motivation and accountability of first line and middle managers, increasing the visibility and impact of all senior managers and putting tools in place to involve employees in discussing the vision for DWP and how it could deliver an excellent customer service.

To realise these priorities, DWP has introduced a number of engagement initiatives including the Making a Difference Programme for first level leaders and the Back to the Floor Programme for senior leaders.

The Making a Difference Programme is designed as the catalyst to enable participants to better engage with, lead and deliver business direction. It emphasises leadership is not just about senior managers and that it is the participants who have the greatest influence on people and who are seen as the DWP leaders people look to. Full implementation began in February 2009 and up to 10,000 people are expected to take part. Stephen Hanshaw (Jobcentre Plus) believes his Making a Difference journey has better equipped him in engaging people in change. "We had lots of opportunities to discuss the barriers which can affect our ability to lead our team through change, and share ideas for overcoming these."

'Back to the Floor' gives senior leaders the opportunity to experience a customer-facing role for up to a week, working with staff and discovering at first hand the issues they face in delivering to the Department's customers. Katherine Courtney (Director of DWP Customer Insight) believes the insights she gained from her Back to the Floor experience have enabled her to influence change for the better. "In my role it is important for me to see things from the customer's perspective. I try to 'walk in the customer's shoes' as often as I can. Back to the Floor was a great opportunity to spend time 'walking in the staff's shoes'. Seeing the real help we provide customers when they need it most reminded me why I joined DWP in the first place. I was able to influence issues arising from lone parent customers transitioning from Income Support to Job Seekers Allowance."

The Department's recent survey results show some positive movement in their engagement scores. 


\section{Case Study Westminster City Council}

In 2002, Westminster City Council realised that it needed a change programme to keep pace with the changing nature of local government. The council has achieved success on many fronts including scoring top marks from the Audit Commission for use of resources assessments and a record 85 per cent satisfaction rate from the public. Much of the success is due to the Worksmart programme which engages the 2,800 employees in the council's drive to find innovative solutions to new challenges.

WorkSmart was launched in 2006 with an Ideas Day, when hundreds of staff gathered at a one-day conference to re-think the way the council approached services. In total, 20 of the 50 -plus projects came from that original event. They included the now famous cashless parking system, which has replaced the iconic parking meter with mobile phones and credit card technology. As well as improving the customer experience, the WorkSmart programme has delivered significant cash savings using a simple maxim - if the customer experience is right then costs will reduce. One of the most successful projects has been 'flexible local working' (FLoW). The key objective of the project was to free up space in the 18-storey city hall offices to let out. Each floor of the building is nearly $10,000 \mathrm{ft}$ sq and worth about $£ 500,000$ a year in rent. So far eight floors have been vacated by more staff working from home or hotdesking, and through the use of flexible computing.

Vic Baylis, Westminster's Director of Customer Services, says: "The secret of the success has been that we have had very visible leadership from both the Chief Executive and leader. And, importantly, staff have seen it as a programme which is being done with them rather than to them. We are now at a stage where thinking about and re-designing services from the customer point of view is in our DNA." Through Worksmart and other projects the council aims to have saved $£ 150$ million by 2012.

\section{Benefits for the Individual}

38 Engagement also brings a clear win for the individual employee. Because it is achieved by making changes that positively impact on how employees think and feel about what they experience at work, it is likely to impact positively on their well-being too. As mentioned in chapter one, Jonathan Austin of Best Companies told us: "Employees who work for engaging organisation get an organisation they feel proud to work for, managers who are more likely to listen and care for them, leaders who listen to and inspire them, more opportunities for personal growth, teams that 
support each other. They are likely to perceive the deal they get from their employer as positive, and they get lower levels of stress and a better work life balance. ${ }^{178}$

39 CIPD found that those who were absorbed in their work (cognitively engaged) were almost three times as likely to have six key positive emotions at work (enthusiasm, cheerfulness, optimism, contentment, to feel calm and relaxed) as negative ones (feeling miserable, worried, depressed, gloomy, tense or uneasy). And those who were physically engaged (committed to completing work tasks) were more than ten times likelier to feel those positive emotions than the negative ones. ${ }^{79}$

40 As CIPD also say in their HR Directors' Guide to Employee Engagement, "engaged employees will have a greater sense of well-being than those who are less engaged. They are more likely to be satisfied with their work, less likely to be sick and less likely to leave the organisation."

41 Towers Perrin in their 2008 Global Workforce Study of employee views ${ }^{80}$ found that the top driver of engagement was senior management demonstrating a sincere interest in employee well-being.

42 Angela Bedford of Standard Life was just one HR professional to point out to us the empowering effect on the individual employee of feeling "they are doing what they do best at work. ${ }^{\prime \prime 1}$

43 David Coats of the Work Foundation emphasised to us that "work is good for you but good work is even better. Employers underestimate at their peril the impact on productivity and performance of stress and physical problems such as muscularskeletal damage, which are directly attributable to the experience of the individual employee in the workplace." Conversely, taking employees' well-being seriously will have benefits for both the organisation and employees. British Gas achieved a 12 per cent reduction in staff absence and a 25 per cent reduction in staff turnover, and increased its employee engagement and commitment scores after implementing a wide range of activities aimed at addressing general well-being at work. These included involving family members in fun activities around the workplace such as Christmas parties and summer barbeques, supporting employees to undertake voluntary work for charities, and twice-yearly health events for all staff. $^{82}$

44 The Sainsbury Centre for Mental Health point to the loss of productivity for those who are ill but still in work; they estimate the cost due to mental ill-health alone is $£ 15$ billion a year. A study by Soane (2008) found that emotional engagement was

\footnotetext{
${ }^{\mathbf{7 8}}$ Provided to the MacLeod Review by Jonathan Austin

${ }^{79}$ CIPD Reflections on Employee Engagement - White Paper (2006)

${ }^{80}$ Towers Perrin Global Workforce Study (2007-2008)

${ }^{81}$ Response to MacLeod Review call for evidence, via email

82 Health Work Wellbeing (2007). Organisational Case Studies - British Gas Business [Online]. Available: http://www.workingforhealth.gov.uk/Case-Studies/Organisations/Organisation-detail.aspx?CaseStudyID=33 [accessed 30 June 2009]
} 
associated particularly strongly with perceived meaningfulness at work as well as with low levels of anxiety and depression.

45 The Health and Safety Executive estimates the total cost to society of work related sickness ranges between $£ 20-32$ billion. ${ }^{83}$

46 As Dame Carol Black emphasised in her 2008 report $^{84}$, "for most people, their work is a key determinant of self-worth, family esteem, identify and standing within the community, besides of course material progress and a means of social participation and fulfilment." Her report went on to say that: "A focus on their [employees] well-being can also add value to organisations by promoting better health and increasing motivation and engagement of employees, in turn helping to drive increases in productivity and profitability. In other words the benefits of health and well-being extend far beyond avoiding or reducing the costs of absence or poor performance."

47 Professor Cary Cooper, Professor of Organisational Psychology and Health at the University of Lancaster and an adviser to the government's Foresight mental capital and well-being project, explains the theoretical background thus: "Of course there is a side of well-being that is just about doing things that make us feel good. However there is another side which is about feeling good about ourselves when we achieve difficult but meaningful goals or objectives." Researchers Boniwell and Henry (2007) identify two broad approaches to the measurement of psychological well-being: the 'hedonic' associates well-being with the experience of positive feelings (moods and emotions) and factors such as overall life satisfaction; the 'eudaimonic' takes account of the importance of having a purpose. Aristotle - the originator of the term eudaimonic -proposed that true happiness is found by 'doing what is worth doing.' Work in the area of positive psychology also supports the idea of purpose and positive emotion as the key ingredients of psychological well-being. ${ }^{85}$ Individuals will maximise their psychological well-being when they are engaged in meaningful work that provides positive emotional experiences. An important study by Waddell and Burton ${ }^{86}$ also identified that work is generally good for physical and mental health and well-being.

\footnotetext{
${ }^{83}$ Health \& Safety Executive: http://www.hse.gov.uk/stress/standards/readmore1.htm. Last accessed 1 July 2009

${ }^{84}$ Black, Carol (2008) Working for a Healthier Tomorrow: Review of the Health of Britain's Working Age Population and at: http://www.workingforhealth.gov.uk/documents/working-for-a-healthier-tomorrow-tagged.pdf

${ }^{85}$ For example, Fredrickson B.L (1998) 'What good are positive emotions?', Review of General Psychology, Vol 2 pp 300-319; Fredrickson B.L. and Joiner T, (2002) 'Positive Emotions trigger upward spiral toward emotional well-being' Psychological Science, Vol. 13 pp 172-175;

${ }^{86}$ Waddell G, Burton AK. Is work good for your health and well being? London, The Stationery Office, 2006
} 


\section{Case Study}

\section{Telefónica O2 UK}

The seven point People Promise outlines O2's commitment to creating the best possible employee experience.

It promises its people a warm welcome, providing a full induction programme and welcome day for all new starters.

People are given the opportunity to get on. Everyone forms a personal development plan with their manager and talks through their career goals at least twice a year. People can learn new skills by applying for a matched contribution Learning Scheme or by using the online academies which offer training on a broad range of subjects.

O2 wants to create a workplace where people trust their senior managers and their line manager. It invests heavily in the leadership skills of its managers, affirming your manager will be there for you.

$\mathrm{O} 2$ people are trusted to do a great job. They're encouraged to suggest new ways of doing things in advisor forums, manager forums, skip level meetings and Ignite, an online system enabling advisors to capture customer insights and share their own.

$\mathrm{O} 2$ wants to be a great place to work. In the current economic climate, it is focusing even harder on looking after its people, improving its total reward offering by introducing new flexible benefits and a broad range of discounts with high street retailers. Vielife, an online health and well-being programme, helps people manage their sleep, nutrition, stress and physical activity. And $\mathrm{O} 2$ Confidential offers free $24 \mathrm{hr}$ advice on issues including benefits, debt, housing, and other financial matters.

O2 people should feel part of something special. For example people are encouraged to volunteer for charities and may be afforded time out for their chosen projects. And they can apply for awards or refer friends and family under the It's Your Community programme, which gives grants of up to $£ 1,000$ to community projects all over the UK.

O2 says thanks for a job well done, praising its people and giving them recognition for their work. A new scheme launching this year will highlight outstanding individual and team contributions to strategic goals, offering people high street vouchers and the chance to attend a glittering annual ceremony. 
Head of Employee Involvement and Experience, Kay Winsper, says: "We want to create an employee experience that appeals to people's emotional and rational commitment. So not only will our people feel proud to work at $\mathrm{O} 2$ - and part of something really special - they'll know it makes financial and professional sense to stay here."

"Working at O2 has many advantages," says Account Manager, Nico Versluys. "One thing that really stands out at the moment is the help and support we get from the management team. They're really listening to their people. They want to know how they can make our working lives better so we in turn can deliver a better service for our customers. I feel we can all have a say in the future of O2. That's something I've never experienced before and certainly never expected to feel in such a large company."

\section{Case Study}

\section{Red Gate Software}

Red Gate Software is a small Cambridge-based software company which produces 'ingeniously simple' software tools for database professionals. They have a low staff turnover rate which they believe is due to the fact that they base their relationships with their staff on communication and trust. They are a rapidly growing company, which has nearly doubled in size over the last two years. In order to maintain high levels of engagement and communication, they have recently taken the relatively simple step of installing a new staff restaurant so that their expanding numbers of staff have a place to relax and interact with new people, breaking down barriers and facilitating effective teamworking.

Red Gate believe strongly that the key to successful engagement is through creating a great culture for people to work in that brings out the best of their creativity and potential.

For Red Gate, engagement is an ongoing, ceaseless, challenge for everyone in the organisation, helping people get the best out of themselves, making them grow, and creating a working environment which is flexible and encourages great work. As one Red Gate employee states: "I've seen more than one person join the company with a fairly low-key, even slightly cynical outlook, only to become one of the company's greatest champions and cheerleaders. That is a real achievement and shows that there's something real going on beneath the 'we invest in people' mantra." 


\section{Case Study}

\section{West Bromwich Tool and Engineering}

One of the workplaces we visited, West Bromwich Tool and Engineering, is a traditional metal-working small company where much of the work is perforce repetitive and not particularly stimulating. Owner Stuart Fell nevertheless believes - and acts on his belief - that his largely unqualified workforce, numbering under 100 , are his greatest asset, and that the way his company succeeds is by creating the circumstances where his employees can - and want to - give of their best. Even in the current tough climate, with staff having to be laid off, the care and consideration with which the workforce are treated means they are willing to go the extra mile when circumstances demand, including hiring vans for a late production run across the country to ensure a delivery deadline was not missed. "It's about fairness, treating people as individuals, about giving individual operators the right to work out for themselves the way they produce the required number of parts per hour. The most stressful thing in life is having no control. We have continuous improvement because the staff here have ownership of the process. We're not an organisation; we're a community. And we all have the pride of knowing that we've contributed a small but essential component to every BMW mini on the road today."

\section{Case Study}

\section{Fujitsu Group}

The European IT services arm of the Fujitsu Group runs an employee survey every 18 months in order to understand the engagement levels and issues of its workforce.

A few years ago, survey results revealed that career development was one of their UK employees' major concerns. After analysing the results more closely with the help of employee focus groups, it became clear that the company did in fact have many tools available to help with career development, but they were not well publicised. Employees had assumed that, having received little communication on their development, the company was unable to support them in this respect.

In response to this feedback, Fujitsu published a detailed 20-page brochure for its 12,000 UK-based employees, summarising its career development principles and practices. This covered a multitude of learning related topics ranging from professional communities and learning academies, to career mapping tools and workshops to help employees manage their own career direction. 
Fujitsu also updated its corporate intranet to include an enhanced and extensive sub-site termed "Invest in Yourself". This included an outline of career development policies, career maps and self-assessment, and a catalogue of over 400 training courses available to employees.

Eighteen months later, Fujitsu's employee survey results showed the impact. People's perception of their career development opportunities had moved strongly upward. Fujitsu is now recognised in the UK as one of only 33 Investors in People Champions. Sue Payne, Head of People Development Services, says: "This is a good example of how we were able to use the results of our engagement survey to identify an issue of great importance to our people. We did have the processes in place to support our people - we just weren't explaining it properly. Once we understood this, we were able to close the gap and have a genuine impact on engagement levels."

48 Engagement-based well-being can be maintained in a recession. Research by Professor Sharon Parker from Sheffield University ${ }^{87}$ suggests that introducing deliberate work organisation and change management strategies can combat the negative effects of reduced headcount. Results from a four-year longitudinal study showed that there was no overall decrease in well-being from before to after downsizing for the 139 employees remaining in an organisation despite an increase in work demands. The potentially detrimental effect of increased demands appeared to have been offset by improvement in work characteristics arising from initiatives introduced as part of the downsizing strategy. The study showed that high demands were associated with poorer well-being, but that increases in control clarity and participation were associated with improved well-being.

\section{Conclusion}

49 This chapter sets out some of the findings to date in what we hope will be a useful and accessible way. Our conclusion from the evidence available, including our own first hand observations of the impact of successful employee engagement in practice, is that the correlation between engagement, well-being and performance is repeated too often for it to be a coincidence.

\footnotetext{
${ }^{87}$ Parker, S.K., Chmiel, N., and Wall, T.D. (1997) 'Work Characteristics and Employee Well-Being Within a Context of Strategic Downsizing' Journal of Occupational Health Psychology
} 


\section{Chapter 3}

\section{The Barriers to Engagement}

1 Despite the compelling case for employee engagement, we know that a significant percentage of the workforce feel disconnected from the work they do and the people they work for. Whilst accepting that all of us are capable of having a 'bad day at work' we do not accept the inevitability of work being just one bad day after another.

2 Britain's workplaces reflect changing attitudes, norms and expectations in wider society. The so-called 'death of deference' has impacted on the employer-employee relationship. Much has also been made of 'generation $Y$ ' who have high expectations about what work will offer them in terms of self-fulfilment. ${ }^{88}$

3 However we would argue that these higher expectations are not limited to one particular demographic. Increasingly employees expect to be treated as human beings with rights and responsibilities as, for example, the introduction of the right to request flexible working for those with children or caring responsibilities recognises.

4 We have, during this review, identified four broad inhibitors to effective engagement by an organisation's leadership and management; these inhibitors occur across private and public sectors;

- Some leaders are not aware of employee engagement. Others do not believe that it is worth considering, or do not fully understand the concept and the benefits it could have for their organisation.

- Others who are interested in the topic do not know how to address the issue.

- Even when leaders place great emphasis on the idea of employee engagement, managers may not share the belief, or may be ill-equipped to implement engagement strategies. As a result the organisational culture is unable to deliver engagement.

- Among those leaders who are concerned with employee engagement, there is great variability in their views and commitment to it. Often the potential of employee engagement is underestimated. For some, engagement is an annual staff survey whose results may be acted on; for others a survey is no more than one tool in an overall approach that places employee engagement at the core of the organisation's strategy.

\footnotetext{
${ }^{88}$ A term often loosely applied and used to describe, broadly, the generation born in the 1980s and now entering the workplace who, according to some observers, have higher (than previous generations) expectations of how they should be treated by employers, are more likely to want to shape their jobs to fit their lives, rather than the other way round, and are less likely to accept the judgment of those in authority.
} 


\section{Lack of awareness}

5 In the course of our review, we spoke to a wide range of stakeholders in all sectors of the economy. It became evident that a large number of leaders remain unaware of the concept of employee engagement, and the benefits it could bring their organisation. Accor report that 75 per cent of leaders have no engagement plan or strategy even though 90 per cent say engagement impacts on business success. ${ }^{89}$ That is why our key recommendation is for a nationwide effort to raise the profile of the issue and to increase the availability of practical support. This lack of appreciation at the most senior level of what employees contribute is underscored by Accenture's finding that over half of Chief Financial Offers surveyed had nothing more than a minimal understanding of the return on their investments in human capital. A further 30 per cent understood it to a modest level and only 16 per cent demonstrated a considerable understanding..$^{90}$ Philip Whitely of the Human Capital Forum told us that what was required was "a Copernican shift, ditching the centuries old dominance of accountancy as the way of understanding the organisation." (web response to call for evidence). On the other hand, Mel Flogell, head of HR policy at Centrica, believes investors are becoming increasingly interested in engagement, as more people realise an engaged workforce delivers value to an organisation. "Ensuring staff are performing to their full potential is how organisations will secure their competitive advantage. Investment in people is imperative for delivering the business strategy, and shareholders are going to look for evidence for this." And in a new departure, AXA WF Human Capital Fund cites human capital as a primary criterion for investment. ${ }^{91}$

6 Uncertainty over engagement is also reflected in a fear that engagement might be seen as too 'soft and fluffy' or as 'not the British way'. As the law firm Freshfields, Bruckhaus Deringer told us, when they introduced their groundbreaking engagement strategy for legal associates, "we could have come at it from a fluffy approach, but it wouldn't have worked. So we put the performance metrics up front."

\section{Uncertainty about starting}

7 Others, while they were interested in what engagement could offer, did not know how to address the topic within their organisation. This lack of certainty about how and where to start can be compounded by the feeling that employee engagement is something that is 'out there' - a product one buys, often at great expense. It is not always helpful to focus on employee engagement as a product; this in itself can be a barrier to action.

\footnotetext{
${ }^{89}$ Accor: Reward to Engage: Rewards, Benefits and Employee Engagement in Today's Organisations and at http://engagement.accorservices.co.uk/website/employee-engagement-whitepaper-form.html. Last accessed 1 July 2009

${ }^{90}$ Accenture, 'An Accenture point of view on Employee Engagement - What it is. Why it matters. How you can change it'. Produced for the MacLeod Review, December 2008

91 Lauren Mills (2008) 'Human Capital: Meaningful Metrics' Management Today, 3 November 2008
} 
8 There are also those who have a tendency to confuse wishful thinking with positive action on employee engagement. Thus the ACCOR Services Report ${ }^{92}$ found that although nearly three in four leaders rate their levels of staff engagement as above average, it appears that the vast majority of them are guessing. "There is a sense that while employers recognise the importance of engagement they don't quite know what to do about it. The issue seems to lie in their unwillingness to talk the talk and truly relinquish command and control styles of leadership in favour of a relationship based on mutuality. As a result many organisations have tapped into what they want from employees as a result of employee engagement - that is high performance - but they haven't tapped into what's in it for the individual who goes the extra mile."

9 When we reviewed current thinking on employee engagement we found that, whilst many appeared to recognise the importance of employee engagement and the strategic role HR and other professionals could play in increasing engagement levels, many are uncertain of how to enable the conditions for engagement to flourish.

\section{Managers and organisational culture}

10 Thirdly there remain a large number of disengaging practices in Britain's workplaces which act as barriers and which if not addressed can stymie attempts to introduce engagement. As Ruth Spellman of the CMI told us, "for a high quality of working life it doesn't matter so much what the business is but how the people in that business behave." 93

11 Kingston Business School identified these practices as:

- Reactive decision-making that fails to address problems in time;

- Inconsistent management style, based on the attitudes of individual managers which leads to perceptions of unfairness;

- Lack of fluidity in communications and knowledge sharing, due to rigid communication channels or cultural norms;

- Low perceptions of senior management visibility and quality of downward communication;

- Poor work-life balance due to long hours culture.

12 The same report goes on to say that "attitudes to senior managers are often quite negative. The evidence is that only a third of employees have confidence in or trust their senior management team, while only two in five say that directors and senior managers treat employees with respect." Kingston's report found that only 40 per cent of employees are satisfied with relations between managers and employees in their organisation; 27 per cent are satisfied with the way their organisation is

\footnotetext{
${ }^{92}$ ACCOR: Reward to Engage

${ }^{93} \mathrm{CMl}$ evidence to the MacLeod Review
} 
managed; 32 per cent say that their manager rarely or never discusses their training and development needs with them, 30 per cent rarely or never got feedback on their performance and 25 per cent are rarely or never made to feel their work counts $^{94}$.

13 In their evidence to the review The Co-operative Group pointed to similar potential barriers to individual engagement, including employees' perceptions that they were not being treated fairly at work, not being helped to improve and develop new skills and realise their potential. ${ }^{95}$ Adrian Askew, the General Secretary of Connect, pointed to "the whinge and blame culture that still exists."

14 Many people we spoke to identified managers' approaches and behaviours as key factors in disengagement - as one respondent said, they sometimes act as "a great impermeable damp-proof course." Jeff Kelly, of the Partnership Institute, told us at a round table discussion for this review: "There is a territorial problem and a comfort zone problem. Many feel comfortable with managing staff on an adversarial basis and don't want to give it up."

15 Kelly's point is underlined in a report on programmes undertaken by Professor John Oliver of the Northern Leadership Academy, on behalf of the North West Automotive Alliance between late 2007 and Spring 200996: "... in our view, the biggest challenge is the nervousness and uncertainty in managers moving outside their comfort zones and dealing with employees they may have managed over a long period. Facing up to initial scepticism or even cynicism can dissuade many in this position, particularly as this negative reaction could last for many months."

16 Ruth Spellman of the CMI also pointed to "poor management skills and 'amateur managers' who have an inability to let go and allow staff to take ownership of their work. This results in very good people becoming frustrated about not being allowed to do a good job and become disengaged."

17 John Oliver believes that the obsession with targets often infects managers' behaviour and detracts from their ability to interact effectively with their staff. He told us: "Ninety-nine per cent of failure to engage staff is down to management behaviour. The management paradigm which introduced management by objectives and KPIs [key performance indicators] changed the whole way of thinking around good and bad management. Managers often focus on what they are judged on i.e. KPls. They give the impression on the shop floor that they are much more concerned with outputs than people. There is less humanity and more mechanistic behaviour despite superficial friendliness and a 'call me Dave' type lack of formality with staff; I call this kind of manager the 'friendly automaton'."

\footnotetext{
${ }^{94}$ Truss, C., Soane, E., Edwards, C., Wisdom, K., Croll, A., And Burnett, J. (2006) Working life: employee attitudes and engagement $2006 \mathrm{CIPD}$

${ }^{95}$ The Co-operative, evidence to the Macleod Review

${ }^{96}$ John Oliver (2009) 'Culture Change and Employee Engagement: Overall Outcomes, Programmes', Team Enterprise Solutions.
} 
18 This is borne out by a study of first line managers reported in the Journal of Management Studies ${ }^{97}$ which found that supervisory duties remained much in evidence and that devolution of responsibility to teams remains rare.

The Henley Centre quotes two employees on the effects of disengaging managers:

"I think one of the things that has surprised me is none of my line managers has asked me what I am interested in. We just get jobs which have been allocated. We've never explored whether this person might be more suited to this kind of work."

"I feel less engaged when I'm micro-managed, when I'm given work which is intellectually unstimulating, bureaucratic and I don't see the impact it is having."

19 Many respondents to the review stressed the need for better training for managers in so-called soft or people skills, both as part of the current syllabus for business qualifications, and more generally. Many felt that current skills training concentrated too heavily on qualifications and too little on how people skills were implemented within the workforce. There was a consistent call, in particular, for the wide range of skills training provided under the government's aegis to reflect this need. As one said, "too often managers are promoted because of their competence in the job they last did - not because they've the right skills for the new one."

20 Managers themselves are critical of the quality of management training they receive from their company. Accenture found that just over three in five middle managers in the UK felt it was either good or fair; less than one in ten deemed it excellent, one in five felt the training was poor and one in seven said they received no training from their companies. Middle managers rating of their own supervisors revealed similar figures. ${ }^{98}$

21 On the other hand, middle managers who become convinced of the need for change can themselves run up against barriers. A study by Alimo Metcalfe et al revealed that the three most formidable blocks to success were the behaviours and attitudes of the most senior managers.

\footnotetext{
${ }^{97}$ Hales C. (2005) 'Rooted in Supervision, Branching into Management: Continuity and Change in the Role of First Line Managers', Journal of Management Studies, Vol 42. No 3 pp 471-507

${ }^{98}$ Accenture survey (2008): Middle Managers Outlook UK
} 
"The first barrier was that these top managers believed that their status in the organisation was evidence enough that they 'had what it took' to be regarded as a leader, and regarded their development as therefore unnecessary. Nonetheless, they believed that the managers below them needed it. However, when the managers returned to the workplace with a clearer idea of what leadership should look like, they became much more aware of the poor quality of leadership role-modelled by their senior managers, and their frustrations increased. This was deepened by another major problem, which was that when the managers attempted to implement their learning, their suggestions for improvement were rejected or ignored by their somewhat defensive and/or reactionary bosses.

"The result was disenchantment, greater cynicism and lower morale among the manager group, who eventually stopped making any suggestions or trying new ways of leading." (Quoted in CIPD Research Insight, Engaging Leadership: creating organisations that maximise the potential of their people).

\section{Underestimating engagement}

22 Respondents to the review expressed concern that some leaders regarded employee engagement as another job on the to-do list that could be ticked off once an annual staff survey had been carried out, and the results, perhaps, delegated to HR and line managers to fix. This is to miss the point that keeping employees engaged is an on-going process that needs to be hard wired into an organisation's DNA. The British Association of Communicators in Business emphasised the importance of the chief executive and the senior management team seeing this issue as "an integral part of higher-level strategic activity rather than something they are supposed to do, but that is not a core function." ${ }^{\prime 9}$

23 Nor is engagement something that can be achieved overnight. Professor John Purcell in a note to the review pointed out that the need for quick results did not sit easily with the extent of culture change that might be needed.

24 There can be an over-emphasis on measurement at the expense of change. Indeed to carry out a survey and then not follow it through by implementing changes based on that survey's results, is more likely to disengage staff than not doing a survey in the first place. Two employees quoted by the Henley Centre illustrate the damage done when lip service is paid to engagement ${ }^{100}$ :

\footnotetext{
${ }^{99}$ Submitted to MacLeod Review by email, Call for Evidence

${ }^{100}$ Henley Centre of HR Excellence
} 
"We have a bi-annual survey and the results were critical. Action plans were prepared by the team members but the manager took it and did something entirely different with it. This was very disengaging."

"I think it's disengaging to be asked for input into something and then not have feedback about what difference that made or whether it contributed in any way."

25 It is, of course, important to take soundings and find out what the state of play is within an organisation. A staff survey may be a useful means of testing out levels of engagement, but it is not enough by itself, particularly if it leads simply to trying to change the engagement score, rather than really fix the issues that make up the score.

26 The Communications Lab were just one organisation pointing to the need for engagement approaches to be bespoke for the organisation. "There is often little consultation with employees about what engagement might mean to them. Often it is defined in the ivory tower and measured by an impersonal on-line survey, and very few people feel listened to via completing an online survey". ${ }^{101}$

27 Others pointed to the key difference between communications and listening, and the need to "move away from transactional two-way communications to listening and demonstrating that you have heard; trusted dialogue rather than two-way communications," as the Communications Lab put it.

\section{Two levels of employee engagement}

28 It has become increasingly clear to us throughout the review that there are broadly two levels at which engagement can operate.

29 The first level sees an employee engagement strategy as essentially a set of activities or targets. This approach often reflects a degree of compartmentalised thinking among the senior leaders: for example they may have individual strategies for their product positioning in the market place, their geographic focus, their IT renewal - and a human resources strategy. The Board takes the engagement strategy seriously; there is an annual or bi-annual survey to measure engagement levels and the views of staff are sought; departments including HR are then tasked to follow up the survey results. There is little about any of the component parts that can be criticised and it certainly does bring benefits. Nonetheless, in this model, employee engagement is still an 'add-on'. It is not integral to the overall business approach. It is essentially a set of transactions.

30 The second level sees employees as an integral part of developing and delivering the overall business strategy. This strategy will cover the values and behaviours that are required from everyone in order to deliver the company's position in the market

\footnotetext{
${ }^{101}$ Submitted to MacLeod Review by email, Call for Evidence
} 
place, its territorial focus and so on. Employees are at the heart of strategy development and of delivery. The insights of the front line, for example, constantly inform the development of the strategy, ensuring it is market responsive. The insights and ideas of employees, wherever they work, about how products and services can be improved, are harnessed, listened to and acted on. Employees' views about the organisation or service as a whole, are regularly sought, and identified improvements acted on. This is transformational engagement.

31 Based on CIPD's experience of talking to organisations who are implementing employee engagement strategies, Chief Executive Jackie Orme estimates that around 75 per cent fall into the first category with 25 per cent in the second.

\section{Particular barriers faced by SMEs}

32 Many of the barriers to engagement described above have the potential to affect organisations of any size. However, during the course of the review we have been told repeatedly of several potential challenges that seem to be particularly relevant for those running and working in SMEs, particularly dealing with the consequences of growth. We deal with engagement and SMEs in the next chapter. 


\section{Chapter 4}

\section{Enablers of Engagement - What has to happen to make engagement work}

1 In the previous chapter we set out some of the key barriers to engagement. In this chapter we identify some of the key enablers.

2 There is a great deal of published academic work on what drives engagement. In addition to this we have garnered views from a wide range of practitioners, employers, academics, consultants and employees themselves. There is, of course, a range of opinions on what the key drivers or enablers of employee engagement are. As an example, the top ten drivers identified by Towers Perrin - ISR through employee-opinion research shows that of seventy five possible drivers of engagement the one that was rated as the most important was the extent to which employees believed that their senior management had a sincere interest in their well-being. This same research goes onto ask employees whether they think their senior managment actually exhibit this attitude and behaviour. Thirty-nine per cent said they did not believe this would be the case, 32 per cent were neutral and only 29 per cent felt that their senior management was sincerely interested in their well-being. The second driver was the extent to which employees believed that they had improved their skills and capabilities over the previous year. Feedback on this driver was significantly more positive with 62 per cent believing that they had improved their skills and capabilities, 23 per cent were neutral, whilst 15 per cent believed they had not ${ }^{102}$. We recognise that there is no 'one size fits all' model of engagement; in addition, different organisations will vary in their needs and their approach.

3 Studies show that pay and conditions are important in attracting people to organisations, but subsequently act as more of a 'hygiene' factor. In other words if handled badly or perceived as unfair, they will act as a demotivator. As Frederick Herzberg pointed out ${ }^{103}$ "the factors involved in producing job satisfaction (and motivation) are separate and distinct from the factors that lead to job dissatisfaction... these two feelings are not opposites of each other. The opposite of job satisfaction is not job dissatisfaction but rather, no job satisfaction; and similarly, the opposite of job dissatisfaction is not job satisfaction, but no job dissatisfaction." IES research has

\footnotetext{
${ }^{\mathbf{1 0 2}}$ Duhaldeborde Yves, ISR 'Review of Employee Engagement, June 2009', slides prepared specifically for the MacLeod Review

${ }^{103}$ Herzberg, Frederick (2003) 'One More Time: How Do You Motivate Employees?' Harvard Business Review
} 
pointed to the varied and organisationally specific mix of financial and non-financial factors that contribute to staff feeling valued and involved. ${ }^{104}$

4 This report is not a 'how to' guide. However, we were struck in the course of the review how often the same four broad enablers / drivers were cited as being critical to employee engagement.

5 LEADERSHIP provides a strong strategic narrative which has widespread ownership and commitment from managers and employees at all levels. The narrative is a clearly expressed story about what the purpose of an organisation is, why it has the broad vision it has, and how an individual contributes to that purpose. Employees have a clear line of sight between their job and the narrative, and understand where their work fits in. These aims and values are reflected in a strong, transparent and explicit organisational culture and way of working. The late Professor Sumantra Ghoshal, formerly of the London Business School, believed that organisations which were successful in the long haul were characterised by stretch, discipline, trust and support; they were 'both tough and tender'.

6 ENGAGING MANAGERS are at the heart of this organisational culture- they facilitate and empower rather than control or restrict their staff; they treat their staff with appreciation and respect and show commitment to developing, increasing and rewarding the capabilities of those they manage. As Chris Bones told us, "the line manager is the lens through which I see the company and the company sees me."

7 VOICE An effective and empowered employee voice - employees' views are sought out; they are listened to and see that their opinions count and make a difference. They speak out and challenge when appropriate. A strong sense of listening and of responsiveness permeates the organisation, enabled by effective communication.

8 INTEGRITY Behaviour throughout the organisation is consistent with stated values, leading to trust and a sense of integrity.

9 Later in this chapter we comment on the particular issues and enablers for SMEs, the role for and types of employee ownership, on corporate social responsibility (CSR) and on talent and diversity.

\footnotetext{
${ }^{104}$ Robinson D., Perryman S., Hayday S (2004), 'The Drivers of Employee Engagement', Report 408 Insitute of Employment Studies; Reilly P., Brown D. (2008), 'Employee Engagement, What is the Relationship with Reward Management?'; HR Network Paper MP83 Institute of Employment Studies
} 


\section{Leadership: Strategic Narrative}

10 A strong narrative that provides a clear, shared vision for the organisation is at the heart of employee engagement. Employees need to understand not only the purpose of the organisation they work for but also how their individual role contributes to that purpose. As Ruth Spellman of CMI told us: "First employees need to have an understanding of the business they are in. Employers need to ensure that jobs fallen into by accident become the 'real deal'". Dianne Thompson, Chief Executive of Camelot said to us: "Particularly in very difficult economic conditions it is vitally important that leaders focus on the morale and motivation of their employees. Understanding the journey that a company is on is critical to keeping employees engaged."

11 Despite a widespread recognition that employees' buy-in to an organisation's mission is important, evidence suggests that too little is being done to achieve this. Accenture's High Performance Workplace study found, for example, that only around 40 per cent of those surveyed understand their organisation's strategy. ${ }^{105}$

12 Visible leadership can also be critical for engagement. Margaret Jackson, HR Director at Aintree NHS Hospital Trust told us: "The CEO keeps in touch with what is happening in AEE and will go down to the department when it is particularly busy and staff are being especially stressed. This visible leadership is encouraged, with all directors being expected to 'walk the floor' on a regular basis and directors and non-executive board members undertaking regular visits to different parts of the trust."

\section{Case Study}

\section{Babcock Marine Clyde}

Babcock Marine Clyde, part of the Babcock International Group PLC, provides engineering support services to the Royal Navy at HM Naval Base Clyde near Glasgow. During its first five years in business to September 2007, it successfully delivered cost savings to its customers amounting to $£ 76 \mathrm{~m}$, whilst also improving performance. As the Company has no fixed assets but only its people as a source of improvement potential it has had to develop a robust method of engagement that gets the best from its 1,400 strong workforce.

\footnotetext{
${ }^{105}$ Accenture (unpublished). 'An Accenture point of view on employee engagement - what it is, why it matters, how you can you change it', Produced specifically for the MacLeod Review, December 2008.
} 
In order to increase the levels of engagement, the company decided to design a narrative graphic outlining the organisation's journey, mission and vision that would be relevant to everyone irrespective of their position in the organisation. The graphic stimulated discussion of the business goals and values, change factors and achievements to date, as well as hopes for the future. It allowed all staff to feel ownership of the company's vision and the strategy required to achieve it. Following on from this exercise, the business management created a business plan which was specifically written in a common language so that every individual would be able to visualise exactly where they contributed to the success of the organisation. Managers and team leaders were challenged individually to identify which high level objectives were most pertinent to their teams and in what ways. A number of Departments created their own 'mini business plan' to contextualise objectives for their people at a local level.

Tangible benefits that have been attributed, at least in part, to various engagement activities include a reduction of 30 per cent in sickness absence between $2005 \& 2009$ and a 50 per cent reduction in reportable accidents from 18 to nine between $2007 / 08$ and 2008/09. Project performance has significantly improved, resulting in overall project performance going from a 48 per cent overrun to less than three per cent. BMC's approach to engagement is summed up by the current Managing Director, Craig Lockhart who says "our people have delivered and I am confident that they will continue to deliver, so long as we are all clear on the expectations we have of each other".

"Three years ago, Warner Bros. UK began work on a staff research project that would eventually grow into a multi-layered employee engagement programme that remains at the heart of the company's commitment to being a best-in-class organisation. The results of that investigation were critical to the successful construction of a robust route map to better employee engagement.

Thanks to the efforts of four staff-led project groups, we have implemented over 50 high impact - and in many cases low cost - initiatives since the end of 2007. Most if not all continue to this day and many have dramatically changed the landscape of working life here at Warner Bros. UK.

The bottom line here is that employee engagement never stops; it is a key business objective for Warner Bros. UK, now and in the future, and its continued success is based on the ongoing allocation of time and resource." Josh Burger, President and Managing Director, Warner Bros. UK 


\section{Case Study}

\section{Telefónica $\mathrm{O} 2$}

O2's 'fandom' aim for 2011 is simple: to have twice as many customers who are fans as its nearest competitor.

But to turn its customers into fans, $\mathrm{O} 2$ must first do the same to its people, engaging their hearts and heads. Only with a workforce that both cares about and fully understands its goals will it succeed.

"We want our people to come with us on the journey, love O2 and love our customers, " says Head of Internal Communication, Jenny Burns. "Gaining their emotional commitment is vital but it's no good if they don't understand the strategy and the role they play in it, so there has to be a clear vision in the first place. We want to paint a picture of where we've been, where we are and where we need to be in the future that is easily shared and often talked about."

The world of fans and 'fandom' is something that resonates with everyone at $\mathrm{O} 2$ and is brought to life through involving and two-way internal communication.

Face-to-face briefings hosted by the CEO and his team demonstrate ownership and direction from the top. And channels including intranet, video, email and print keep telling the story, demonstrating proof points along the way.

Open communication is key to everything. With the company constantly evolving and growing, the long term plan for $\mathrm{O} 2$ isn't kept for a privileged few.

"It's not unusual for a company to have a three year business plan," says CEO, Ronan Dunne. "What's unique about ours is that we're articulating the journey to everyone. We're creating visibility across the entire organisation regarding decisions, investments and choices that will define the path we'll travel in later years."

7side is a good example of a small business that has seen great success in recent years following a change of culture which was predicated on the belief that employees were integral to the business and needed to fully understand and share the 7side strategy. Sam Lloyd, Managing Director of 7side told us: "I believe that the key to success in engendering a culture of employee engagement is a sound foundation with all employees fully understanding why we are here and, more importantly, where we are going. It is extremely important to underpin the agreed foundation with regular communication and complete financial transparency." 


\section{Case Study}

\section{7side}

7side is a small business based in Cardiff providing corporate and property search data, documents and services. For 23 years it was a traditional successful organic growth partnership with a focus on protection of senior owner equity. Five years ago it became a limited company with a new board of directors, eager to break away from its historical approach of command and control and ready to compete in a new technology driven market place dominated by the commercial giants. This could only be achieved by taking bold investment steps and changing the longstanding culture of employee expectancy that strategy, innovation and development was purely in the hands of the business owners. They recognised that radical change was needed to survive and thrive, with every single member of the organisation being a critical component of the process.

7side developed a new Foundation with its employees which included Mission, Vision, Values and Culture statements that were discussed and communicated with staff to deliver a clear message on the direction of the organisation and create a clear framework for all decisions and behaviours. Positive culture changes, shared values, agreed attitudes, beliefs and behaviours are now profoundly imbedded within the organisation. Strategic business planning involves input from all staff resulting in an inclusive system that encourages innovation and creates a strong sense of personal ownership and destiny control. Tangible profit share and recognition benefits have been implemented and multiple fora for active regular and structured communication are in place.

Continual development of the business leaders was also seen as critical and 7side has called on expert external support for diagnostics and coaching support.

7side is convinced that its total engagement culture has been critical in its business success as it has led to consensus employee decisions to combat the economic crisis, resulting in significant 'bottom line cost savings' and a true sense of positive team spirit. It has helped them gain recognition as a market leader and win contracts against industry heavyweight competitors. They have attracted at least 75 per cent of the top 100 UK legal law and accountancy firms as customers and boast the position of world's biggest customer and reseller of the Companies House Direct on-line service.

Their compounded growth for the last three years was 49 per cent and despite a financially challenging six month period from June 2008 as a result of inactivity within their client base of corporate and property legal clients, they have managed to turn the situation around and are back on course to grow turnover by a further 30 per cent by the end 2010, operating effectively with leaner, more efficient operating systems and costs. 
14 Strategic narrative also plays a vital role in the public sector, very much including the local government sector, where both the Chief Executive and the Council Leader influence the development of the organisational direction.

\section{Case Study Chorley Borough Council}

In 2006, Donna Hall arrived at Chorley Borough Council as Chief Executive bringing a new and very different style of leadership, and setting the organisation's focus clearly on the customer. Prior to her arrival, Chorley's performance was average; Donna streamlined the workforce and the management team and the council is now rated as excellent by the Audit Commission, is a Beacon council for customer service and the best improver in The Times Best Council to Work for 2008.

Turnaround has been quick yet welcomed by staff who warmed to the new open culture that Donna has put in place and have embraced the 'customer first' vision. Listening days where all staff contribute ideas that get acted upon, back to the floor exercises to keep managers in touch with staff and residents, a well-being programme and a focus on sickness absence have all proved their worth. Levels of sickness absence have reduced, morale is higher and staff are increasingly ambassadors and proud to say they work for Chorley.

Mechanisms like the top 50 manager forums and management development programme mean that the style and vision which Donna has set out permeates through the organisation. As Donna says: "I don't have the monopoly on good ideas, the people who do the job are now being asked and because we're a small council we need everyone to play their part. Our Chorley Smile campaign helps communities tell us what would make life better and our people are proud to help make that happen. We simply needed to remind ourselves what we are here to do - serve the public - and put that at the heart of the way we work."

\section{Engaging Managers}

15 An engaging manager is at the heart of success in engaging the workforce. Accenture's internal research showed that 80 per cent of the variation in engagement levels was down to the line manager. ${ }^{106}$ As a result, employees' most important relationship at work is with their line manager; people join organisations, but they leave managers.

16 Employees need managers who are themselves engaged and who are seen to be committed to the organisation. Standard Chartered Bank in a submission to this review said that organisations need to 'know, focus, care and inspire employees'.

\footnotetext{
${ }^{106}$ Note from MacLeod Review round table meeting held with Accenture, 11 February 2009
} 
The role of the manager was key. "We need consistencies between values and behaviours. We need to have honest conversations and sometimes difficult conversations. We need to talk to employees about 'what really gets you out of bed'. We really need to understand people."

17 The role of the manager is also key to the engagement levers with the greatest impact on discretionary effort identified by $\mathrm{CLC}$ research on this topic ${ }^{107}$ : understanding how to do one's job, a belief in the importance of it and understanding how to complete one's work. These are more critical in driving effort than any other day-to-day work factors including resources, job quality, suitability for role and personal goals.

18 From a rich and varied set of submissions for this report we have concluded that three things are required from managers so that they become, and are seen to be, engaging managers. Firstly, engaging managers offer clarity for what is expected from individual members of staff, which involves some stretch, and much appreciation and feedback/coaching and training. The second key area is treating their people as individuals, with fairness and respect and with a concern for the employee's well-being. Thirdly, managers have a very important role in ensuring that work is designed efficiently and effectively.

\section{Engaging managers offer clarity, appreciation, positive feedback and coaching}

19 The Gallup Q12 ${ }^{108}$ questions which the company believes are a very important underpinning to engagement are: 'I know what is expected of me at work', 'in the last seven days I received recognition and praise for doing good work' and 'at work my opinion seems to count'. 'Knowing what is expected of me' seems to be enhanced when it is accompanied by some positive stretch. Saks et al in $2006^{109}$ point out challenge plays a key role providing that it offers stretch and can be overcome successfully, but is not so great that it leads to stress and disengagement.

20 Coaching and feedback are critical. A Watson Wyatt survey" says that "our data shows that engaged employees have frequent work related discussions with their immediate manager in comparison to their colleagues with medium to low engagement levels. Forty-three per cent of high engaged employees receive feedback at least once a week compared to only 18 per cent of employees with low engagement".

\footnotetext{
${ }^{107}$ Corporate Leadership Council Presentation to MacLeod Review, 2009

${ }^{108}$ http://www.gallup.com/consulting/52/employee-engagement.aspx

${ }^{109}$ Saks, A.M.(2006) 'Antecedents and Consequences of Employee Engagement'. Journal of Managerial Psychology Vol 21 (no. 7)

${ }^{110}$ Watson Wyatt, 2008-2009 Work Survey Report, Continuous Engagement: The Key to Unlocking the Value of Your People During Tough Times
} 
21 CLC argue much the same ${ }^{111}$; their research reveals a general lack of specific enough feedback on good performance. They define this as differentiating performance: in other words that really good performance is recognised. This feedback needs to be commensurate with the contribution. It is important to differentiate between basic respect for the individual and recognising and rewarding people commensurate with their contribution. Ensuring that managers had the capability to carry out performance management was identified as key in a Work Foundation report, What Makes for Effective Performance Management. ${ }^{112}$ Many respondents pointed to the feedback from employees who make it clear they resent the fact that bad performance is not properly addressed or managed, or differentiated from good performance.

\section{Soft skills for leaders and managers}

22 The Leitch Review of 2006 concluded that the UK spends less per manager than any other European country on management development. Acas and CIPD point out that in 2008 just three per cent of the government's Train to Gain budget was allocated to the development of generic leadership and management skills. ${ }^{113}$ One of the top issues highlighted throughout reports from the Sector Skill Councils is the need to address leadership and management skills almost above all else. Attendees at our review round tables held with the Institute of Hospitality and the Financial Services Skills Council also stressed the need for better soft skills training and support. The 2004 WERS report concluded that the main reason for failures of SMEs is down to poor leadership and management.

23 So what is good leadership and management when it comes to soft skills? It starts by understanding the role of leaders. Stephen Taylor, former Chief Executive of the Leadership Centre for Local Government, offers a useful and simple working definition of leadership as "creating a space in which people can do and want to do what needs to be done." He goes on to argue that by understanding oneself, the team, the organisation and the operating environment, the leader is in a better place to address the more practical tasks.

24 The Acas and CIPD report identifies these practical tasks simply and clearly as: managing work now and in the future; managing the team; managing the individual; managing conflict and difficult decisions and lastly managing yourself.

25 Gillian Stamp in evidence to the review talked of the tripod: the need for leaders and managers to 'task, trust and tend' people. She also spoke of the need for leadership and management to manifest itself differently and appropriately to the different levels of activity inherent in all organisations; managers' capability similarly needed to be appropriately matched to their level in the organisation.

\footnotetext{
${ }^{111}$ Corporate Leadership Council, Presentation to MacLeod Review, 2009.

${ }^{112}$ Armstrong K., Ward A. (2006) What Makes for Effective Performance Management? Work Foundation

Publication in their Corporate Partners Research Programme.

${ }^{113}$ Acas and CIPD (2009) 'Meeting the UK's people management skills deficit'
} 
A report by Towers Perrin conducted for O.C. Tanner in 2008 showed that in organisations with generally low levels of engagement, strong manager performance in recognising employee performance increases engagement from 33 per cent of employees giving a favourable engagement score to 52 per cent. ${ }^{114}$ In generally higher-engagement organisations, where opportunity and well-being are clearly part of the culture, the effect of manager recognition is less striking but nevertheless significant.

\section{Case Study \\ Mace Group}

Mace Group is an international consultancy and construction company. It has a projected $£ 700$ million turnover for 2009 and employs approximately 2,800 staff in 35 countries. By engaging employees, Mace aims to attract and retain the best people. The company has developed its own engagement model that focuses on providing interesting work, opportunities for two way communication, training and development and corporate social responsibility. But the company also believes that line managers play a critical role in engaging employees, and consequently invests considerable resources in training and supporting them. Good basic management skills, rather than specific training on how to engage staff, have improved engagement across the company.

Roles at Mace are designed to be challenging, varied and rewarding in order to sustain interest and encourage engagement. Employees are encouraged to move around the company to vary their work and support their development. They are given responsibility for decision making and the independence to deliver in ways they see fit.

This flexible approach to job organisation has challenged Mace to develop effective line management. Micro-management would undermine the autonomy which Mace believes is crucial for engaging staff; as Mace's Employee Engagement Manager said, "It is not the job of our managers to constantly look over their team members' shoulders." Instead, Mace have developed a Manager's Charter which defines a new role for line managers as people who successfully recruit, lead, enable, appraise, develop, evaluate and recruit people in their teams. Mace has also instituted leadership programmes and skills training called 'Managing people @ Mace' to support those in line management roles.

${ }^{114}$ OC Tanner/Towers Perrin 'Turbocharging Employee Engagement: The Power of Recognition from Managers' (2009) 
A recent survey of Mace employees conducted by Kingston Business School's Employee Engagement Consortium shows that investment in good line management is paying off and that roles remain engaging. Approximately 90 per cent of employees strongly or very strongly agreed that they were intellectually and affectively engaged in their roles, and 80 per cent agreed that their manager helped them to fulfil their potential. Mace has also found other business benefits to engagement: engaged employees are more prepared to recommend their organisation to others as a good place to work, which is an important objective for Mace. Engagement has also benefited retention, with 94 per cent of employees saying they plan to stay at the company. Mace has a lower turnover rate than the industry average. Although it is hard to directly account for the impact of engagement on Mace's profit margins, the company believes that engaged employees increases customer satisfaction and loyalty, which in turn, boosts profitability.

\section{Case Study}

\section{Network Rail}

When Network Rail was formed in 2003, it brought in a consultancy firm to measure engagement and found very low levels of engagement in the organisation. In their business, employee engagement is key in a number of areas of business performance, including safety, and action had to be taken to improve engagement as a means of improving performance.

Network Rail saw good leadership and good management as being the most important elements of high engagement, as Bob Hughes, Talent and Employee Engagement Manager says. "There is no magic bullet to high engagement; it's simply about improving the relationship between manager and managed. So, we invested in leadership development programmes designed to move us away from a command and control system to one where people felt able to show leadership wherever they were in the organisation - people taking ownership and being accountable; managers trusting their people and delegating tasks to them."

Core to this cultural change was a training programme for managers showing them how to take a coaching approach to leadership of their teams. So far, Network Rail have put around 1,000 managers - about 25 per cent - through the accredited training programme. In addition, around 100 of Network Rail's managers went on to volunteer as an internal coach, and that pool of coaches is used to coach others across the company. 
The results of this investment are clear: engagement scores of the teams managed by attendees of the programme are significantly higher than teams where the manager hasn't been on the course. And this positive engagement outcome translates into vital business indicators. Absenteeism in engaged teams is around three-quarters that of the less engaged teams, and engaged managers are responsible for half the number of signalling errors and incidents compared with less engaged managers.

\section{Case Study \\ Telefónica $\mathrm{O} 2$}

At one of its largest contact centres, $\mathbf{O 2}$ found that some of its managers were spending too long on administrative tasks - time that could have been spent face-to-face with their teams.

Over two months, managers at Preston Brook were asked to track what they were spending their time on, enabling $\mathrm{O} 2$ to build a picture of how they spent their average working day. It found too much of their time was being taken up with administration that it could train non-managers to do.

"We trained up our admin team so they could perform some of these activities things like auditing goodwill credits and reporting sickness absence stats," says Customer Service Operations Manager, Lorraine Connolly.

"That freed up our managers to spend more of their time where they should be - in amongst their teams taking care of their people with one-to-ones, coaching and so on." Only by spending quality face-to-face time with their teams can O2's managers meet the company's promise that your manager will be there for you.

Account Manager at Preston Brook, Nico Versluys, whose 11-year-old stepson has cerebral palsy, said he was grateful his manager made time for him. "Ryan needed a series of operations on his legs and it was a very stressful time," said Nico. "But my manager always made time for me to talk about it. He said if things ever got too stressful then he'd give me the space I needed to get my head around things and talk it through. I never really needed to in the end but it was reassuring to know the offer was there if I needed it.

"Customer Service can be a very busy and stressful part of the business, so it's easy for managers to look at their team as a bunch of KPls that need to be monitored or improved. But the best managers are those who appreciate that their team are human beings and will perform at their best when they feel supported, listened to and involved. As the saying goes: 'happy people equals happy customers.'” 


\section{Case Study Standard Chartered}

A strong focus on the importance of the relationship between manager and individual is at the heart of Standard Chartered's approach to employee engagement. At Standard Chartered, people management is placed on a par with task and financial management, and managers' performance is assessed accordingly. Great effort is put into developing effective managers and the organisation has developed four manager principles ('know me'; 'focus me'; 'care about me' and 'inspire me') designed to encourage managers to put themselves in the position of their direct reports so that they can make the most of their employees' strengths, interests and career aspirations.

The Bank's 9,000 managers are supported through the Great Managers Programme (GMP) which includes a mix of training and online tools and communications which equip them to bring the Standard Chartered story to life for their team members, and ensure they regularly hold effective and productive conversations with their people which address the four principles. The Bank's unwritten motto is 'treat no behaviour with indifference', and managers are encouraged to treat every interaction with their staff as an opportunity to have a performance conversation - giving praise and recognising a job well done, giving constructive feedback on areas requiring more work, or discussing what help and support might be needed to carry out the job. As a result, staff are better focused, motivated and engaged, which is reflected in business outcomes - lower levels of staff turnover, and improved financial performance. 


\section{Case Study Ministry of Justice}

Two years ago the Ministry of Justice (MoJ), which includes the Courts Service, Tribunals and the Prison Service, became the third largest Government department. Its senior management recognised evidence of the links between employee engagement and performance and its potential for the newly merged organisation. At a strategic level it was clear that the MoJ would have to achieve more with less and that a deeper appreciation of employee engagement across the MoJ could assist in meeting the required cost savings target of over $£ 1 \mathrm{bn}$ within three years.

A project team was formed towards the end of 2007 with an initial focus on building on existing good practice and raising managers' understanding of employee engagement and their roles in 'making it happen'.

A range of branded leadership development materials and activities, including a practical engagement toolkit, was quickly produced.

Alongside this, the team established a framework to roll-out an MoJ-wide employee engagement survey and gain initial 'stake in the ground' data. The survey took place in September 2008 across the organisation's 80,000 strong population.

The framework was developed to involve and infiltrate all parts and levels of the organisation. High level business sponsors formed a Steering Group to achieve 'executive buy-in' across the MoJ. A Working Group, representing all parts of the business, looked at the practical issues such as the composition of questions, the organisational hierarchy, and who should receive reports. Employee Engagement Champions helped bring things to life at a local level.

A major internal marketing push, with a branded slogan 'Start a Chain Reaction', was developed and managed not just as a corporate communications campaign, but actively built on by local champions and advocates. A 65 per cent survey response rate resulted.

The MoJ's approach has been recognised as an example of good practice within the public sector. Its approach and lessons learned are playing a valuable role in informing the roll-out of the single pan-Whitehall engagement survey being co-ordinated out of the Cabinet Office for implementation in the final quarter of 2009. Going forward, the 'project' has been absorbed into business as usual and employee engagement now forms part of the MoJ's corporate university, the JusticeAcademy. Already the synergies between learning and engagement are bearing fruit.

At the time of writing this report, the Ministry is still collating evidence of the effect of actions implemented on the basis of the survey results. 
27 The second key area in effective managers' approach is that of treating people as individuals; they are treated with fairness and respect with a concern for the employee's well-being.

28 ORC research concludes that "the question I am treated with fairness and respect in this organisation has the strongest correlation with the percentage of citizens satisfied with the overall service provided from local authorities". ${ }^{115}$

29 In their submission to this review the Nationwide Building Society said their research showed that if employees feel managers care about them they are much more likely to work harder.

30 Marcus Buckingham who has significant experience in the employee engagement area believes the critical question from employee research is "do I feel as if this job calls on the best in me?' This requires the local manager to know the individual and get the best out of them".

31 This broadly emotional area of a manager's role is critical. The Corporate Leadership Council conclude that: "emotional commitment drives effort, emotional commitment is four times as valuable as rational commitment in producing discretionary effort. Indeed the search for a high performance workforce is synonymous with the search for emotional commitment. Rational commitment is based around financial, developmental and professional issues while emotional commitment is the extent to which employees value, enjoy and believe in their jobs, managers, teams or organisations." 116

32 Research by IES (Robinson 2007) found that feeling valued and involved was an overwhelming driver for engagement in the NHS.

"At a basic level, emotional engagement is about making a strategy personal. It's about seeing the connection between what I do and delivering something larger and more meaningful, the overall result. An emotionally intelligent strategy is about people getting fired up by the thought that the world will somehow be a better place as a result of what they're doing, playing their part in delivering the strategy. If a strategy engages people emotionally, there's an authentic commitment to making it happen." Stuart Fletcher, President of the international division of Diageo. ${ }^{117}$

\footnotetext{
${ }^{115}$ ORC International Presentation to MacLeod Review February 2009

${ }^{116}$ Ibid.

${ }^{117}$ Quoted in Stern, S. 'Feel The Strategy: Leaders Must Engage Hearts as Well as Minds' Management Today 1 Nov 2008
} 
33 Stephen Taylor quoted a colleague saying of a manager: "He believed that what we were trying to do was not impossible, and he made us believe it too, so much so that we wanted very much to do it with him - and that very thing made it possible." ${ }^{\text {"118 }}$

"Working with children and young people including some who are vulnerable is semi-vocational work - it requires a real commitment to the work we do. We are not in a position to offer rewards so we need to ensure everyone feels valued for the part they play in making a difference." Josie Warwick, Education Leeds (submitted via the review's call for evidence).

\section{Case Study \\ The Co-operative Group Customer Relations Team}

\section{There is no doubt that being a member of The Co-operative Group}

Customer Relations team can be a tough job. Part of The Co-operative Food marketing function, the team are responsible for dealing with all contact from customers who have comments, suggestions, general enquiries and complaints.

They deal with over 3000 phone calls and 1500 emails and letters each week; covering all issues from store service and product queries, to recipes and the Group's ethical policies. Individuals have diverse backgrounds and ages span the entire working spectrum.

Despite the sometimes stressful volume and nature of the work, the Customer Relations team, led by manager Anita Young, has consistently high levels of employee engagement, a strong team culture, extremely low absence and virtually no staff turnover - in fact, team members who have officially retired from the Group can often be found covering an occasional shift to help their former colleagues out.

Anita believes that there are a small number of fundamental principles that can be applied to any call centre environment that will build a highly engaged team. First and foremost is the belief that you cannot ask employees to deliver more customer care than they believe their employer shows them in return.

Respect and value for individuals is demonstrated in the team in many ways. The workstations are not in the 'call centre' culture of row upon row of desks but are carefully grouped to encourage natural social interactions that help build strong teams. Team members are encouraged to take a break from the phones if they need one, and wireless headsets allow the freedom to move around the office.

\footnotetext{
${ }^{118}$ Review of Employee Engagement: Notes for a Discussion, April 2009, unpublished paper prepared by Stephen Taylor (Director of Taylor HAIG and former Chief Executive of the Leadership Centre for Local Government) specifically for the MacLeod Review
} 
A supportive management team is also crucial for highly engaged teams. Team Managers sit within their teams to provide support and short interactive briefings are held regularly. In addition, informal team meetings are held outside of the office environment and all team members are encouraged to contribute over coffee and a cake. Special occasions and milestones in the team's lives are celebrated with gusto. Every Friday, Anita and another member of the Management team ensure that everyone else can go home a little early, by covering the phone lines themselves until they close.

The challenge of the job is openly acknowledged and successes are celebrated in many ways. Case handling statistics adorn the walls and chart the productivity of the team. The statistics are then brought to life through stories shared informally by team members who have gone the extra mile to delight customers.

Anita believes that it is possible for managers to demonstrate consistent, authentic concern for individuals in a way that also delivers strong productivity for the business in a fast paced, target driven environment.

\section{Case Study Hillingdon Council}

With public sector sickness rates often above the private sector, Hillingdon Council put in place an initiative to tackle the problem and help employees be more productive through 'Healthy, Happy and Here' - its approach to wellbeing. It needed to act; at its worst Hillingdon recorded an average of 15 days sickness per employee. A thorough review of the benefits package and HR policies was undertaken to not only bring down rates but also to improve engagement. So far the changes are showing results - sickness rates have fallen by almost half and the staff survey shows improving levels of motivation.

34 Many organisations are introducing specific health and well-being programmes, and reaping the benefits. For example, AstraZeneca introduced a range of health promotion activities, work-life balance initiatives, ergonomically-designed working environments, counselling and life management programmes and integrated occupational health/human resources intervention. Amongst the benefits:

- UK absence rates for 2004 were 8.5 per cent lower than 2003 , resulting in a reduction of $£ 1.2 \mathrm{~m}$ in total absence costs; and 
- global accident and occupational illness rates fell by 61 per cent against a target of 30 per cent. ${ }^{119}$

35 Somerset County Council invested $£ 510,000$ in a stress management programme which led to:

- Sickness absence levels dropping from 10.75 days per employee per year to 7.2 between $2002 \& 2005$, amounting to a total saving on sickness absence of $£ 4.2$ million.

- Improved recruitment and reduced staff turnover in key areas. ${ }^{120}$

\section{Managers have a very important role in ensuring that work is designed efficiently and effectively}

36 Research makes clear it is very difficult for employees to remain fully engaged over the long term if work is poorly designed and essentially very frustrating. This perhaps requires more effort to ensure that work is well designed, adopting, where appropriate, Lean methodologies to solve individual issues and/or taking more of a systems approach which emphasises how all the component parts of the overall operation fit together.

37 Pfizer also reminded us that field-based employees experience different employment challenges to those who work together on one site. Mark Mitcheson, Talent and Organisation Capability Lead at Pfizer said, "the actions that field managers take to heighten the engagement of their teams add measurable value".

${ }^{119}$ Business in the Community (2009) Business Action on Health: Healthy People = Healthy Profits on-line at: www.bitc.org.uk/document.rm?id=9097 (accessed 1 July 2009); and BiTC (2007) Organisational case studies - AstraZeneca [Online] http://www.bitc.org.uk/resources/case_studies/afe_1167_astraz.htm] (accessed 30 June 2009)

${ }^{120}$ Robertson I., Cooper C. Case Study: Somerset County Council - The Business Case for managing pressure and stress at work [Online] http://www.robertsoncooper.co.uk/Pages/Resources/Case-Studies.aspy (accessed 1 July 2009) 


\section{Case Study Unipart Group}

Unipart Group is an international logistics company, developed out of the parts operation of British Leyland. It supplies automotive vehicle products, supply chain services and operational excellence consultancy to a number of different market sectors. Unipart relies on high levels of engagement for continuous improvement and innovation which characterise its productive way of working.

Engagement is at the centre of the Unipart way of working. Unipart has engaged its workforce through a commitment to employee well-being and development, a shared culture which defines a set of guiding principles and behaviours, a good understanding of how each employee fits within the business, and structures which encourage and reward employee contributions and voice.

For Unipart, engagement is essential for the continuous improvement and innovation that make them market leaders. The company uses Lean processes to ensure continuous improvement, but this technique relies on employees being engaged in the improvement of the business in order to identify problems and solve them at a local level. Unipart has developed a range of methods to empower employees to undertake team working and joint problem solving, and identify solutions which can improve Unipart products and processes. Contribution Counts Circles train all employees in problem solving and daily improvements occur through the ' $3 \mathrm{Cs}$ ' in which employees identify concerns, the causes of the concerns and the countermeasures.

Unipart believe that the engagement of their workforce has led to greater productivity - CC Circles, for example, which have 100 per cent participation at some sites, have delivered benefits of approximately $£ 3$ million of direct cash savings year on year. The success of Unipart's way of working is also reflected in their diversification into consultancy services. Unipart have advised organisations such as HMRC and Zurich on engagement and process improvement. 


\section{Case Study}

\section{Aberdeenshire Council}

Aberdeenshire Council prioritises the need for continuous improvement throughout the council. It brings together the key people involved in a process, be it keeping the streets clean or provision of social services, in a structured way to identify ways of securing efficiencies, improve customer service, with the full support of management. A group of employees with the appropriate skills and experience from around the council and from all levels work together for a week, away from the day job, to tease out the issues and find a solution, which they then work to implement.

In a recent Best Value report the Council was praised for its motivated workforce who demonstrated a clear commitment to the organisational vision and priorities. Evidence from interviews with employees shows that its 'Kaizen' continuous improvement process has also had a very healthy effect on internal communications and relationship building, which has ongoing organisational benefits.

This genuine approach to involving the people who understand the processes best, because they are the ones involved in them, has ensured that tasks are completed in a more efficient way, saving resources and improving the service provided to residents. Employees feel more involved and empowered and there is improved morale and customer service.

\section{Employee Voice}

38 The 'Sunday Times Top 100 Companies to Work for' found that feeling listened to was the most important factor in determining how much respondents valued their organisation. Being heard reinforces a sense of belonging within an organisation and a belief that ones actions can have an impact. Richard Baker, Non-executive Chairman of Virgin Active (and former CEO of Alliance Boots) told us: "Employee morale is the first step to productivity improvements. Give your people a damn good listening to, and act on what you learn." 


\section{Case Study John Lewis Partnership}

On our site visit to John Lewis Partnership we were told: "If all members of staff feel that they have a voice on issues that matter to them, then they feel more involved and feel part of the company. If they feel that they are not being listened to, then they feel distant not just from the company but from their team."

The company has a multi-layered approach to employee engagement and voice. The Partnership promotes engagement in a number of ways, by sharing knowledge, making a huge amount of information available to partners (employees) and taking time to ensure people understand it; sharing power, operating a range of councils and committees with which partners can become involved; and sharing profit through a number of means including an annual bonus and non-contributory final salary pensions scheme. Partners have oversight of strategic business issues through the Partnership Council - this body is able to hold the chairman of the business to account and to question senior management in a similar way as shareholders would in a plc. Partners are informed about strategic business decisions through a wide range of communications, and can influence their working environments through the open structure, particularly newly revamped branch-level fora; the suggestion scheme, and through management consultations on key areas and issues such as performance management.

The difference made by employees having a voice and being empowered to intervene in, and contribute to, organisational strategy and problem solving is demonstrated by the London Ambulance Service.

\section{Case Study}

\section{London Ambulance Service}

The London Ambulance Service (LAS) has transformed its service delivery through engagement and partnership working in the past few years. A service that was criticised by London's media as the 'worst' ambulance service in Britain in 1997 was hailed ten years later as the best. The LAS is the largest ambulance service in the country, serving the metropolitan area within the boundary of the M25 and employing around 4,400 staff. 
Unions and management recognised in 1999 that the future of service was being placed in jeopardy by the perceived failures, in particular response times, and a lack of public confidence as a result of sustained negative media coverage. Staff morale was at its lowest ebb. It was clear that drastic steps including breaking up an integrated London service were being considered. Major investment of $£ 50$ million was needed to start to bring the service up to scratch, but the funds would not be forthcoming unless confidence could be built within government that the service could be reformed.

Both sides came together to begin discussions on a critical path to recovery. Senior managers admitted publicly that the service was struggling - an honest admission that was vital in gaining the trust of staff who were only too aware of the situation. Both sides accepted that the relationship between the unions and management was dysfunctional and was itself contributing to difficulties at service and station level, with constant threats of industrial action, petty disputes erupting regularly and large numbers of grievances. Above all, they recognised that the poor relationship made it difficult to get issues of importance to staff discussed and resolved. Engagement was at a low ebb.

A new approach was developed, based on a partnership framework, setting out new ways of working, based on the principles of building trust and mutual respect, honesty and transparency, a positive approach and willingness to learn together and from each other, and early discussion of emerging issues. Staff engagement and involvement was at the heart of the new approach; for the first time staff were involved from the beginning in major decisions such as the procurement of new ambulances.

The involvement of staff, often through their union representatives has been institutionalised across the Service. Regular consultation involves union reps in decision making. Senior managers and union reps make annual visits across the service to engage directly with staff at station level. The LAS partnership forum meets every six weeks. Service wide partnership conferences involving reps and managers are also held annually, with presentations on strategic issues. At the same time regular informal meetings are also held to ensure partnership operates on a day-to-day level.

The results of the efforts to engage staff in the improvement of the service are clear. LAS is the only ambulance service to receive a Good/Good rating from the Health Care Commission for its services and its use of resources two years in a row, and has the highest clinical performance indicator compliance results in England. The service won the NHS Innovator of the Year Award for London in 2008 and achieved the best emergency preparedness independent audit results in England. 
Impressive service achievements also include the doubling of cardiac arrest survival to discharge, and the LAS is the only ambulance service to undertake region-wide direct admission for percutaneous coronary intervention 24/7. Fifty-six thousand fewer patients have been admitted to A\&E over the last two years. There has also been a 30 per cent reduction in complaints.

\section{Case Study}

\section{United Welsh}

United Welsh is a medium-sized housing association based in South Wales, which employs 130 people, has over 4,000 homes in management and a total annual turnover of $£ 50$ million. It has an excellent reputation for employee relations and was recognised as the fourth Best Workplace in the UK and the Top Not-for-Profit Workplace in the European Union in 2005 (Great Places to Work Institute in conjunction with the Financial Times).

In 2001, the organisation recognised it needed to respond more quickly to change, specifically to move away from a command and control working culture to a learning and empowered culture. Working in partnership with its recognised trade union, Unison, United Welsh introduced its People Engagement Model which has a people strategy and partnership working at its core. Staff at United Welsh have the opportunity to be involved in the decision-making process, whilst recognising management's responsibility to manage. In practice the majority of people are happy to be informed or consulted on issues that affect them, but the fact that they have the ability to influence decisions before they are made ensures that there is a real 'buy-in' and commitment to decisions made. Staff have been involved in decision-making on a wide range of issues including opening a regional office, departmental restructures and reviews of terms and conditions of employment.

United Welsh would argue strongly that their approach to employee engagement through the pillars of a people strategy and partnership at work is at the heart of improvements in business performance. Tony Whittaker, Chief Executive, says: "In our experience, running the company in this way really motivates people. This in turn leads to improved services and satisfied customers, as well as increased profitability." And this is borne out in their results:

- Rent unpaid as a percentage of rent roll decreased from 4.4 per cent in 2001 to 1.5 per cent in 2007

- Rent loss (due to empty properties) as a percentage of rent roll decreased from 2.6 per cent in 2001 to 0.45 per cent in 2007

- sickness absence decreased from an average of 5 days in 2001 to 2 days in 2006 and employee turnover has also gone down 


\section{Case Study Microsoft}

Microsoft understands the changing nature of the work place and the move towards the new world of work, and therefore use a variety of different communication tools including: e-mail newsletters, internal web sites, blogs, webcasts, live meetings, site wide e-mail, physical notice boards, and audio visual presentations throughout their buildings. There is a strong emphasis on regular communication recognising that this cannot always be face-to-face with monthly team meetings and everyone has a monthly one-to-one meeting with their manager. As a leader in innovation and software development they use the latest technology, such as RoundTable conferencing technology and equipping everyone with a laptop, headset and the relevant software, to enable people to connect easily and effectively wherever they are and save costs as well as having a significant environmental impact.

Each year Microsoft hosts a company meeting to kick off the year with a look at their most recent accomplishments and the opportunities and challenges ahead. To make viewing of this meeting as convenient as possible for all employees across the globe, the full length Company Meeting is also available via on-demand web cast. Other executives at Microsoft offer regular talks and updates such as Chris Liddell, Chief Financial Officer, who gives a quarterly 'street talk' on financial performance. Kevin Turner, Chief Operating Officer, gives a quarterly 'wireside chat' on the current performance of the business and the priorities and focus for the next quarter. These are recorded and can be viewed directly over the network via streaming or downloaded to laptops or mobile devices.

The research into Microsoft's corporate culture is an ongoing process. MSPoll, the annual employee attitude survey, is a critical checkpoint to validate how the culture is evolving. The actions that stem from the analysis of the survey results are focused to further shape Microsoft's culture. Microsoft has been conducting employee surveys since 1994. Participation in the MS Poll survey is voluntary and all employees are encouraged to respond honestly as a means to offer opinions and affect change. Microsoft has recently undertaken analysis that shows that a correlation does exists between higher customer satisfaction scores and higher employee engagement scores across its businesses. 


\section{Case Study}

\section{Marks and Spencer}

Marks and Spencer is, like most retailers, feeling the effects of the current difficult economic climate. Cost base reduction and resource maximisation are key issues facing the company at present and it is working with its employees to help find solutions.

Marks and Spencer has long involved and consulted with staff to good effect through its network of elected employee representatives. Their Business Involvement Group (BIG) gives employees the opportunity to voice their opinions and ideas and to have their views represented when the Company considers changes that impact on them.

The Marks and Spencer BIG network took a proactive approach to supporting the company in addressing cost improvement by canvassing employee ideas on ways to improve the filling of stock in their food departments. They highlighted the best ideas to senior stakeholders at Marks and Spencer via their National BIG team and a set of guidelines for 'Food Fill' were produced incorporating many of the ideas suggested by employees. As a result of the improvements made to 'Food fill' processes, over $£ 4$ million has been saved.

Tanith Dodge, HR Director at Marks and Spencer says, "We are very proud at Marks and Spencer of our Business Involvement Group (BIG) and the way they represent our employees' opinions and ideas. We believe it is vital to the success of our business to engage our employees and listen to their views, and by doing this we ensure that our employees feel motivated and are aware that they can influence the business to change things for the better."

40 Work by Kingston Business School and Ipsos Mori for the CIPD based on a nationwide survey of employee attitudes and engagement from 2,000 employees across the country in July 2006 found a key driver of engagement to be the ability of employees to feed their views upwards, feeling well informed about what was happening in the organisation, and thinking that one's manager was committed to the organisation. ${ }^{121}$ Acting on feedback is critical as discussed in Hockey and Ley's recent work on leadership and engagement. ${ }^{122}$ They quote Sue Davies, Head of Human Resources at Bourne Leisure Limited, who says "If somebody says there is a particular area that we are not good at we do something about it as quickly as possible. We don't just do the surveys and ignore them. Each survey is done by brand, site and department so we can feed back on specific areas. "123

\footnotetext{
${ }^{121}$ Truss C., Soane E., Edwards C., Croll ., and Burnett J. (2006) Working Life: Employee attitudes and engagement published by the Chartered Institute for Personnel Management

122 Hockey, J, \& Ley, I. (2009). Leading for Engagement: How Senior Leaders Engage Their People. Sunningdale: National School of Government ${ }^{123}$ Ibid.
} 
41 Nevertheless, communication and transparency are two areas that require a greater focus from business leaders. According to Towers Perrin, only 31 per cent of employees feel that their senior managers communicate openly and honestly. Moreover only 41 per cent agree that their senior managers try to be visible and accessible. ${ }^{124}$

\section{The role of workplace representatives}

42 During the course of our review, we received evidence from employers and trade unions of the value of engaging with a collective voice in the workplace, as an integral part of engagement approaches. Many companies with trade union or collective representation pointed to the importance of aligning their industrial relations with engagement strategies. As one said: "You don't want to find yourself in the position where the union tells staff not to fill in the survey."

43 In the past, trade unions have expressed wariness about employee engagement, regarding it as a potential alternative to the traditional model where employers communicated with their workforce through the union machinery. They have also expressed concern about the term 'discretionary effort.' As a report for the Wales Public Service Workforce Forum put it, trade unionists felt, "the inferences were too close to a case for effort over and above the agreed, contracted job, and so tantamount to unpaid overtime." 125

44 The TUC in a note to the review emphasised that properly done, engagement could be of significant benefit to employees, and pointed to their emerging work with Tesco and $\mathrm{O} 2$ as showing the importance of, "getting real employee engagement, both for the benefits of providing 'good work' for employees but also in terms of achieving better productivity through best working practice." Organisations benefited too: "If relationships of trust can be built around areas of common agreement, such as health and safety, skills, performance and quality of work, these relationships can be useful in more difficult situations, most obviously at times of downsizing, when workforce insecurity is high."

45 But independent voice was crucial: "If employees were to engage constructively and put in discretionary effort they would need to be given the opportunity to put their views to employers and be assured that their views would be at least heard, if not acted upon. Although individual engagement between managers and employees was important, to build the necessary trust between employees and employers, employees should be allowed and encouraged to express their views through independent collective representation."

46 Employers and unions said that an independent voice could be important for the individual employee too. Union learning reps for example acted as important

\footnotetext{
${ }^{124}$ Towers Perrin Global Workforce Study (2007-2008)

${ }^{125}$ A Report to the Wales Public Service Workforce Forum: May 2009.

www.wlga.gov.uk/download.php?id=2757\&l=1 (last accessed 1 July 2009)
} 
intermediaries; employees were often fearful of admitting to their manager that they could not read a spreadsheet for example, but would talk to their union rep about it. The development of a substantial workplace learning strategy centred on union learning reps has been at the heart of Mersey Travel's engagement strategy with unions and employees. "Engagement over learning has impacted positively on industrial relations generally; it has helped to break down barriers and build trust, and well as focusing efforts on one of our strategic priorities - improving staff training and development," said Personnel Manager, Peter Hughes.

47 According to UNITE, the presence of a trade union voice in the workplace can help boost important aspects of engagement. In a 2006 survey, individual members in workplaces with a trade union voice responded more positively to questions around control of the working environment, whether or not their jobs were interesting and whether they were treated with dignity and fairness at work, than those where no voice was present. ${ }^{126}$

48 There are synergies between engagement approaches and partnership working between unions and employers, where trust, co-operation and information sharing are key; many organisations with partnership agreements emphasised to us that it complemented and enhanced their engagement strategies.

49 The NHS, for example, is putting considerable effort into encouraging the development of partnership relationships between unions and managers at local Trust level, at the same time as supporting the roll-out of employee engagement as a key strategy in delivering improvements in patient care.

50 There are also well known examples of partnership working as an integral part of employee engagement in the private sector; Tesco has a long standing partnership agreement with USDAW, which other unions and employers have used as an exemplar.

\footnotetext{
${ }^{126}$ UNITE membership survey, 2006
} 


\section{Case Study}

\section{BAE Systems}

BAE Systems is an international company engaged in the development, delivery and support of advanced defence and aerospace systems. The company is at the forefront of innovation, working to develop the next generation of intelligent defence and security systems: in the air, on land, at sea and in space. The company designs, manufactures and supports military aircraft, surface ships, submarines, combat vehicles, radar, avionics, communications, electronics and guided weapons systems.

The company believes the success of the business depends on the skills, innovation and contribution of all its employees. To get the best from its employees BAE Systems aims to treat them with respect, create a supportive work environment and provide opportunities for training and development.

In the UK, BAE Systems employs approximately 32,000 employees in its wholly-owned businesses. Trade union membership is approximately 55 per cent across the UK BAE Systems businesses and collective bargaining covers approximately 70 per cent of the UK workforce.

BAE HR director (employee relations) Dave Ryan said: "BAE Systems' industrial relations history in the early 1990's was typical of many British engineering firms, with a long history of industrial action and a relationship between management and unions that was aggressive, adversarial and characterised by a complete lack of trust. This traditional approach has been replaced by a process of solving issues together through joint working parties based on partnership, not conflict. The aim of the whole process is to solve problems, not to create disputes. At first it was hard for managers and trade union representatives to change culturally embedded behaviours, because change of this nature is uncomfortable, and in some cases it was more comfortable to adopt a traditional 'us and them' approach. However, both parties have shifted towards a collegiate attitude to such matters.

"BAE Systems management recognises and respects the importance of the role of the trade unions to represent their members and equally the trade unions acknowledge the responsibility of management to manage the business. It is accepted that, in the best interests of both the business and its employees, a close working relationship based on meaningful consultation and mutual trust is fostered and continuously developed between the trade unions and management. This approach has led to a real openness between management and the unions to new ideas and influences that are at the heart of the company's very creativity. 
"There is a strong emphasis on skills development and training to enable our employees to fulfil their potential. This is self enlightenment at work, as a more skilled workforce is able to adapt more rapidly to organisational and technological change. These processes give our employees a voice in the process of change and restructuring and in the design of jobs and organisation of work."

The company has a range of consultation processes in place to deliver its industrial relations strategy. Management and trade unions meet on a regular basis through a structured meeting schedule. Twice a year the CEO, Ian King, briefs senior union representatives from across the business on the current business position and the challenges ahead. At the meeting there is an opportunity to ask the CEO questions about all aspects of the business. Trade unions are consulted on a wide range of issues including business strategy, pensions, training, employment policy, general organisation of the company and restructuring. The focus of consultation is through the BAE Systems UK Corporate Consultative Committee (CCC) meetings which are held quarterly and attended by union representatives and senior managers. Typically topics discussed at these meetings include business strategy, pensions, job loss mitigation, diversity, health, safety and environment, lobbying and government relations, apprentice training and education partnerships.

Among the agreements secured by partnership and consultation have been changes to company pensions arrangements, a best practice guide on protecting jobs and handling rationalisation and a 'New Start' skills training initiative.

According to Dave Ryan: "A modern industrial and employment policy, developed through partnership with the trade unions can help BAE Systems, its employees and the unions cope successfully with the challenges of a global defence market and sustain capabilities and high levels of technical skills in the UK. The continuation of the BAE Systems management and trade union partnership model will be a fundamental element in this process going forward."

51 In recent years, the potential use of collective machinery in the workplace has increased. Employees have statutory rights to be informed and consulted over a wide range of issues, including major strategic business decisions; health and safety at work; workforce planning and medium term threats to employment; collective redundancies; the transfer of the business from one owner to another; major changes in work organisation or contracts of employment; aspects of working time policy; and changes to occupational pension schemes. Regulations providing for information and consultation (I\&C) now apply to all workplaces with at least 50 employees. ${ }^{127}$

\footnotetext{
${ }^{\mathbf{1 2 7}}$ BERR, The Information and Consultation of Employees Regulations 2004 www.berr.gov.uk/employment/employment.../ice/index.html - (last accessed 1 July 2009)
} 
52 The take-up of some of these collective rights has been patchy, and some commentators have questioned their effectiveness. Nevertheless, some employers have extended the remit of information and consultation forums or works councils to encompass detailed discussions on the way work is carried out, including job design, production methods and so on. Keith Thomson of Ultra Electronics described how, in the UK, the company uses I\&C forums as an important strand in learning and action planning, alongside team and all-hands briefings.

53 Despite the long-term falls in union density and in coverage of collective bargaining, there is evidence of a continued appetite among British employees for a collective voice at work. Research by Professor John Purcell indicates that there are a substantial number of non-union reps in the UK perhaps equalling the number of union representatives. ${ }^{128}$ They can be found in unionised as well as non-unionised workplaces. They can aspire to play a strategic role in the success of their employer: Vivo, the staff forum in Standard Life, has set the strategic goal of their partnership with the company as becoming the catalyst for increasing employee engagement.

54 In its evidence to the review, the IPA suggested although there were examples of good practice: "Management and employee representatives have not yet fully developed a role for collective representation in improving workplace effectiveness." In particular, many of these collective arrangements constituted an underutilised resource; companies were investing significant sums in works councils or information and consultation machinery, but there was evidence that the lack of a focus on strategic issues around performance and productivity was leading to agendas being dominated by 'tea and toilets' issues. In other cases, discussions were confined to facilitating changes in HR policies.

55 Nevertheless, best practice examples demonstrate the potential role of collective arrangements in engagement. The TUC and CBI suggested in 2001: "Optimal results are achieved where there is a mix of direct employee involvement and indirect participation through a trade union or works council."129

\footnotetext{
${ }^{128}$ Presentation to the UK Work Organisation Network (UKWON) 'Future of Employment Relations' seminar 2008

${ }^{129}$ CBI-TUC, 2001. Submission to the Productivity Initiative, HMT (quoted in Edwards P.(2007) 'Justice in the Workplace: Why it is important and why a new public policy initiative is needed' Paper for the Work Foundation,)
} 


\section{Integrity - behaviour consistent with values}

56 Most organisations have espoused values and all have behavioural norms. Where there is a gap between the two, the size of the gap is reflected in the degree of distrust within the organisation; if the gap is closed, high levels of trust usually result. If an employee sees the stated values of an organisation being lived by the leadership and colleagues, a sense of trust in the organisation is more likely to be developed, and this constitutes a powerful enabler of engagement.

57 Examples of the sorts of gaps between espoused values and what actually happens in practice might include a company claiming to be passionate about the environment, whilst failing to provide staff with recycling bins; or having a sign outside the office that reads 'employees are our most important asset', whilst tolerating a culture of bullying; or failing to provide the basics that keep working conditions tolerable (such as air cooling, heating, replacing broken office furniture).

58 first direct has a reputation for being a bank with a strong focus on customer service. The case study below shows how, by ensuring that its behaviour towards its employees aligns with its public values, first direct has been able to maintain and even increase employee engagement even during tough times. 


\section{Case Study}

\section{first direct}

first direct has had an enviable reputation for customer service for 20 years. This has been based heavily on the foundation of a strong value based culture and an 'expect respect' philosophy.

The credit crunch of the past two years has provided a particularly challenging environment for the bank and its 3,500 staff, but despite this the first direct philosophy of 'people matter more' has never been more important or effective. first direct has put additional effort into ensuring employee engagement is maintained, and improved, in spite of the particular challenges facing the banking sector at the moment.

In January 2009, 'Direction' sessions were held so that all 3,500 staff had the chance to hear from and challenge the CEO and all of the top team on where the company was headed and the significant challenges that lay ahead. Even though some of these messages were difficult and challenging, these events recorded high levels (90 per cent plus) of understanding and commitment to the direction and path that the company was taking. Chris Pilling, Head of Direct Banking at HSBC (first direct's parent company), is clear that sharing the organisation's vision is key to business success: "It is vital that you are open and honest with staff about the organisation and how it fits into the bigger market picture. If you want your people to work with you and really buy in to what you are trying to achieve, you need to treat them like adults - give them the information and trust them to help you develop and implement the solutions."

The Direction sessions were supported by a series of activities for colleagues and customers to actively engage with what was needed. These included the introduction of a programme to support the NSPCC Childline. A re-launched 'thank you' internet site for 'peer to peer' celebration of success which averages more than 1000 'thank you's per month and has increased 100 per cent in the last two quarters. The Chief Financial Officer launched a 'tell Colin' programme to solicit hundreds of cost saving ideas to help first direct through the downturn, which have generated tens of thousands of pounds worth of delivered savings in only a few weeks.

The overall effect has been a significant reduction in sickness levels, as well as community day involvement up by 50 per cent, an underlying sales performance well ahead of plan in the toughest of sales markets, and critically a customer recommendation level that is at an 18 month high. 


\section{Case Study School Trends}

School Trends is a medium-sized company supplying uniforms directly to schools. It is employee owned and has approximately 130 members of staff. The company has developed a unique culture which establishes the rights and responsibilities of the workforce, and informs behaviours and decisions throughout the organisation.

School Trends' 'community culture' was developed by the founders of the company who wanted to create a better place to work. The emphasis on rights and responsibilities ties values to behaviours, and provides a reference point for all employees to hold one another to account. The culture is founded on six pillars: information and involvement; fair reward; shared prosperity; employment protection; application of organisational values; development opportunities.

School Trends have firmly embedded the culture within the organisation. Employees are made aware of the culture during recruitment, their rights and responsibilities are written into the employment contract, and there are community classes to inform employees about the culture's origins and development. There is an emphasis on all employees taking ownership of the values, but those in management roles are particularly responsible for upholding the culture or 'walking the talk'.

A strong organisational culture builds trust by ensuring consistency of attitudes, behaviours, treatment and support. Employees more readily engage, and give more to their work, in an environment where they are sure that the values espoused by the organisation's leaders are genuine, and that there is buy-in throughout.

For School Trends, engagement is vital in order to maintain its position as market leader in an increasingly competitive field. Engaging the workforce is seen as an important tool in achieving the customer service and improved efficiency that lead to greater profitability. 


\section{Case Study}

\section{Eden Project}

The Eden Project is a botanical garden and a centre for education and biodiversity awareness in Cornwall. It is an educational charity and social enterprise, employing around 500 staff. Since fully opening in 2001, the Project has developed a clear 'personality' and a set of values which make it unique. Maintaining this culture, and therefore the identity of the Eden Project, is dependent on the engagement of the employees, and their ability to exemplify and communicate the values of the organisation.

Tim Smit, the chief executive, has created a set of management practices called 'Monkey Business' in order to help engage employees more fully in the Project's culture. The first tenet of Monkey Business is that each employee should say hello to 20 of their colleagues before they start work in the morning as a means of getting to know one another better, and supporting a team spirit.

The second is that each employee should read two books a year that they would not normally read, and review them for colleagues. This encourages freshness in employees' thinking and openness to new ideas, one of the Eden Project's key values.

The final rule is called working by 'wine light'. When a team is struggling to solve a particular problem, managers suggest they go out to dinner together, and discuss the problem there. The Eden Project wants employees to bring all of their talents and experiences to work to benefit the organisation, but recognises that sometimes people only use a limited amount of their abilities at work. Encouraging teams to spend time together outside working hours not only helps them to bring more of themselves to work, it also builds closer relationships within teams.

The practices developed at the Eden Project make it a fresh and creative place to work; matching the organisation's values with the employee's experience of work. Engaging employees in the culture of the organisation helps to strengthen the identity of the Eden Project, which is then communicated to the one million plus visitors who come to the Project each year. Since 2001, the Eden Project has welcomed 11 million visitors and the 'Eden effect' has contributed $£ 900 \mathrm{~m}$ to the regional economy. 


\section{Case Study \\ Department for Communities and Local Government (CLG)}

The Department for Communities and Local Government is making significant progress in staff engagement, initially through engaging over 50 per cent of staff directly in the creation of a statement of departmental values and behaviours. These have given the department a stronger basis for employee engagement work, by establishing core values around the propositions that we should 'Give People a Voice' and 'A Chance to Shine'. To help embed these values and drive them forward, each leadership team developed an action plan to set out the steps they would take to ensure staff were living the values within their areas

Staff survey scores however indicated a particular issue on the visibility of senior managers and of their collective discussions and decision taking. In response, an innovative programme of activity was put in place including 'Meet the Board' world café style events; a Board Question time; web-chats and signed articles and features to show the human face of Board members. These activities were well received by both Senior Managers and Staff, and the Department continues to build on the programme offering, based on views and suggestions from all staff.

In March of this year a further employee engagement survey demonstrated a significant improvement in attitudes towards senior management. Seventynine per cent agreed that 'people in my team are encouraged to come up with innovative solutions to work related problems' and 53 per cent of participants agreed that 'Senior Managers are sufficiently visible in this organisation' which is higher than the central government benchmark.

\section{Enabling Employee Engagement in Small and Medium- sized Enterprises}

59 Given the importance of the SME sector to the economy, supporting the sector in developing engagement approaches is vital. 1.2 million SMEs (organisations with fewer than 250 employees) employ 30.55 per cent of the total workforce in the UK, delivering 44 per cent of the total turnover of UK private sector companies. The majority of employees in SMEs are owner-managed (61 per cent compared to 9 per cent in larger firms).

60 There is a lack of research data to help evaluate the importance of employee engagement within SMEs. The 2004 WERS contains useful data regarding employee involvement and voice, as well as the role of managers in SMEs; for example it 
suggested that job-related well-being is higher in small workplaces and small organisations than in larger ones. Anecdotal and qualitative evidence does however provide a strong case for employee engagement in smaller firms.

\section{Case Study}

\section{Westlakes Engineering}

After achieving his initial business objective, set in 2004, of growing Westlakes Engineering, an independent Civil, Structural and Architectural Design Consultancy, to two offices and 20 employees, Andy Hooper found himself faced with a glass ceiling, experiencing stagnated profits and unsure how to bring the business to the next level. With the aim of finding a way to step back and think about where to take the business, he joined the LEAD programme at Lancaster University in October 2008. Activities within the course served as a catalyst for Andy's realisation that his leadership style and role within the business needed changing, and helped him to view the business from a more strategic perspective.

As a result of this, Andy identified ways to restructure the business to better capitalise on the existing market and along, with other key managers, adopted an increasingly strategic role in the business, encouraging other employees to step-up into more responsible positions. In consulting everybody in the company for ideas when restructuring, Andy was able to implement changes with the full support of his employees, resulting in no staff turnover and employees who feel more engaged with the business.

He also believes that the more strategic role he now plays and the higher levels of engagement in his staff have been significant factors in enabling the business to open a third office in Manchester, and placed him in a strong position to weather the current recession, with 66 per cent predicted turnover growth over the next couple of years.

\section{Case Study Buy-the-House}

When opening a second showroom for her Accrington based estate agency, Buy-the-House, Lesley Swinn chose to recruit the 11 new employees required from outside the market, to avoid the potential conflict associated with taking employees from local competitors. However, used to dealing with just three employees, Lesley found herself under constant pressure to carry out individual on-the-job coaching, with little time left to lead the business. 
To address this, Lesley took the costly risk of closing her business for one hour per week to carry out group training. Based on masterclasses Lesley attended as part of her participation in the LEAD programme at Lancaster University, each week a specific topic was covered, with focus ranging from soft skills and industry requirements such as Data Protection to addressing the bigger picture. At the same time, Lesley realised that her business culture didn't match the formal appraisal methods in place, and so changed her approach to appraisals, renaming them "good chats with good people" and using them as an empowering opportunity for employees to contribute ideas and question the business owners.

Internally, Lesley has seen this approach generate bonding and a culture of interdependency, as employees began to coach each other, creating a stronger and more-informed team and allowing natural leaders to emerge as candidates for promotion. From this Lesley has created a more tiered approach to the organisational structure, allowing her to delegate most operational activities and adopt a more leadership focused role. In turn employees have begun to take more responsibility for the business. The improvements to Buy-the-House have also had external impact, allowing them to become the only company ever to score 100 per cent for customer service by the independent company commissioned to help measure the success of the changes.

\section{The challenges}

61 For some SMEs conducting a staff survey can be perceived as an unnecessary cost. Owner/managers, who have often built their business from scratch, may find it difficult to involve staff in decision-making; they may be reluctant to 'step back' from the business and focus more on the strategy. As Ellie Hamilton, from Lancaster University Management School, commented: "For many managers of SMEs, handing responsibility to employees is a significant barrier to be overcome as the business grows; learning to delegate effectively can be challenging".

62 Nevertheless, as John Wright of the FSB pointed out: "In a SME everyone must be prepared to make the tea or clean the office - and this includes the owner-manager. SMEs rely on people working together and mucking in for the common goodsomething that is often lost in larger firms where roles and responsibilities are more clearly defined, and there is often a greater sense of hierarchy."

63 Not making assumptions about high engagement levels - and managing enthusiasm productively - is also an important issue for third sector organisations. Oxfam's Head of Resourcing and Talent David Benson describes his organisation's journey from an ad hoc approach before 2005 to an engagement approach based on empowerment, inclusivity and accountability. "In most voluntary sector organisations staff are highly motivated, believe in the work, and want to make a 
difference. You have to ensure staff have a voice, that conflicting views are heard. At the same time effective line management is crucial to balance and direct the enthusiasm and to ensure that decisions are made. That trade off between professionalism and passion can sometimes be challenging."

64 Some of the SMEs we spoke to were wary of employee engagement as 'management speak'. However whether individual SME leaders articulate it in that way or as 'effective management', it is often key to their business success. As Martin Hellawell, Managing Driector of Softcat Ltd says: “We don't talk about employee engagement here at all but if it's involving the staff and the business and communications then that's what we're all about and we do it all the time. We haven't got a programme to engage people, we're just a very engaging company. Most of it comes from very regular and very open communications at all levels in the organisation and we do lots of it. ${ }^{\prime \prime 30}$

65 The key challenge for many SMEs is keeping up the 'direct' engagement when the business grows. Most SME managers seem to agree that the first time 'employee engagement' features is when their business reaches around 20 employees, or, as Christina Domecq of Spinvox described it to us: "When there are too many people to take to the pub at once". It is at this stage when the owner/manager may begin to lose sight of the individual employee and their role, at the same time as feeling anxious about relinquishing control of a business they have nurtured into existence. The engagement challenge can reappear again when the organisation reaches around 50 employees, by which time middle management will usually have been put in place, as well as someone responsible for HR. It is throughout this period of growth when SME owner managers are most in need of advice and support.

66 As small business owners on the Lancaster University LEAD programme told us, although many owner/managers of SMEs may be technical experts or have in-depth sector specific knowledge, they often have little or no business or management experience. It can be difficult to move away from engagement based on personal relationships to an approach that is more closely linked to the strategy of the business. It is also often a challenge to introduce middle management into an organisation whilst still retaining the 'message' and values of the enterprise, as well as ensuring that the original owner / manager is still regarded as the leading figure in the enterprise.

67 Investing in management skills can also be seen as wasteful in the context of staff turnover or a lack of internal promotion opportunities. Small business managers may fear that trained staff may leave for better opportunities elsewhere, negating the investment in training and development.

68 On the whole, SMEs place less emphasis on formal training than larger organisations; they may not know what training is available, or may struggle to find

\footnotetext{
${ }^{130}$ Hockey, J, \& Ley, I. (2009). Leading for Engagement: How Senior Leaders Engage Their People. Sunningdale: National School of Government.
} 
appropriate training that does not take their employees out of the workplace for long periods of time. In 2007/8, 28 per cent of SME employers provided leadership/ management training for their management team; only 11 per cent of all SME employers provided training for all of their management team. ${ }^{131}$ As John Wright comments: "There is a lack of leadership and management training focussed at SMEs which is 'bite sized', accredited and affordable." In his view training for SMEs needed to be focused on everyday practicalities, not 'management jargon' that failed to reflect the reality of a small business and that demonstrated in a practical way how engagement could contribute to improving the business It is important that the help available to SMEs includes support in the areas of soft skills development.

69 Small businesses we spoke to emphasised that opportunities for networking with people in similar positions experiencing similar challenges was vital, and those able to participate in networking and training such as in the LEAD programme at Lancaster University have found the experience to be extremely beneficial.

\section{Enablers of engagement in SMEs}

70 Owner/managers of SMEs we spoke to highlighted their determination to ensure that employees were provided with the right conditions to make a full contribution to the business.

71 SMEs often evidenced some of the most innovative approaches to enabling engagement. As Sir Eric Peacock remarked: "Innovation is of course key to the SME sector, whose major concern (aside from the state of the economy) is competition. SMEs are constantly striving to improve and to create new products and services to beat the competition."

72 As Simon Galbraith at Red Gate Software commented: "For Red Gate it's about getting the best out of people, making them grow and creating a working environment which is flexible and encourages creative working." Red Gate, and other businesses in the technology sector, have to meet the constant challenge of innovation and competition by recruiting the best employees and providing the environment where they can produce their best work for the company.

73 The visibility of the leader is often even more crucial than in larger organisations. As Matt Kingdon of the innovation company, ?What If!, pointed out: "The leader delivers the script 'why bother?' to employees and it is critical for the leader to communicate through deeds, not just by sitting in an ivory tower sending e-mails."

74 Despite the strong belief among SME managers that the leader was best placed to make decisions, small firm managers were likely to at least discuss the implication of changes with employees, with three quarters of small-firm managers (fewer than 50 employees) agreeing that: "We do not introduce any changes here without first

\footnotetext{
${ }^{131}$ BERR Annual Small Business Survey 2007/8 .24 and at www.berr.gov.uk/files/file50124.dod (accessed 1 July 2009)
} 
discussing the implications with employees." ${ }^{132}$ This is reflected in 47 per cent of SME employees feeling satisfied with their involvement in decision making in the workplace compared to 37 per cent in large firms ${ }^{133}$.

75 Creating a community within the business is also important in smaller business, as Jacinta Phelan (from Harvey Nichols Restaurants) remarked: "People love working here because of the people they work with and the atmosphere. Engagement is about creating a community and getting staff to become part of the customer experience."

\section{Employee Ownership}

Employee owned companies who spoke to the review emphasised that ownership - in its many forms - was a profound and distinctive enabler of high engagement. We include case studies from John Lewis Partnership, Unipart and School Trends in this review; further case studies of the approach towards engagement taken by other employee-owned organisations can be found in the Guide to Making Employee Ownership Work, published by the Employee Ownership Association.

The Employee Ownership Association pointed to their study Good Business - the employee ownership experience, which surveyed 96 companies' own views of the experience of employee ownership. Ninety-one per cent said greater employee commitment was 'the biggest win of being employee owned'; 81 per cent said staff take on more responsibility; 72 per cent said staff worked harder; 66 per cent believed staff were more innovative; and 61 per cent said they were more productive.

Research done by HMRC into Share Incentive Plans (SIP) and Save as You Earn (SAYE) plans (all-employee share schemes) similarly indicated a positive relationship between employee views and ownership. Eighty-one per cent of the 984 organisations in the study said that increasing employee commitment was a major reason for setting up SAYE schemes; 87 per cent said there had been a positive impact on relations between the organisation and its employees. (The equivalent figures for SIP schemes are 79 per cent and 82 per cent).

Forty-five per cent of the SIP participants and 48 per cent of the SAYE participants in a survey undertaken for the research said the provision of the scheme encouraged them to stay with the organisation, and eight in ten SIP and SAYE participants strongly agreed or agreed that they felt loyal to their organisation compared to seven in ten non-participants. (Evaluation of Taxadvantaged all employee share schemes, HMRC research report September 2008)

\footnotetext{
${ }^{132}$ Kelsey, Alpin, Forth et al (2006) Inside the Workplace: Findings from the 2004 Workplace Employment Relations Survey(page 27) also at ttp://www.berr.gov.uk/whatwedo/employment/research-evaluation/wers-2004 .Accessed 1 July 2009

133 Ibid p. 29
} 


\section{The Challenge for HR}

The evidence indicates that for it to be successful, leaders have to champion and line managers have to lead engagement. But the HR profession and HR practitioners have a vital role to play. As Jackie Orme, the Chief Executive of CIPD emphasised to us, a key challenge for the profession was to ensure that employee engagement 'gets put on the table' in companies and organisations. "HR can't manufacture engagement, but we have a key role in helping companies develop the kind of organisational culture where engagement can thrive, and ensuring that managers have the skills to make engagement a reality." According to CIPD's recent discussion paper An HR Director's Guide to Employee Engagement (June 2009) HR professionals needed both to recognise the importance of engagement and ensure access to a wide range of tools and techniques to facilitate line management effectiveness at engagement.

At the same time, engagement underlines the importance of HR engaging with business strategy and goals, as well as ensuring that wider HR policies and practices which impact on engagement, such as training and development, are in place. According to the Economist Intelligence Unit, there is a danger that HR can get separated from people issues such as engagement. "When business executives talk about HR, they focus on things like reward and benefits, performance evaluations, and HR operating efficiency. But when these same executives talk about people issues, they focus on strategic challenges such as talent management, workforce productivity and leadership development."134 Many respondents to this review pointed to the strategic opportunity that employee engagement represented for HR to re-establish the profession at the heart of business and organisational success, rather than being viewed as a cost centre or administrative function.

\section{Corporate Social Responsibility (CSR)}

76 Many organisations told us of the important role community and corporate social responsibility programmes played in developing and maintaining engagement.

77 A study by IPSOS Mori in November $2006^{135}$ suggested that "aligning corporate values with employee ethics had a significant impact on employee engagement". Fifty-five per cent of employees thought it very important that their own employer was responsible to society and the environment, with a further 31 per cent thinking it very important. Only 12 per cent thought it not very or not at all important. It went on to suggest that companies with strong CSR policies found it easier to recruit good employees. Almost half of all job seekers say they are more likely to

\footnotetext{
${ }^{134}$ Deloitte Touche Tohmatsu and the Economist Intelligence Unit (EIU) (2007) Aligned at the Top.

${ }^{135}$ Ipsos Mori (2006) Engaging employees through corporate responsibility
} 
join or stay with a company that addresses social issues (Manpower 2005). Evidence from the US demonstrated that CSR also has an effect on retention: seven out of ten employees with a favourable perception of their company's community commitment planned to stay with their company for the next two years, compared to half of those with a less favourable perception. Seventy-five per cent of employees who believed their organisation paid enough attention to sustainability would recommend it as an employer to a friend or family member; on the other hand 56 per cent of employees who did not believe their employer was doing enough would not make any such recommendation. And commitment levels varied between the two groups, with 75 per cent with positive views saying their commitment was high, as against 49 per cent with negative perceptions. ${ }^{136}$

\section{Talent and diversity}

78 There is a strong read-across between organisations' increasing determination to find talent from within their own ranks, and maximise the opportunities and effectiveness of existing employees, to employee engagement. As Sir Michael Rake, chair of BT and of the UKCES, puts it: "The biggest challenge for global companies is to unleash the power of our people. ${ }^{\prime 137}$

79 Companies are increasingly moving away from the concept of the 'war for talent' the battle to recruit from the small number of talented stars available - to 'growing your own'. According to Tomorrow's Company: "Once we move away from old mindsets and start to see talent as abundant then we will start to do what is needed to ensure the survival and sustainability of our companies as well as the economy, environment and society of which they are a part. This means thinking about the new kinds of talent that will be needed, defining it in new ways, finding it in new places and from new generations. Tomorrow's companies will be good at discovering, engaging and leading every ounce of individual and collective capacity in people."

80 Lucy Parker, chair of the Talent and Enterprise Task Force told us: "The question for employers in the future will increasingly be 'how do we get the best out of you, wherever you play in the organisation.' That's what the new concept driving the talent world will be about; how to tap into the full potential of the workforce. Engagement will be critical to success in this endeavour, because it is the way to release the talent and creativity that will deliver the innovation we need for future competitveness."

81 There is an equally strong relationship between engagement and the drive in most organisations to ensure their workforce reflects the diversity of the UK's people. Baroness Margaret Prosser, Vice-chair of the Equality and Human Rights Commission and Chair of the Women at Work Commission, believes that ensuring fairness and equal opportunities at work for all employees lies at the heart of engagement. "It's hard to imagine an engaged workforce where one group felt that

\footnotetext{
${ }^{136}$ Marr J., (ed) Walker Information, US national employee benchmark survey 2001

${ }^{137}$ Quoted in Tomorrow's Company report Tomorrow's Global Talent 2009
} 
their voice was being ignored. Ensuring equal opportunities and fair treatment is an essential strand of an engagement strategy."

82 Her view was echoed by Donna Miller, European HR director of Enterprise rent-acar. "Our view has long been that there shouldn't be engagement differences among different sets of people[...]But we are changing this view now. We're coming round to the idea that so much of engagement and management practice success is precisely how they deal with diversity, be it working with people of different ages, sex, ethnicity. As a business we must understand different types of people have different inclinations. It makes sense when you think about it. We're about to pilot a management training project which specifically looks at how to build trust within teams that are made up of different people and ethnic backgrounds. Our focus is keeping the widest possible pool of talent available, and this now means looking at all types of employee. ${ }^{\text {"138 }}$

${ }^{138}$ Quoted in Stern Stefan, 'Feel The Strategy: Leaders Must Engage Hearts as Well as Minds' Management Today 1 Nov 2008 


\section{Chapter 5}

\section{Recommendations}

\section{What needs to happen now?}

1 We were asked by Ministers to describe what employee engagement is and how it can help organisations improve their performance. We were asked to make recommendations on what the government could do to help extend levels of employee engagement across the economy as a whole.

2 The evidence is clear: engagement levels across the economy need to be higher to meet the future challenges of international competition and of providing public services with constrained resources. We are not proposing that this should be remedied by a top down, heavy handed government intervention. In our view extending employee engagement is not an issue for legislation or regulation: it requires culture change. More people need to 'get it' - and more people need to do it.

3 The major task ahead therefore is to raise the profile of the issue with leaders in all sectors of the economy. Key to this will be extending understanding of the business case for employee engagement, and ensuring that the necessary advice and assistance is available. Government could and should use its unique power to convene debates on matters of national significance, and its ability to bring together all the interested parties to develop solutions designed to meet their specific needs. We are therefore, in summary, making three broad recommendations.

4. Firstly, in order to meet demand, more tailored support and help needs to be made available for companies and organisations wanting to develop engagement. We suggest that by March 2010 a series of practical aids, provided by both government and non-government sources, should be put in place including web-based support (for example utilising businesslink.gov.uk) and easy access to best practice and experience as well as coaching and advice. These new sources of support will need to be accessible, and to be articulated and delivered in a way that meets the needs of the potential users, particularly those in the SME sector. Where this additional support is provided by government it should be aligned with Solutions for Business, the government's streamlined portfolio of business support. 
5 Secondly, that existing support offered under the government's umbrella - such as Acas, Investors in People (liP), UKCES and businesslink.gov.uk - should be better aligned to deliver engagement outcomes. This will involve all the delivery parties coming together with those who will use the resources, in an organised way, to work out in detail how to achieve this goal. It will be important that external stakeholders such as CIPD and CMI play a role in this discussion too.

6 Thirdly, to extend understanding, and knowledge of engagement, the topic needs to be more widely aired through a nationwide discussion, again involving all the key stakeholders, which can bring together those with experience in developing engagement with those who wish to learn more or to develop their own strategies further. This should include a series of events such as conferences, workshops, regional road shows and research papers. Again it will be vital that all the relevant stakeholders are involved in this conversation, including the CBI, TUC, FSB, BITC, $\mathrm{BCC}$ and the regional development agencies (RDAs).

7 We set out below in more detail these three recommendations. We explain them, below, in chronological order; recommendations 1 and 2 would run in parallel to the end of March 2010, while recommendation 3 involves the launch of more practical support in March 2010.

\section{Recommendation one: A national awareness campaign}

8 There should be a nationwide awareness raising campaign over the next eight months, to expose the widest range of companies, businesses and organisations in the public, private and third sector to the potential benefits of employee engagement.

9 Under the stewardship of BIS and the Secretary of State, guided by a high level sponsor group, implemented by a small core group, we envisage a series of nationwide and regional events and conferences, seminars, workshops, and papers. We would want to see the widest possible range of leaders of organisations and stakeholders involved. They would include members of the CBI, TUC, other employer bodies, the Institute of Directors, BCC, BITC, the Federation of Small Businesses, the professional bodies including the CIPD and the CMI, central government, local government and the NHS. 
A number of senior figures from across the economy have already indicated their willingness to serve on the high level sponsor group, should the Secretary of State accept our recommendations. The list to date includes:

Adrian Askew - General Secretary, Connect Union

Richard Baker - Non Executive Chairman, Virgin Active

Brendan Barber - General Secretary, TUC

Sir Michael Bichard - Director, Institute for Government

Dame Carol Black - Director, UK Government's Health and Work Programme Stephen Bubb - Chief Executive, ACEVO

Mike Carr - RDA Enterprise Director

Clare Chapman - Director General of Workforce, Department of Health Cary Cooper - Professor, Lancaster University Management School \& UK Government Foresight Programme

Rona Fairhead - CEO, Financial Times Group

Gordon Frazer - UK Managing Director, Microsoft

John Hannett - General Secretary, Union of Shop, Distributive and Allied Workers (USDAW)

Chris Humphries - Chief Executive, UK Commission for Employment \& Skills (UKCES)

Will Hutton - Executive Vice Chair, Work Foundation

Justin King - CEO, Sainsbury's

Sir Alan Jones - Chairman Emeritus, Toyota UK

Richard Lambert - Director General, CBI

Leigh Lewis - Permanent Secretary, Department of Work \& Pensions (DWP) Tim Melville-Ross - Chairman, Higher Education Funding Council for England (HEFCE) \& DTZ

John M Neill CBE - Group Chief Executive, Unipart Group

Sir Gus O'Donnell - Cabinet Secretary \& Head of the Home Civil Service Jackie Orme - Chief Executive, CIPD

Sir Eric Peacock - Current or former Chairman/leader of 10 SMEs

Chris Pilling - Head of Direct Banking, HSBC

Peter Sands - CEO, Standard Chartered Bank

Sir Martin Sorrell - CEO, WPP

Ruth Spellman OBE - Chief Executive, Chartered Management Institute John Taylor - Chief Executive, Acas

Miles Templeman - Director General, Institute of Directors (IoD)

Alex Wilmot-Sitwell - Co-CEO, UBS Investment Bank

John Wright - National Chairman, Federation of Small Businesses (FSB) 


\section{Recommendation Two: Aligning Resources}

10 We believe that government-funded organisations should ensure that they further align their support for those seeking to address this issue.

11 Firstly, there is a great deal of business support provided by central government and government agencies - nationally, regionally and locally. Acas for example has a model workplace guide. Solutions for Business, the government's package of business support products currently has 29 products to help businesses including skills and training via Train to Gain. ${ }^{139}$ UKCES supports a wide range of training; IIP has had a major impact on improving workplace performance and in enhancing employees' experience, as research from Cranfield University School of Management has shown. The RDAs have an important role in co-ordinating and delivering this business support. Ensuring that these considerable resources respond to the demands for support in developing the skills required for engagement will be vital.

12 In addition other government departments and agencies are making an input to people's working lives. The DWP is taking forward work on Dame Carol Black's health, work and well-being workstream, which has a significant focus on good people management; the Health and Safety Executive (HSE) have produced stress management standards, which make the link between the importance of good people management and effective work organisation, employee health and wellbeing; and the National Institute for Clinical Excellence (NICE) is looking at the importance of good people management from a public health perspective with the aim of developing guidance on healthy and productive workplaces. It would make sense for these different work streams to make an input into the developing work on engagement.

13 Evidence to the review suggested that more support should be devoted to the people skills vital to leadership and management which lie at the heart of engagement, in addition to generic management skills. These softer skills include: the ability to consult; engage; communicate effectively; have difficult conversations; and interpersonal skills. It is vital that these softer skills are incorporated into the offer to business from the agencies outlined above - in a way that is accessible and appropriate. The access points to this advice and support, particularly for smaller businesses, need to be well-signposted.

14. To take this aligning and co-ordinating work forward we recommend that a '2010 group' be established, tasked with ensuring that the procurers of resources and the resources themselves are fully aligned and equipped to give the support which organisations want. Represented on this group should be the RDAs, UKCES, the

\footnotetext{
139 Products can be accessed via Business Link by phone (0845 600 9006), online (www.businesslink.gov.uk or face to face from a local Business Link Provider.
} 
Sector Skills Councils, and Acas together with representatives of those using these services, including the FSB and EEF.

15 Higher education institutions also have an important role in extending engagement. Business Schools in general and some specific schools in particular have made significant progress in developing people management and leadership approaches and we look forward to engaging with them on what more could be done.

16 We were impressed with the LEAD programme at Lancaster University, a ten-month leadership and management development programme which has been specifically designed for owner-managers of small to medium-sized businesses. The programme concentrates on two areas: the business itself and the personal development of the owner-manager.

\section{Recommendation three: Increasing support}

17 During the course of the review we heard many requests for improving the quality and quantity of support available for those who want to develop engagement. Practical proposals included:

- Ability to visit workplaces that are achieving high levels of employee engagement;

- Ability to access evidence and emerging evidence of the drivers of employee engagement;

- Coaching from those who have done it;

- Ability to listen, possibly on-line, to line managers and leaders who have been through the journey of enhancing employee engagement;

- Hearing about specific and easily actionable ideas for interventions and events that engage employees;

- Knowledge of first class events at which those who have achieved it will be speaking;

- Networks to pool experiences and to develop new ideas to enhance levels of engagement.

18 We recognise that the final list of ideas will need to be tailored to suit the specific needs of different sectors of the economy. Most importantly it needs to be developed and designed in collaboration with those who will be using it. The key to the success of such a programme will be that those who want the support and those who can provide it, collaborate to design and own the process and the outputs. We believe this will be a much more effective way of ensuring that the help meets the need. 
19 Underpinning this developmental work will be the advice and support of a wide range of practitioners and engagement specialists who have agreed to participate in this work. They include individuals from:

\section{Practitioner Forum}

Private Sector

7side Ltd

Accenture

BAE

BT

The Cooperative

Coopertive Financial Services

Diageo

Fujitsu

Google

JCB

John Lewis Partnership

JWT

KPMG

M\&S Money

Marks and Spencer

McDonalds

Metro

Microsoft

Nationwide

Northern Leadership Academy

Reed Elsevier

ROK

Sainsbury's

Serco

Standard Chartered

Telefónica 02 UK

Unipart

Virgin

Vodafone

VT Group

\section{Public Sector}

Blackpool NHS trust

Cabinet Office

Department for Communities and Local

Government (CLG)

Department for Environment, Food

and Rural Affairs (Defra)

Department for Work and Pensions (DWP)

Ministry of Justice (MoJ)

National School of Government

Ofsted

UK Border Agency, Home Office

Wychavon Council

\section{Third Sector}

Oxfam

United Welsh 


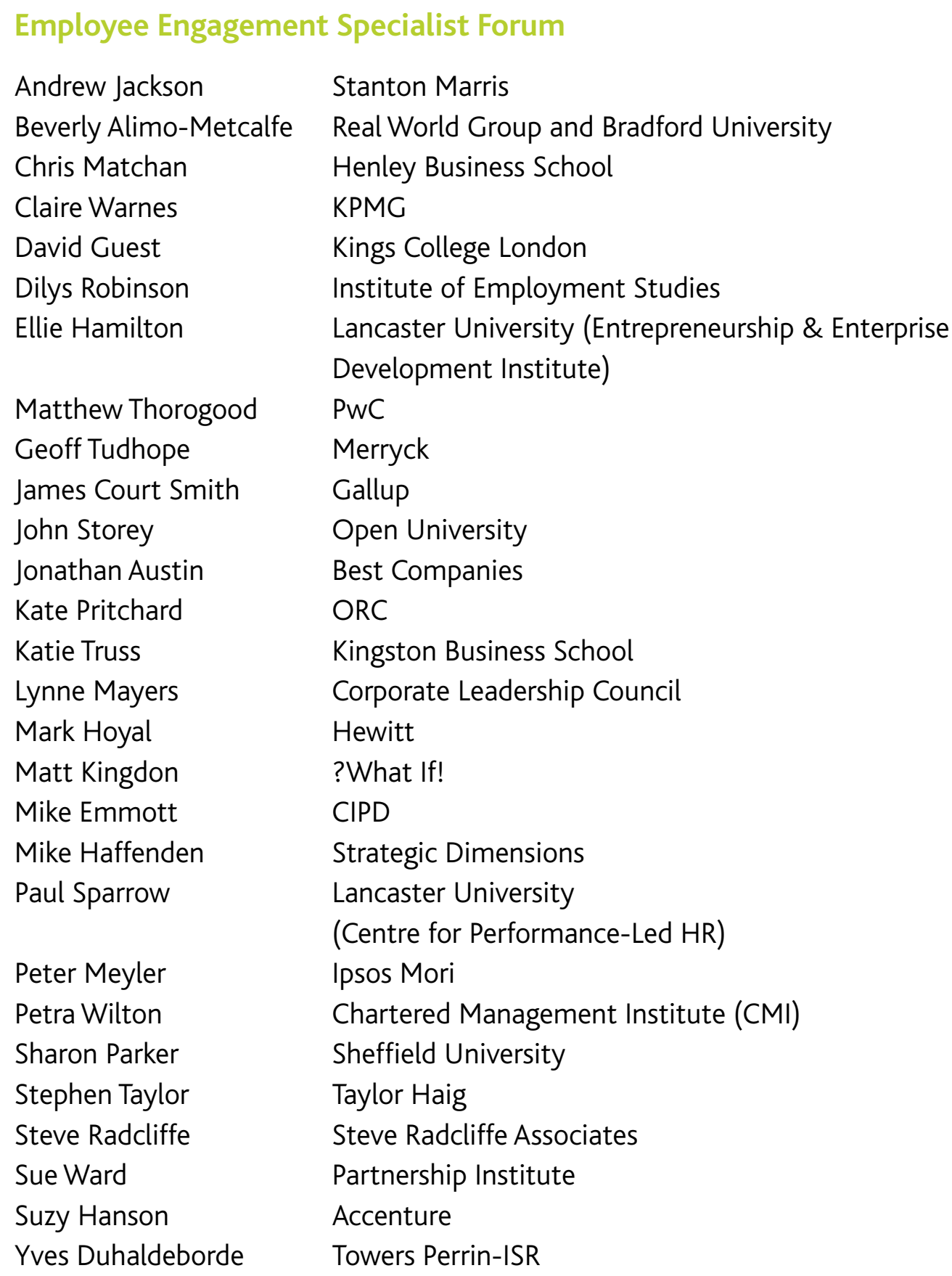

Andrew Jackson

Beverly Alimo-Metcalfe

Chris Matchan

Claire Warnes

David Guest

Dilys Robinson

Ellie Hamilton

Matthew Thorogood

Geoff Tudhope

James Court Smith

John Storey

Jonathan Austin

Kate Pritchard

Katie Truss

Lynne Mayers

Mark Hoyal

Matt Kingdon

Mike Emmott

Mike Haffenden

Paul Sparrow

Peter Meyler

Petra Wilton

Sharon Parker

Stephen Taylor

Steve Radcliffe

Sue Ward

Suzy Hanson

Yves Duhaldeborde

Stanton Marris

Real World Group and Bradford University

Henley Business School

KPMG

Kings College London

Institute of Employment Studies

Lancaster University (Entrepreneurship \& Enterprise

Development Institute)

PwC

Merryck

Gallup

Open University

Best Companies

ORC

Kingston Business School

Corporate Leadership Council

Hewitt

?What If!

CIPD

Strategic Dimensions

Lancaster University

(Centre for Performance-Led HR)

Ipsos Mori

Chartered Management Institute (CMI)

Sheffield University

Taylor Haig

Steve Radcliffe Associates

Partnership Institute

Accenture

Towers Perrin-ISR

20 We also recommend that further research continues to be carried out into the effectiveness of engagement approaches; for example, the work being carried out by the Kingston Business School Employee Engagement Consortium. 


\section{Annexes}

\section{Annex A}

\section{Contributors to the MacLeod Review}

David and Nita are grateful for contributions from the following (although final responsibility for the text of this report remains with them):

3M United Kingdom

Jeff Skinner

7side

Aberdeenshire Council

Accenture

Adair Turner, Lord

Advantage West Midlands

Advisory, Conciliation and Arbitration Service (ACAS)

Aintree University Hospitals NHS Foundation Trust

Amey

Association of Business Schools (ABS)

Jonathan Slack

Association of Chief Executives of Voluntary Organisations (ACEVO)

Astra Zeneca

Babcock Marine Clyde

BAE Systems

Best Companies

Johnathan Austin

Birmingham City Council

Blackpool Fylde \& Wyre Hospitals Trust

Bring Yourself to Work

lan Buckingham

British Association of Communicators in Business

British Chambers of Commerce (BCC)

British Printing Industries Federation (BPIF)

Broadway

BT

Business in the Community (BITC)

Buy the House

Cabinet Office

Gill Rider

Alison Khan

Andrew Templeman,

Jonas Nystrom \&

Liz McKeown

Cambridgeshire County Council

Stephen Moir 
Canada School of Public Service \& Waterloo University

Cardiff Business School, Advanced Institute of Management

Research \& Sunningdale Institute

Cary Cooper

Cass Business School

Chartered Institute of Personnel Development (CIPD)

Chartered Management Institute (CMI)

Chorley Borough Council

Clive Hollick, Lord

Cognosis Consulting

Confederation of British Industry (CBI)

Connect Union

Co-operatives Group

Cooperatives UK

Corporate Leadership Council (CLC)

David Varney, Sir

Deloitte

Demos

Department for Business, Innovation and Skills (BIS)

Department for Children, Schools and Families (DCSF)

Department for Communities and Local Government (CLG)

Department for Environment, Food and Rural Affairs (Defra)

Department for Transport (DfT)

Department for Work \& Pensions (DWP)

Department of Health (DH)

Des Dearlove \& Stuart Crainer

Doncasters Aeronautics

East Midlands Development Agency

East of England Development Agency (EEDA)

Employee Ownership Association (EOA)

Engage Group

Engineering Employers Federation (EEF)

Equality and Human Rights Commission (EHRC)
Jocelyne Bourgon

Rick Delbridge

Veronica Hope Hailey

Richard Brown

Sabri Challah

Will Davies

Bill Wells, Dhiren

Patel, Jitinder Kohli,

Kirsty Pierce, Mike

Paice, Peter Davidson,

Tim Harrison, Tracy

Vegro \& Vicky Pryce

John A. Patterson

John Smythe \&

Peter Agertoft 
Eric Peacock, Sir

Federation of Small Businesses (FSB)

Financial Services Skills Council (FSSC)

Financial Times Group

Finmeccanica

first direct

Freshfield Brauckhaus Deringer

Fujitsu

Gallup

Gillian Stamp

Google

Hanson Green

Peter Waine

Harvey Nichols Restaurant

HansenGlass

Hay Group

Health and Safety Executive (HSE)

Health Services Management Centre, Birmingham University Jo Ellins \& Chris Ham

Helen Alexander

Henley Business School

Chris Bones

Henry Mintzberg

Hewitt Associates

Jamil Husain

Higher Education Funding Council for England (HEFCE)

Tim Melville-Ross

CBE

Hillingdon Council

HM Prison Service

HM Revenue \& Customs (HMRC)

HM Treasury

Home Office

Richard Williams

HSBC

ifs School of Finance

IHG

Improvement and Development Agency (IDeA) on behalf of the

Local Government Association Group

Institute of Chartered Accountants in England and Wales (ICAEW) Sustainability

Department

Institute of Directors (IoD)

Institute of Employment Studies (IES)

Investors in People UK (liP)

Involvement Participation Association (IPA)

Ipsos Mori 
Ivan Robertson

J C Bamford Excavators (JCB)

J Sainsbury plc

John Lewis Partnership

Stuart Hampson, Sir

Jonathan Agnew

JWT

Peter Womsley

Kings College, London

David Guest

Kingston Business School

Katie Truss

KPMG

Lancaster University (Centre for Performance-Led HR)

Paul Sparrow

Lancaster University (Entrepreneurship \& Enterprise Development

Ellie Hamilton Institute)

Legal and General

Neil Perry

Liz Sands

Lloyds Banking Group

Lloyds Pharmacy

London Ambulance Service

London Business School

Lynda Gratton

London Development Agency

London Fire Brigade

London School of Economics

Tim Besley

LSG Sky Chefs

M\&S Money

McDonald's

McKinseys

Michael Barber, Sir

Mace Group

Make your Mark

Malmaison and Hotel du Vin

Marcus Buckingham

Margaret Prosser, Baroness

Mark Stanhope, Admiral Sir KCB OBE

Marks \& Spencer

Merryck \& Co

Geoff Tudhope

Mervyn Davies, Lord

Mersey Travel

Metro

Michael Bichard, Sir

Michael Gibbons

Microsoft

Terry Smith 
Ministry of Justice (MoJ)

Nampak Plastics

Eric Collins

National School of Goverment's Sunningdale Institute

Nationwide

Network Rail

NHS Employers

North West Regional Development Agency

Northern Leadership Academy

John Oliver

$\mathrm{O} 2$

Office for Public Management (OPM)

One North East

Open University Business School

John Storey

ORC

Oxfam

Partnership Institute

Pfizer

PricewaterhouseCoopers (PwC)

Prime Minister's Delivery Unit

Prime Minister's Strategy Unit

Quantum Consultancy

Real World Group/Bradford University

Beverly Alimo-

Metcalfe \& Juliette

Alban-Metcalfe

Red Gate Software

Reed Elsevier

Resolis Associates

Rob Lummis

ROK Group

Royal Society (RSA)

Matthew Taylor

Runshaw College

School Trends

Sector Skills Council Alliance

Serco

Social Partnership Forum

South East of England Development Agency (SEEDA)

South West of England Regional Development Agency

Southern Railway

Spinvox

Standard Chartered Bank 
Stanton Marris

Steve Radcliffe Associates

Strategic Dimensions

Talent and Enterprise Task Force

Taylor Haig

Tesco

Tomorrow's Company

Towers Perrin-ISR

Toyota

Trade Union Congress (TUC)

UBS

UK Border Agency

UK Commission for Employment and Skills (UKCES)

Ultra Electronics

Unipart

Unison

Unite the Union

United Welsh

University of Sheffield

USDAW

Vanguard Consulting

Virgin Active

Virgin Media

Vodafone UK

VT Group

Waitrose

Warner Brothers

Wates Group

Watson Wyatt

West Bromwich Machine and Tools

Westlakes Engineering

?What If!

Whitbread

Whitehall \& Industry Group (WIG)

Work Foundation

Wychavon District Council

Yorkshire Forward

Young Foundation
Andrew Jackson

Steve Radcliffe

Mike Haffenden

Lucy Parker

Stephen Taylor

Mark Goyder

Hugh Shanks

Alan Jones, Sir

John Mahoney-Phillips
Sharon Parker

Gemma Webb

Annette Ware

Paul Dreschsler

Matt Kingdon

Louise Smalley

Fiona Narburgh 


\section{Annex B}

\section{MacLeod Review events}

The following events were held as part of the review process:

\section{3/11/08 - A CIPD Action Learning Group: The Future of Employee Relations}

A group of 15 CIPD members brought together as part of a CIPD Action Learning Group for initial discussions on the MacLeod Review.

\section{0/11/08 - BIS Advisory Forum on the Impact of Employment Policies}

This group is made up of around 15 senior business academics and economists who specifically discussed the MacLeod Review at this meeting.

10/12/08 - Employee Ownership Association consultation meeting

A meeting comprising a selection of members from the Employee Ownership Association.

\section{5/12/08 - IPA Advisory Council}

David MacLeod addressed around 40 members of the IPA Advisory Council, from the public, private and third sectors.

\section{7/12/08 - CBI Members event}

A small group of $\mathrm{CBI}$ members from the private sector attended this meeting held at BIS to discuss their experiences of engagement.

\section{7/12/08 - Roundtable discussion with members of Cooperatives UK}

Around 10 members of Cooperatives UK visited BIS to discuss the review.

\section{7/01/09 - High level public sector roundtable}

Cabinet Office hosted a meeting for a small number of senior officials from across Whitehall.

\section{4/01/09 - South of England regional event}

Regional consultation roundtable held in London, arranged in conjunction with the South East of England Development Agency (SEEDA), also with input from South West of England Regional Development Agency and London Development Agency. Approximately 30 delegates attended from a mixture of public and private sector organisations.

\section{6/01/09 - Midlands regional event}

Regional consultation roundtable held in Leicester, in conjunction with East Midlands Development Agency (EMDA), also with input from East of England Development Agency (EEDA) and Advantage West Midlands. This was the second in a series of regional events, attended by around 30 people from the public and private sectors.

\section{2/01/09 - Working level public sector roundtable}

A meeting to discuss the practical implementation of employee engagement in the public sector. Attended by around 15 delegates from across the public sector.

\section{2/01/09 - Institute of Hospitality Roundtable}

Around 15 delegates attended a meeting at BIS for a discussion on engagement in the hospitality sector. 
26/01/09 - Consultation Workshop on employee engagement in conjunction with the Whitehall and Industry Group

Around 40 delegates from both the public and private sectors attended this workshop held at BIS and organised by the Whitehall and Industry Group.

\section{7/01/09 - CIPD Employee Engagement Conference}

David MacLeod presented at the conference in front of an audience of around 100 delegates from the public and private sectors.

30/01/09 - North of England regional event

A regional consultation event held in Leeds, arranged in conjunction with Yorkshire Forward, One North East and North West Regional Development Agency. Around 20 delegates attended, from the public, private and third sectors.

\section{0/02/09 - EEF Employment Policy Committee Dinner}

David MacLeod and Nita Clarke attended the dinner of the EEF Employment Policy Committee. They gave a brief presentation and then consulted around 15 committee members for their views.

\section{1/02/09 - Accenture roundtable}

Accenture kindly organised a roundtable event at which David MacLeod discussed the topic of employee engagement with a handful of Accenture's private sector clients.

\section{4/02/09 - Financial Services Skills Council roundtable}

A selection of private sectors organisations attended a meeting organised by the FSSC.

\section{5/03/09 - CBI Sectoral Employment Issues Committee}

David MacLeod addressed 15 members of the CBI's Sectoral Employment Issues Committee.

\section{1/03/09 - Sunningdale Institute Fellows Dinner}

David addressed 11 fellows of the Sunningdale Institute on the topic of employee engagement at a dinner in London.

\section{8/03/09 - Wales event in conjunction with the Welsh Assembly Government}

A consultation workshop, held in Cardiff and attended by around 30 delegates from the public and private sectors, was organised by the Welsh Assembly Government.

\section{5/03/09 - CIPD Network Event}

A discussion of engagement during the recession hosted by CIPD and attended by small number of CIPD members. The MacLeod review team participated in discussions.

\section{6/03/09 - Lancaster University SME roundtable}

A small group of SMEs attended a workshop chaired by David MacLeod as part of Lancaster University Management School's LEAD programme.

27/03/09 - Scottish event in conjunction with CIPD

A consultation workshop held in Edinburgh and attended by around 30 delegates from the public and private sectors, organised in conjunction with CIPD. 


\section{7/03/09 - Wychavon district council local government event}

Representatives from 9 different councils and 7 partner organisations met at Wychavon to review progress and what actions would help foster engagement within councils.

02/04/09 - Birmingham City Council local government conference 'Engagement 2.0' This event, hosted by Birmingham City Council, brought together representatives from around 30 councils and partner organisations. Birmingham City Council shared their experiences of engagement, and the event generated discussion and knowledge sharing between councils.

\section{6/04/09 - MacLeod Review event for academics and consultants}

This event brought together around 25 leading academics and consultants to discuss the evidence for the importance of employee engagement.

\section{7/04/09 - MacLeod Review practitioners event}

Around 50 leading practitioners of employee engagement came together at BIS to discuss the emerging conclusions of the Review and offer their feedback.

\section{2/05/09- ICAEW breakfast briefing}

Around 20 members of the Institute of Chartered Accountants of England and Wales met at BIS to discuss the emerging conclusions of the Review.

\section{2/05/09 - IPA anUMan Employee Relations Conference}

David MacLeod presented at the anUMan Employee Relations Conference, in conjunction with IPA. The audience consisted of around 20 delegates from the public, private and third sectors.

\section{3/05/09 - Association of Business Schools (ABS) Executive Committee meeting}

David MacLeod presented to the leaders of several business schools in Cardiff and invited their feedback on emerging conclusions.

\section{4/05/09 - Business Well-being Network event}

A well-being networking event in London where the relationship between well-being and employee engagement was discussed. Around 40 delegates attended, from the public, private and third sectors. 


\section{Annex C}

\section{MacLeod Review Call for Evidence}

We received over 300 responses to the call for evidence on the BIS website. Contributors included:

A G Parfetts \& Sons

Aber Instruments

Barry Wise

Able and How

Accomplice

Nicky Spencer

Barrett Valves Centre

Phil Clothier

Brand Union

Sean Trainor

Bring Yourself to Work

lan Buckingham

Caledonian Business School, Glasgow Caledonian

Morag Mclean

University

Career Innovation (Ci)

Hugh Flouch

Employee Ownership Association

Four Groups

Bruce Lewin

GoSkills

Clare Jones

Harrow Council

Homeloan Management

Denise Davies

Kellan Group

Amanda Hesketh

KHI Energy Saver

Lancashire County Council

Karen Gregory \& Suzanne Ward

Lloyds Banking Group

David Littlechild

Lloyds Pharmacy

Ixia Consultancy

Marks \& Spencer

Sarah Mclntyre

Network Rail

Bob Hughes

Nottingham County Council

Moira Whelan

Partnership Institute

Prospect

Sarah Page

Quintessa

Resolis Associates \& Vanguard Scotland

Andy Lippock

Scandinavian Airlines System, SAS Ground Services UK

Select Appointments, Portsmouth

Serco Group

South Cambridgeshire District Council

Ian Cawthra

Standard Life 
Stockport Council

Suma Workers Cooperative and Cooperatives UK

Ultra Electronics

Unison Media Engagament

Wakefield College

Wates Group

York Management Tool
Frank Fielding

Bob Cannell

Keith Thompson

Gill Weston

Karen L Sykes

Prof Andrew Pendleton

Alasdair Fraser

Doug Shaw

Eamon Wadley

Ian Buckingham

Sharon O'Dea

Tasha Reilly 


\section{Annex D}

\section{Extracts from the MacLeod Review regional discussions}

Below is not a summary of discussions, but rather highlight particular issues raised at the event.

\section{Scotland event}

The Scottish event, held jointly with CIPD, was extremely productive. There was much discussion around not just employee engagement but also organisational structures, with some consideration of how systems thinking and LEAN were relevant to the Review. Some of the delegates believed that the barriers to engagement included overcomplicated employment law, as well as the fact that some organisations only looked at the purpose of the organisation from the customer's point of view. Delegates were wary of involving government too much in this area for fear or further legislation, however they also believed that recommendations should include raising the profile of $\mathrm{HR}$ and offering clear and direct support to organisations.

\section{Wales event}

The roundtable discussion in Cardiff highlighted the emphasis that is being placed on employee engagement in the public sector. Work has been taken forward by the Welsh Assembly Government's Wales Public Services Workforce Forum and by the University of Glamorgan to consider the implications of an engaged workforce in Welsh public services, in order to understand and measure employee engagement in the public sector and identify examples of good practice.

During the course of roundtable discussions, it was recognised that there was not a shared understanding of employee engagement; that engagement means different things to different organisations, and also to the different players such as business leaders, employees, trade union representatives and HR professionals. Participants felt that without a shared understanding within an organisation of what engagement means, it is very difficult to achieve. Structured employee voice and/or partnership working with trade unions were recognised as a key component of effective engagement. Engagement as a means of reducing the costs of staff turn over was seen as one of the most important benefits for many organisations, particularly SMEs. Engagement was also seen as a potential solution for organisations with unusually low levels of staff turnover as a means of keeping staff motivated and invigorated. There was a general sense that employee engagement was beneficial to organisations, but much confusion about how and where to start. There was an agreement that trust was a key aspect of engagement, without it quality could not be achieved. 


\section{South of England regional event}

Delegates thought that HR and Comms could actually be a barrier to employee engagement. There is a lack of respect for the so called 'soft skills' and an attitude of 'it's not real work'. Resources are also a real issue especially for SMEs. The government should make advice on where to start easy to find. There should be a re-branding of $\mathrm{HR}$ and a focus/re-naming of 'soft skills'. Bigger companies should be encouraged to train people in organisations in their supply chain (and the government should be one of the organisations doing this). It was felt that leadership coaching/training needs to be happening lower down in organisations as "it's too late when people have got to senior positions!"

Delegates identified the following key enablers: putting as much effort into marketing internally as marketing externally; treating your employees as well as you treat your customers; and focusing on agreements with staff not policies about them.

The group agreed that key barriers included: impatience (expecting engagement to become a reality overnight); human blockers (one cynic in the management chain can badly disrupt a change programme and prevent engagement becoming really embedded); lack of resources; and the top team not wanting to hear how people really feel or make changes in the way they work.

\section{Midlands regional event}

The group agreed that a key enabler of employee engagement was to get the people right and the right people; for example, addressing poor performance, dealing with blockers and investing in training to enhance the personal effectiveness of managers. Also, a clear cultural vision should be considered as important as the business plan, in order to clarify for employees where you want the company to go and what kind of place it is to work in.

Delegates identified the following key barriers: lack of openness/culture of secrecy; lack of resources, especially for SMEs; unwillingness to invest over time ("you must be in it for the long haul"); suspicious/negative attitudes ("it's not real work"); and employees who do not pick up or believe the messages they hear.

\section{North of England regional event}

Carole Reid from lip argued strongly that this agenda is already being acted on by Investors in People and the Government needs to be joined up about this. liP can provide leaders with the tools they need to make this happen.

There was general agreement that employers are doing things differently this time around (in terms of dealing with the recession). They are less willing to let people go and lose their skills and are more concerned with being seen to act fairly when redundancies are unavoidable. Sabbaticals, shorter working weeks and retraining or upskilling are being offered as a means of avoiding outright job cuts. 
Ninety-nine per cent of companies in the region are SMEs who employ 60 per cent of the workforce. These organisations 'don't do HR' but there may be some appetite for support services. Delegates felt it is important for the government to offer an appropriate level of help: don't just throw another piece of 'business support' into the mix - make it part of an existing mechanism such as Business Link. Business support needs to be simplified and signposted. There is a danger of being patronising to SMEs, which are often world class.

Delegates identified the following key enablers: trust, confidence and belief; communication; and values embedded and filtered down throughout the organisation.

Key barriers were considered to be the following: management and leadership blaming staff for problems and under-performance rather than critiquing themselves; the right training not being available; and the long time it takes to change behaviour, causing people to lose heart.

\section{Key quotes from delegates at the events included:}

"HR is fundamental but HR strategies alone won't deliver. Employees need to identify with their organisations and have pride. High profile employee engagement activity that is not followed through has a negative effect - it has to be real."

"My definition of an SME is an organisation without an HR function!"

"Senior leadership often use channels of communication instead of communicating."

"There is a lack of understanding that trust works two ways and that not trusting your employees has a negative impact".

"Engagement matters because people matter - they are your only competitive edge. It is people, not machines that will make the difference and drive the business." 


\section{Annex E}

\section{MacLeod Review Secretariat at the Department for Business}

Tom Ridge

Mary Smeeth

Alison Zhu

Debra MacLeod

Tahamina Khan

Susan Hawker

Gemma Cook and then Amy Jordan

Administrative Support

Pauline Wright, followed by Sean Skerritt and then Bernadette Folkes

Hansard Scholars (1 month each)

Alexander Faust (USA)

Tamunia Chincharauli (Georgia)

Acas Part-time Secondee

Rob Vondy 


\section{Annex F}

\section{Bibliography}

Acas-CIPD (2009) Meeting the UK's people management skills deficit

Accenture (2006) The High Performance Workforce Study 2006, Executive Summary.

Accenture (unpublished) Employee Engagement Roundtable: Presentation to the MacLeod Review, February 11th 2008.

Accenture (unpublished) An Accenture point of view on employee engagement - what it is, why it matters, how you can you change it, produced specifically for the MacLeod Review, December 2008.

Accenture (unpublished) Engaged employees are good for business - summary of external research findings 2008.

Accenture (2008) Middle Managers Outlook, UK.

Accenture (unpublished) Personal engagement list.

Accor: Reward to Engage: Rewards, Benefits and Employee Engagement in Today's

Organisations and at http://engagement.accorservices.co.uk/website/employeeengagement-whitepaper-form.htm, [Accessed 1 July 2009].

Ackers, P.M., Marchington, M., Wilkinson, A. and Dundon, T. (2005) Partnership and Voice, with it without trade unions: Changing UK management approaches to organisational participation, in Stuart, M. and Lucio M. (eds), Partnership and Modernisation In Employment Relations.

Aijala, A., Walsh, B., Schwartz, J. (2007) Aligned at the Top. Deloitte Development International.

Alimo-Metcalfe, B. et al (2007) The impact of leadership factors in implementing change in complex health and social care environments: NHS Plan critical priority for mental health crises resolution teams, Real World Group/Sainsbury Centre for Mental Health.

Alimo-Metcalfe, B. and Bradley, M. (2008) Cast in a new light. People Management, 24 January 2008.

Alimo-Metcalfe. (2008) Building leadership capacity through engaging leadership, Selected Reports from the 12th World HR Congress, London.

Alimo-Metcalfe, B. and Alban-Metcalfe, J. (2009) Engaging leadership: creating organisations that maximise the potential of their people, CIPD.

Allman, A. (2008) Employee communication in tough times. [on-line survey] www.allmancommunication.co.uk/.../Employee-Communication-meetings-This-Week.aspx [last accessed 1 July 2009].

All Party Parliamentary Group on Employee Ownership (2008) Share value - how employee ownership is changing the face of business. A short inquiry.

Armstrong, K. Ward, A. (2006) What makes for effective performance management?, The Work Foundation in the Corporate Partners Research Programme. 
Assessment \& Development Consultancy (2008) Enhancing employee productivity, [pdf Online] http://www.y2cp.com/public/ressources/publications/tests/adc/enhancing employee.pdf.

Australian Public Services Commission (2007) Changing behaviour - a public policy perspective. [Online] Www.apsc.gov.au/publications07/changingbehaviour.pdf [accessed 1 July 2009].

Axtell, C. M., Harrington, E., Holman, D. J., Unsworth, K. L., Wall, T. D. and Waterson, P. E. (2000) Shopfloor innovation: facilitating the suggestion and implementation of ideas, Journal of Occupational and Organisational Psychology, 73.

Bacon, N. and Samuel, P. (2007) Mapping partnership agreements in Britain: patterns and explanations, at 8th European Congress of the International Industrial relations Association, Manchester, UK, September 3-7th.

Barber, L., Hayday, S. and Bevan, S. (1999) From People to Profits The HR link in the serviceprofit chain. Report 355, Institute for Employment Studies, June 1999

BERR, The Information and Consultation of Employees Regulations 2004 www.berr.gov.ukd employment/employment.../ice/index.htmh - [Accessed 1 July 2009]

BERR, 2009 SME Business Barometer, February 2009. URN: 09/P75b. By IFF Research.

Bevan, S. Cowling, M. (July 2007) Job Matching in the UK and Europe. Research Report RR25, Sector Skills Development Agency.

Birdi, K., Clegg, C., Patterson, M., Robinson, A., Stride, C. B., Wall, T. D. and Wood, S. J. (2008) The impact of human resource and operational management practices on company productivity: a longitudinal study, Personnel Psychology.

Birmingham City Council, Kingston Business School Results Presentation: February 2009 Black, Carol (2008) Working for a Healthier Tomorrow: Review of the Health of Britain's Working Age Population and at: http://www.workingforhealth.gov.uk/documents/workingfor-a-healthier-tomorrow-tagged.pdf [Accessed 1 July 2009]

Blessing White (2004) The organizational dance card - a Blessing White survey report on employee engagement.

Blizzard, R. (2005) Nurses Engagement Key to reducing Medical Errors, Gallup.

Boaden, R., Marchington, M., Hyde, P., Harris, C., Sparrow, P., Pass, S., Carroll, M., and Cortvriend, $P$. (2008) Improving health through human resource management: the process of engagement and alignment, London: CIPD.

Bourne, M., France-Santos, M., Pavlov, A., Lucianetti, L., Martinez, V. and Mura, M. (2008) The impact of Investors in People on people management practices and firm performance, Cranfield School of Management.

Brewster, C., Higgs, M., Holley, N. and McBain, R. (2007) Employee engagement-report from HR Centre of Excellence Research and members meeting, Henley.

Brown, D. and Reilly, P. (2008) Employee Engagement: what is the relationship with reward management? World at Work Journal vol 17, no 4. 
Brown, W. (2000) Putting participation into practice in Britain, British Journal of Industrial Relations, 38: 299-316.

BT (2008) Corporate and social responsibility in BT - employee survey 2008.

Burns, P. (2006) Good business - the employee ownership experience, Job Ownership Ltd (JOL) and Co-operatives UK.

Business in the Community (BITC) (2007) Organisational case studies - AstraZeneca [On-line] http://www.bitc.org.uk/resources/case_studies/afe_1167_astraz.htm [Accessed 30 June 2009]

Business in the Community (BITC) (2009) Business Action on Health: Healthy People = Healthy Profits Online at: www.bitc.org.uk/document.rm?id=9097 [Accessed 1 July 2009].

Cabinet Office (undated) Linking employee engagement to organisational performance.

Cabinet Office (undated) Employee Engagement Working Group report, Annex C

Canadian Government Executive (June/July 2006) [On-line]

http://www.tbs-sct.gc.ca/rp/pstc-eng.asp [Accessed 1 July 2009].

CBI-AXA (2007) Annual Absence and Labour Turnover Survey.

CBI-TUC (2001) Submission to the Productivity Initiative, HMT.

CFE (2008) Skills utilisation literature review, Scottish Government Social Research.

Chapman, Jake (undated). 'Introducing Systems Thinking'. [On-line]

http://systems.open.ac.uk/objects/events/Jakes\%20pres\%20for\%20website.ppt.

[Accessed 1 July 2009].

CIPD (2006) Reflections on Employee Engagement, White Paper.

CIPD Annual Survey Report 2006, How engaged are British employees?.

CIPD (2008) Employee engagement fact sheet.

CIPD (2008) Gen UP - how the four generations work.

CIPD (2009) Employee attitudes survey May 2009.

CIPD (draft for June 2009) HR Directors guide to employee engagement.

CIPD Presentations to Employee Engagement Conference, 27 January 2009: Alison Heron, KPMG; Annette Ware, Vodaphone; Katie Truss, Kingston Business School; Bob Hughes, Network Rail.

Civil Service (undated) First steps in designing a model [of employee engagement] a review of best practice models and Civil Service model design.

Coats, D. (April 2009) Advancing opportunity: the future of good, The Smith Institute. http://www.smith-institute.org.uk/pdfs/good_work.pdf

Cleland, A., Townend, A. and Mitchinson, W. (2008) Engagement Assertiveness and Performance. White Paper, Ixia in partnership with Henley Management College.

Coats, D. (2004). Speaking Up! Voice, industrial democracy and organisational performance, Work Foundation. 
Coats, D. Lehki, R. (2008) Good Work: Job Quality in a Changing Economy, Work Foundation.

Cognosis (2007) Edge 1: fresh insights into strategy making, engagement and business performance.

Cognosis (2008). Leading EDGE overview - making strategy intelligently emotional.

Cognosis (2008). Igniting growth.

Constable, S. Coats, D. Bevan, S. Mahdon, M (undated) Good Jobs - a report prepared for the Health and Safety Executive.

Corporate Leadership Council (2004) Driving performance and retention through employee engagement: a quantitative analysis of effective engagement strategies, Corporate Executive Board.

Corporate Leadership Council Best Practice Profiles (2004).

Corporate Leadership Council (2004) Engaging the workforce - focusing on critical leverage points to drive employee engagement, Corporate Executive Board.

Corporate Leadership Council /Corporate Executive Board (2008) Improving employee performance in the economic downturn, Corporate Executive Board.

Corporate Leadership Council Employee Engagement Database Report.

Corporate Leadership Council (2009) Managing in the Downturn, four imperatives to drive employee innovation and performance.

Corporate Leadership Council Concerning trends for $H R$ - three challenges that require immediate responses.

Crabtree, S. (2005) Engagement keeps the Doctor Away, Gallup Management Journal Cranfield University School of Management. Investors in People Executive Summary and Impact Report 2008.

Cranfield University School of Management (2008) The impact of Investors in People on people management practices and firm performance.

Davies, G. and Chun, R. (2007) To thine own staff be agreeable, Harvard Business Review, June.

Deloitte Touche Tohmatsu and the Economist Intelligence Unit (EIU) Report (2007) Aligned at the Top

Duhaldeborde, Y. (unpublished) Review of Employee Engagement Slides prepared specifically for the MacLeod Review, 2009

Ednams A. (2008) Does the Stock Market Fully Value Intangibles? Employee Satisfaction and Equity Prices, University of Philadelphia, Working Paper Series.

Edwards, P. (2007) Justice in the Workplace: Why it is important and why a new public policy initiative is needed.

Ellins, J. and Ham, C. (undated) Unpublished summary of a literature review on employee ownership and summary of options for the NHS. 
Employee Ownership Association (2007) Submission to the All Party Parliamentary Group on employee ownership.

Engage Group (2008) Empowering employees: the new rules of engagement.

ESRC Centre for Organisation and Innovation (2006) Final report, University of Sheffield/ Institute of Work Psychology.

Felstead, A. Gallie, D. Green, F. and Zhou, Y (2007) Skills at Work, 1986 - 2006, ESRC. http://www.skope.ox.ac.uk/WorkingPapers/2006SkillsSurvey.FinalDraft4.pdf.

Financial Dynamics International Ltd (2009) A question of leadership. How can business leaders bet engage with their employees in the downturn? A survey in association with YouGov.

Finniear, J. (April 2009) Welsh Public Sector Workforce Engagement Inquiry Final Report, Wales Public Service Workforce Forum, Glamorgan Business, University of Glamorgan.

Fleming, J. H., Coffman, C. and Harter, J. K. (2005) Manage your Human Sigma. Harvard Business Review.

Forth, J., Bewley, H., Bryson, A. (2006) 'Small and Medium-sized Enterprises: Findings from the 2004 Workplace Employment Relations Survey.

Fredrickson B.L (1998) What good are positive emotions?, Review of General Psychology, Vol 2 pp 300-319.

Fredrickson B.L. and Joiner T, (2002) Positive Emotions trigger upward spiral toward emotional well-being' Psychological Science, Vol. 13 pp 172-175.

Fulmer, I. S., Gerhart, B. and Scott, K. S. (2003) Are the 100 best better? An empirical investigation of the relationship between being 'a great place to work' and firm performance, Personnel Psychology.

Gallup Organization (2006) Engagement predicts earnings per share.

Gallup (2006) Gallup Study: Feeling Good Matters in the Workplace.

Gallup Human Capital (2008) Engaging Employees through times of crisis and abnormal change, Gallup Consulting.

Gallup (2008) UK retailer - 174 stores over two years., Gallup Management Journal, 19 February (2009)

Garrow, V. (2008) Staff engagement: summary literature review, Institute for Employment Studies.

Gatenby, M., Rees, C., Soane, E. and Truss, C, Employee engagement in context, CIPD/ Kingston Business School.

Globoforce (2008) Empowering employees: the new rules of engagement.

Globoforce (2008) The new era of strategic recognition.

Gonzalez-Roma, V., Schaufeli, W. B., Bakker, A. B. And Lloret, S. (2006) Burnout and work engagement: independent factors or opposite poles? Journal of Vocational Behaviour 68. 
Goyder, M. (undated) Value and values: lessons for tomorrow's company, Tomorrow's Company.

Gray, R. (2008) Generation Y - time to grow up, Management Today, October.

Griffin, M.A., Parker, S. K.. And Neal, A. (2008) Is behavioural engagement a distinct and useful construct?, Industrial and Organizational Psychology: Perspectives on Science and Practice, vol 1, issue 1.

Guest, D. and Peccei, R. (2001) Partnership at work: mutuality and the balance of advantage, British Journal of Industrial Relations, 39(2): p207-236.

Guest, D. (2006) Smarter ways of working - the benefits of and barriers to adoption of high performance working, SSDA Catalyst, issue 3.

Guest, D., Clinton, M. and Woollard. S. (2009) Riding the recession? The state of HR in the current economic downturn, Speechly Bircham and Kings College, London.

Guest, D. (unpublished) Review of Employee Engagement: Notes for a discussion' prepared specifically for the MacLeod Review.

Gutheridge, M., McPherson, J. R. and Wolf, W. J. (2008) Upgrading talent, The McKinsey Quarterly, December.

Hales C. (2005) Rooted in Supervision, Branching into Management: Continuity and Change in the Role of First Line Managers, Journal of Management Studies, Vol 42. No 3 pp 471-507.

Ham, C. (undated) Unpublished note on 'Engaging staff in the NHS: aligning incentives to achieve higher levels of performance. A project supported by the Nuffield Trust.

Harter, J. K., Schmidt, F. L. and Hayes, T. L. (2002) Business-unit level relationship between employee satisfaction, employee engagement and business outcomes: a meta analysis, Journal of Applied Psychology, vol 86 no 2.

Harter, J. K., Schmidt, F. L., Kilham, E. A., Asplund, J. W. (2006) Q12 meta-analysis, The Gallup Organisation.

Hay Group (2001) Engage Employees and Boost Performance.

Hay Group (2007) In a league of their own - how the world's most admired stay ahead of the game.

Hay Group (2008) Hay Group Insight's employee effectiveness framework

Hay Group (2008) The frustrated employee: help me help you.

Hay Group (2008) The long slow road to recovery.

Health \& Safety Executive:http://www.hse.gov.uk/stress/standards/readmore1.htm.

[Accessed 1 July 2009].

Healthcare Commission (2008) Sixth Annual National NHS staff survey.

Health Work Wellbeing (2007) Organisational Case Studies - Boots [Online].

Available: http://www.workingforhealth.gov.uk/Case-Studies/Organisations/Organisationdetail.aspx?CaseStudyID=44 [accessed 30 June 2009] 
Health Work Wellbeing (2007) Organisational Case Studies - Chess plc [On-line]. Available: http://www.workingforhealth.gov.uk/Case-Studies/Organisations/Organisationdetail.aspx?CaseStudyID=11] [accessed 30 June 2009]

Health Work Wellbeing (2007) Organisational Case Studies - British Gas Business [On-line]. Available: http://www.workingforhealth.gov.uk/Case-Studies/Organisations/Organisationdetail.aspx?CaseStudylD=33 [accessed 30 June 2009]

Heery, E. (2002) Partnership versus organisating: alternative futures for British trade unionism, Industrial relations Journal, 33(1): p20-35,

Heskett, J.L., Jones, T. O., Loveman, G. W., Sasser, W. E. And Schlesinger, L.A. (1994) Putting the service-profit chain to work, Harvard Business Review, March-April.

Herzberg, F. (2002) One more time - how do you motivate employees? Harvard Business Review,

Hewitt Associates (2004) Employee engagement higher in double-digit growth companies. Research Brief.

Hewitt Associates (2009) Best employers in Canada study finds link between high engagement and employees health and well being.

Hockey, J, \& Ley, I. (2009) Leading for Engagement: How Senior Leaders Engage Their People. Sunningdale: National School of Government.

Holley, N., McBain, R. and Parkinson, A. (2008) Employee engagement phase 2 - report from HR Centre of Excellence Research and members meeting, April.

IDS (2007) Employee Engagement, IDS HR Study Update 846, May.

IPA (2008) Maintaining workforce engagement in an economic downturn, IPA Bulletin, October.

Ipsos MORI/Improvement and Development Agency (2006) Lessons in Leadership. Ipsos MORI (2006) Engaging employees through corporate responsibility. Ipsos MORI (2008) What matters to staff in the NHS? Ipsos MORI (undated) Common sense in a changing world - employee relationship ISR (2004) Bottom line is better by engaging employees.

John Lewis Partnership (2008) Additional information for BERR Review of employee engagement.

Kelly, J. (2005) Social partnership agreements in Britain. In M.Stuart and M.Martinez Lucio (eds) Partnership and Modernisation in Employment Relations. London: Routledge: p188209.

Kelsey, Alpin, Forth et al (2006) Inside the Workplace: Findings from the 2004 Workplace Employment Relations Survey also on-line at http://www.berr.gov.uk/whatwedo/ employment/research-evaluation/wers-2004. [Accessed 1 July 2009].

Khan, W. A (1990) Psychological conditions of personal engagement and disengagement at work, Academy of Management Journal, vol 33 no 4. 
Khan, W. A. (1992) To be full there: psychological presence at work' Human Relations Vol 45 pp321-349.

KLI Consulting (2008) What stops businesses from turning great strategy into action?, Financier Worldwide, October.

KPMG (undated) People Strategy and Drivers.

Krueger, J. and Kilham, E. (2007) The Innovation Equation, Gallup Management Journal, April.

Kular, S., Gatenby, M., Rees, C., Sloane, E. and Truss, K (@ 2007) Employee engagement a literature review, Kingston Business School.

Kulesa, P. (2007) The new employer-employee relationship.

Kumar, V. and Wilton, P. (2008) Briefing note for the McLeod Review, Chartered Management Institute.

Lancaster University Management School (undated) LEAD Leadership \& Management Development Programme

Ley, I. (2008) Predicting employee engagement: the effects of transformational, transactional and passive/avoidant leadership styles, Unpublished MSc thesis.

Morgan, L, Driving Performance and Retention Through Employee Engagement. Productivity, LSE.

Macey, W. H and Schneider, B. (2008) The Meaning of Employee Engagement, Industrial and Organisational Psychology' Volume 1 Issue 1 3-30.

Macquarie Research (2005) National Australia Bank - when it's time to change.

Mahdon, M. and Bevan, S. (2007) The definitive analysis of current internal communication practice, The Work Foundation and Communicators in Business.

Maitland, R. (2004) Leaders in the Driving Seat: the importance and the performance of Europe's Business leaders, ISR.

Maitland, R. (undated briefing) All change, ISR.

Maitland, R. (2006) Leaders must do more for high performers, People Management, April.

Marr, J. (ed) (2001) US National Employee Benchmark Survey 2001, Walker Information,

M\&S BIG Constitution (revised December2008) Business Involvement Groups Constitution - an Agreement for informing and consulting our people.

Maslach, C., Schaufeli, W. B. and Leiter, M. (2001) Job burnout, Annual Review of Psychology., vol. 52.

Matthews, V. (2008) Engagement that could lead to a lasting relationship, Personnel Today, October.

McDaniel Partners (undated) Employee engagement - leadership matters.

Melcrum (2005) Employee engagement - how to build a high-performance workforce

Melcrum (2008) Melcrum employee engagement survey 2007/08 - summary of findings. 
Mercer (2007) Engaging employees to drive global business success.

Miller, T. (2007) Human Resource Management, employee engagement and business performance: shedding light into the black box, DBA thesis.

Mills, L. (2008) Human capital: meaningful metrics, Management Today, November.

Mintzberg, H. (January 2009) Rebuilding Companies as Communities.

Neugebauer, J. (2008) Best practice guide to employee engagement - hitting the right note, Osney Media.

NHS Employers (2007) Staff engagement and involvement www.nhsemployers.org/excellence/excellence-3756.cfm [Accessed 1 July 2009]. OC Tanner - Towers Perrin (2009) Turbocharging Employee Engagement: The Power of Recognition from Managers.

Oliver, J. (undated) Submission to the MacLeod Review.

Oliver, J (2009) Culture Change and Employee Engagement: Overall Outcomes, Team Enterprise Solutions.

ORC (undated) Linking employee and customer data - a new way forward for local government.

ORC (undated) Employees really are your biggest asset - it's a fact at Nationwide.

ORC (2009) Introduction to employee research at ORC International - presentation for the MacLeod Review.

Oxenbridge, S. and Brown, W. (2002) The two faces of partnership? An assessment of partnership and co-operative employer/trade union relationships, Employee Relations, 24(3):262-276.

Oxenbridge, S. and Brown, W. (2004) Achieving a new equilibrium? The stability of cooperative employer-union relationships, Industrial relations Journal, 35(S): p388-402.

Page, B. and Horton, M. (2006) Lessons in leadership, Ipsos MORI.

Parker, S. K. (2008) Illustrative IWP research on engagement, Institute of Work Psychology, University of Sheffield.

Parker, S. K. (2003) Longitudinal Effects of Lean Production of Employee Outcome and the Mediating Role of Work Characteristics, Sheffield University.

Parker, S.K, Chmiel, N. and Wall, T.D., Sheffield University (1997) Work characteristics and employee well-being within a context of strategic downsizing. Extracted from The Journal of Occupational Health Psychology, Vol 2, No4, 289-303.

Parsley, A. (undated) Why internal communications must never be seen as a cure all for poor employee engagement, Green Lion.

Peirce, M. and Madden, K. (undated) Driving success: human resources and sustainable development, World Business Council for Sustainable Development, HRH the Prince of Wales. Business and the Environment Programme and University of Cambridge Programme for Industry. 
Pritchard, M. \& Silvestro, R. (2004) Applying the service profit chain to analyse retail performance. PRT Consultants.

Postlethwaite, R., Michie, J., Burns, P. and Nuttall G. (2005) Shared company - how employee ownership works, Job Ownership Ltd.

Purcell, J. (2002) Sustaining the HR and performance link in difficult times, University of Bath.

Purcell, J., Kinnie, N., Hutchinson, S., Rayton, B and Swart, J. (2003) Understanding the People and Performance Link: Unlocking the Black Box. London, CIPD

Purcell J. and Kinnie N. (2007) HRM and business performance, Chapter 26 from The Oxford Handbook of Human Resource Management, Oxford University Press.

Purcell, J. (2008) A note on the research literature on high-performance working and employee engagement, Acas.

Reed Elsevier (2007) Bright ideas for creating high-performing, great places to work in Reed Elsevier, Corporate Responsibility Report (2007),

Reeves, (2007) CoCo companies - work, happiness and employee ownership, Employee Ownership Association.

Reilly, P and Brown, D (2009) Employee Engagement: What is the Relationships with Reward Management?, HR Network Paper MP83, Institute of Employment Studies, Right Management (2006) Measuring True Employee Engagement, A CIPD Research Report Robertson I., Cooper C. Case Study: Somerset County Council - The Business Case for managing pressure and stress at work [On line]

http://www.robertsoncooper.co.uk/Pages/Resources/Case-Studies.asp

[accessed 1 July 2009]

Robertson-Smith, G. Markwick, C (2009) Employee engagement-a review of current thinking. IES HR Network.

Robinson, D., Perryman, S. and Hayday S. (2004) The drivers of employee engagement, Institute of Employment Studies, HR Network, Report 408.

Robinson, D., Hooker, H. and Hayday, S. (2007) Engagement: the continuing story, IES.

Robinson, D., Perryman, S., Hayday, S (2007) The drivers of employee engagement, Institute for Employment Studies Report 408.

Robinson, D. (2008) Employee engagement: an IES perspective, Presentation to the IES HR Network.

Rucci, A.J., Kirn, S.P. and Quinn R.T (1998) The Employee-Customer Profit Chain at Sears, Harvard Business Review.

Sadev, K. Vinnicombe, S. (1998) Downsizing and survivor syndrome: a study of HR's perceptions of survivor's responses. Cranfield University School of Management. Saks, A. M. (2006) Antecedents and consequences of employee engagement, Journal of Managerial Psychology, vol 21 no 7. 
Schaufeli, W. B., Salanova, M., Gonzalez-Roma, V. and Bakker, A. B.(2002) The measurement of engagement and burnout: a two sample confirmatory approach. Journal of Happiness Studies.3.

Scottish Executive Social Research (2007) Employee engagement in the public sector. Sirota, D., Mischkind, L. and Meltzer, M. (2006) High moral again pays off in stock market gains, Sirota Survey Intelligence.

Smythe, J. (2004) Engaging people at work to drive strategy and change.

Soane, E. et al (2008) The association between individual responses to work, employee engagement and performance.

Spreier, S. W., Fontaine, M. H. and Malloy, R. L. (2006) Leadership run amok - the destructive potential of overachievers, Harvard Business Review.

Strack, R., Dyer, A., Caye, J-M., Minto, A, Leicht, M., Francoeur, F., Ang, D., Bohm, H., McDonnell, M. (2008) Creating People Advantage' Executive Summary, Boston Consulting Group.

Standard Chartered Bank Leadership and Development Programme.

Standard Chartered Bank Strategic Intent.

Steele, J. (1999) Wasted Values: harnessing the commitment of public managers, Public Management Foundation.

Stern, S. (2008) Feel the strategy: leaders must engage hearts as well as minds, Management Today, November.

Stern, S. (2008) Engaging a worried workforce, Financial Times, 9 February.

Storey, J., Wright, P.M., Ulrich, D. eds. (2008) The Routledge Companion to Strategic Human Resource Management.

Storey, J. and Salaman, G. (2009) Nature has no outline but imagination has, contrasting executive renditions of the commitment to innovation, European Management Journal.

Suff, P. and Reilly, P. (2008) Going the extra mile. The relationship between reward and employee engagement, IES HR Network.

Talent Drain (2009) Employee engagement and retention survey 2009.

Tamkin, P. (2005) Measuring the contribution of skills to business performance, IES.

Tamkin, P., Giles, L., Campbell, M. and Hillage, J. (2004) Skills pay: the contribution of skills to business success, IES for the Sector Skills Development Agency (SSDA)

Tamkin, P., Cowling M. and Hunt W (2008) People and the Bottom Line, Report 488, Institute of Employment Studies.

Terry, M. (2003) Can 'partnership' reverse the decline of British trade unions?, Work, Employment and Society, 17(3).

The Conference Board (2006) Employee Engagement - a review of current research and its implications.

The Co-operative (2009) Evidence to the MacLeod enquiry. 
The Co-operative (2009) Talkback: engagement and performance.

Towers Perrin (2005) Towers Perrin 2004 European Talent Survey: Reconnecting with Employees: Attracting, retaining, and engaging your workforce. Research Report. London, UK.

Towers Perrin (2005) Reconnecting with employees: quantifying the value of engaging your workforce.

Towers Perrin-ISR (2006) ISR Employment Engagement Report.

Towers Perrin (2007) The transition to transformation - the dynamics of organisational change.

Towers Perrin Global Workforce Study (2007-2008) - United Kingdom.

Towers Perrin (2007) Executive Briefing: Engagement in the Public Sector.

Towers Perrin (2008) Engagement in images.

Towers Perrin (2008) Overview of UK high performance companies norm.

Towers Perrin (2009) Towers Perrin-ISR's employment engagement framework, Methodology Validation.

Truss, C., Soane, E., Edwards, C., Wisdom, K., Croll, A., and Burnett, J. (2006) Working life: employee attitudes and engagement 2006' CIPD.

TUC (2008) What do Workers Want?, YouGov poll carried out for the TUC in August 2008

UNITE membership survey, 2006

Watson Wyatt, Continuous Engagement: The Key to Unlocking the Value of Your People

During Tough Times, Work Europe Survey- 2008-2009

Waddell G, Burton AK. Is work good for your health and well being? London, The Stationery Office, 2006

Wales Public Service Workforce Forum: May 2009 [Online] Www.wlga.gov.uk/download.php?id=2757\&l=1 ([Accessed] 1 July 2009) ,

Wellins, R. S., Bernthal, P. and Phelps, M (2005) Employee engagement: the key to realizing competitive advantage, DDI and at:

http://www.ddiworld.com/pdf/ddi_employeeengagement_mg.pdf [accessed 1 July 2009], Wellins, R., and Concelman, J. (April 2005) 'Workforce Performance Solutions.

West et al. (2005) The link between the management of employees and patient mortality in acute hospitals.

?What If!, The Innovation Company, Top Dog Learnings.

Wildermouth, Christine de Mello e Souza, \& Pauken Patrick (2008) Industrial and Commercial Training A Perfect Match: decoding employee engagement-Part1: Engaging Cultures and Leaders.

Williams, M., Cowling, M (2009) BERR Annual Small Business Survey 2007/082, Institute for Employment Studies. 
Worrall, L. \& Cooper, C. L. (2007) The Quality of Working Life: Managers' health, motivation and productivity. Chartered Management Institute.

C. Wren and J. Jones, Ex-post Evaluation of the LEAD Programme. Lancaster University: Institute for Entrepreneurship and Enterprise Development, 2006. 


\section{Annex G}

\section{Biographies}

\section{David MacLeod}

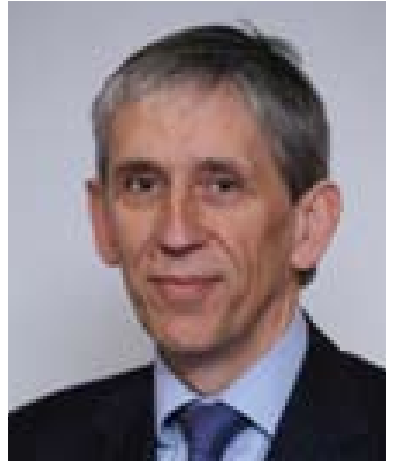

David MacLeod was chair of the MacLeod Review. David has spent the majority of his career leading private sector organisations through major programmes of change and worked at the Cabinet office as Senior Adviser on Change and Performance. He was head of marketing for the Dulux brand, and a divisional $\mathrm{CEO}$ with $\mathrm{ICl}$. He has also worked at Towers Perrin as Senior Adviser supporting chief executives in both the public and private sectors to implement change in order to enhance performance. David now has a portfolio of responsibilities which include being a Non Executive Director of the Department for International Development, Non Executive Director of the Ministry of Justice, Fellow of the Sunningdale Institute, Senior Associate of Towers Perrin and Visiting Professor of the Cass Business School. He is also a Fellow of the RSA, Institute of Marketing and Ashridge Business School.

\section{Nita Clarke}

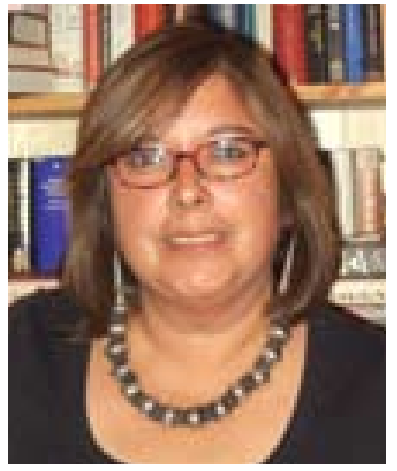

Nita Clarke was Vice-Chair of the MacLeod Review, and is Director of the Involvement \& Participation Association. Nita was a former adviser to Prime Minister Tony Blair, working as assistant political secretary in the Political Office at 10 Downing Street from January 2001 to June 2007 . Her role included liaising with individual unions and the TUC, developing national policy areas such as the two-tier work-life balance and supporting ministers by trouble-shooting in individual disputes. From 1992-2001 she was a senior official with the public services union UNISON. 


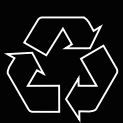

Printed in the UK on recycled paper containing a minimum of $75 \%$ post consumer waste. -

Department for Business, Innovation and Skills www.bis.gov.uk

First published July 2009. Crown Copyright. BIS/Pub 8859/07/09NP. URN09/1075 - 